\title{
Repackaging Packaging: Using Plastic Waste as an Architectural Material to Rehabilitate Ecosystems
}

by

Adam Paquette

A thesis submitted to the Faculty of Graduate and Postdoctoral Affairs in partial fulfillment of the requirements for the degree of

Master of Architecture

Carleton University

Ottawa, Ontario

(C) 2017, Adam Paquette 


\begin{abstract}
Plastic waste and microplastics are wreaking havoc on aquatic ecosystems everywhere. Removal of this plastic waste is essential, however, once removed most plastic items end up in landfills and microplastics are almost impossible to recover. This speculative design and research paper aims to combine real-world technologies with future possibility and utilize repurposed plastic packaging to create 'plastic eating' machines. These machines would passively roam bodies of water remediating microplastics and other plastic waste from the ecosystem while functioning as an interdisciplinary research facility.
\end{abstract}

Shredding and melting experiments are undertaken to determine the best and most economic techniques to reform reclaimed plastic. Research is presented on innovative biotechnology that makes use of bacteria to both gather and eliminate plastic from water. Architectural drawings, sketches and designs for the machines are proposed. 


\section{Acknowledgements}

I would first like to express my gratitude to all my undergraduate studio professors who fostered my creativity. Specifically, I would like to thank David Lepage for lighting the fire and igniting the passion I have for Architecture today. A special thanks to my thesis advisor Johan Voordouw for his comments, engagement, and dedicated review. To Steve Macleod for not only providing many of the objects that were used in this thesis, but also the space required to successfully complete my degree. Further, I would like to thank Olivier Larocque and Matthew Lerch for providing a stimulating environment in which countless hours were spent developing my ideas and ultimately, this thesis. To Kyle Tousant for spontaneous transportation and late night edits.

Finally, I must express my profound gratitude to my girlfriend, Meagan Milanne Jesmer, for thoroughly editing this thesis and more importantly, for her support and encouragement throughout my graduate studies. This accomplishment would not have been possible without all of you. Thank you. 


\section{Table of Contents}

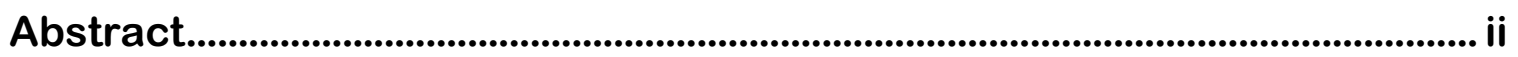

Acknowledgements .............................................................................................. ii

Table of Contents ................................................................................................................. iv

List of Illustrations.......................................................................................................... vi

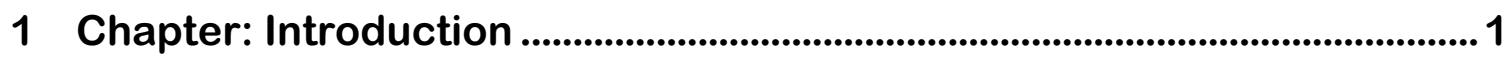

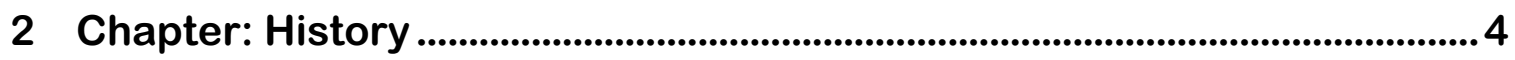

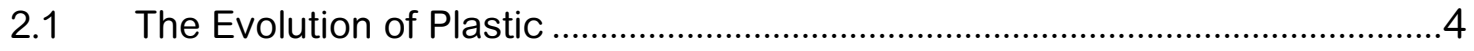

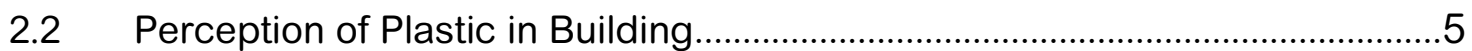

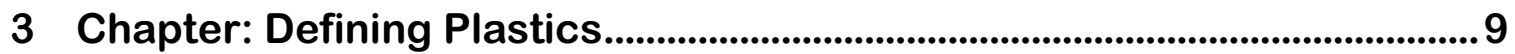

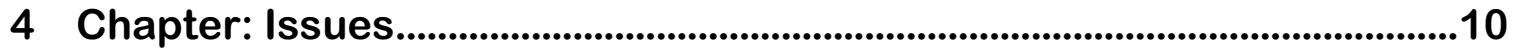

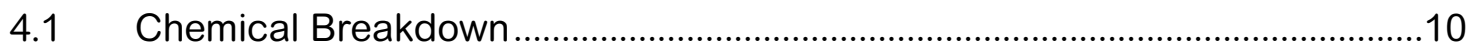

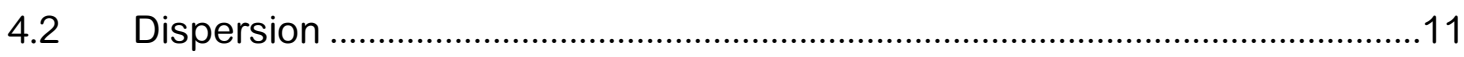

5 Chapter: Proposal of Project...........................................................................19

$5.1 \quad$ Project Strategy ..........................................................................................28

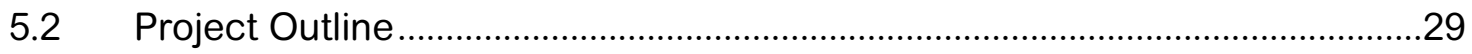

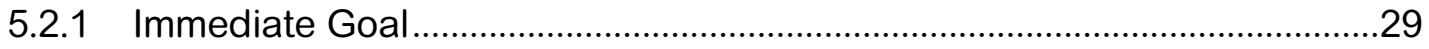

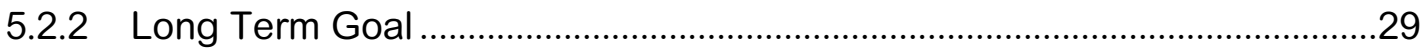

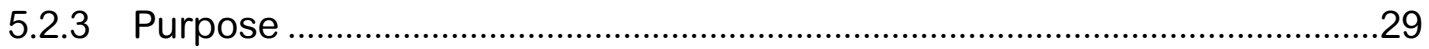

5.2.4 Tasks: Support of Ocean and Great Lake Preservation................................30

5.2.5 Importance of Restoration Program ………………………………..................30

6 Chapter: Methods .............................................................................................49

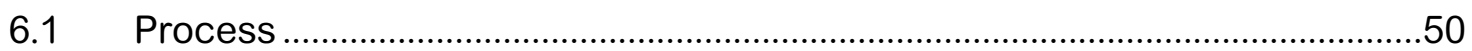


6.2 Representation - Design Methodology ...

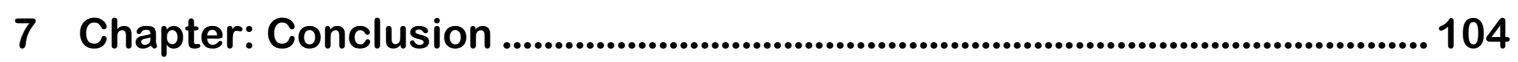

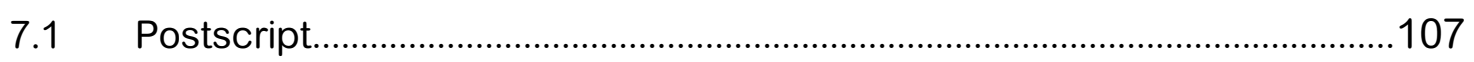

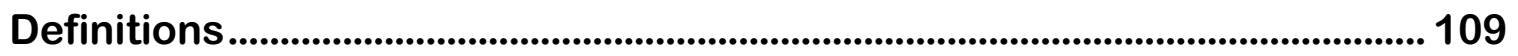

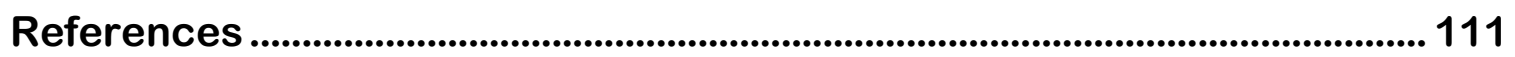




\section{List of Illustrations}

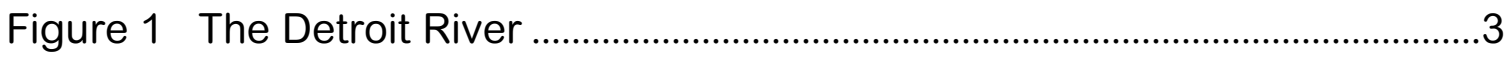

Figure 2 Mind Map ....................................................................................

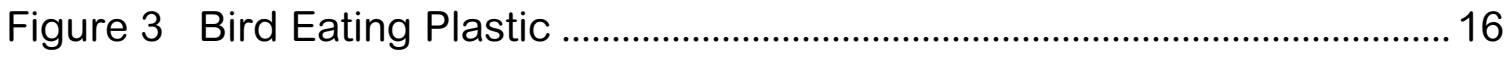

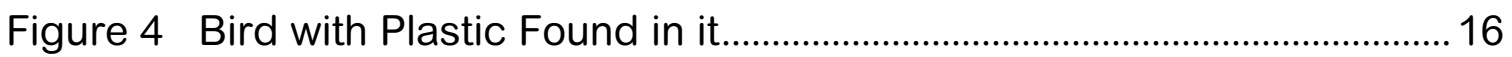

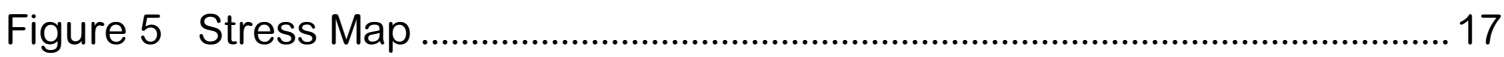

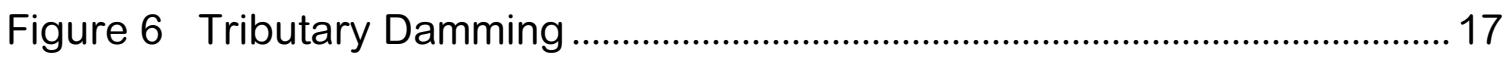

Figure 7 Aerial view of Grosse lle in the Detroit River ........................................ 18

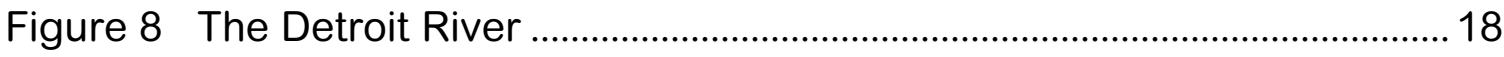

Figure 9 Freeze Over the Great Lakes ................................................................ 23

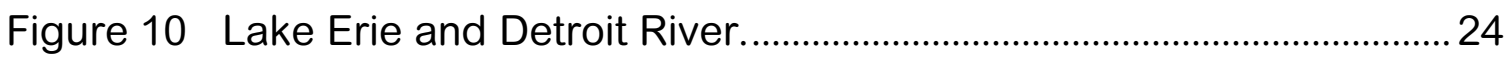

Figure 11 Process Sketch - Colour Exploration .................................................... 33

Figure 12 Process Sketch - Growth of Plastic Island (10 year intervals) ....... 34

Figure 13 Growth of Docking Facilities with Context............................................ 35

Figure 14 Roaming Plastic Eating Machines.......................................................... 36

Figure 15 Cross Section of Single Scientific Research Facility .......................... 37

Figure 16 Longitudinal Section of Single Scientific Research Facility ............ 37

Figure 17 PEP Machine Establishing Quarantine Area .................................... 38

Figure 18 Aerial View of Plastic Rehabilitation Zone ............................................... 39

Figure 19 Plastic Eating Machine ..................................................................... 40

Figure 20 Bacteria and Plastic Growth Layered on Façade ............................... 41

Figure 21 Plastic Panelized Skin ......................................................................... 42 


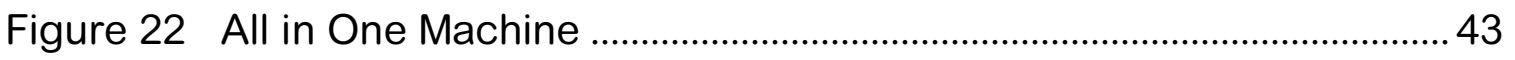

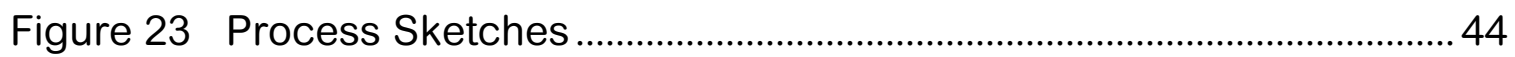

Figure 24 Traditional Recycling Process and Bioremediation Process .......... 45

Figure 25 Plan and Section of Research Facility ............................................... 46

Figure 26 Identifying the Zones ........................................................................... 47

Figure 27 Integrating Multiple Bacterial Processes ............................................. 48

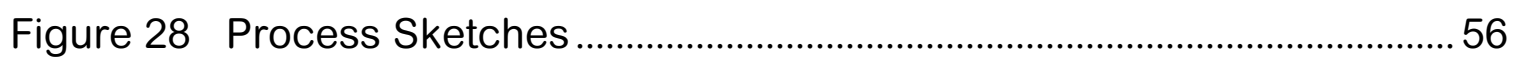

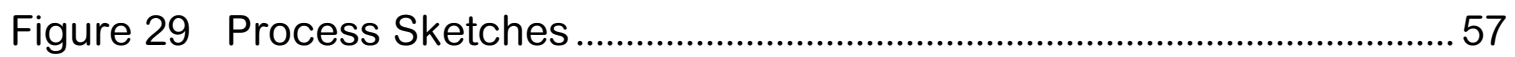

Figure 30 Progression of Bottle Cutter .............................................................. 58

Figure 31 Progression of Bottle Cutter ...............................................................59

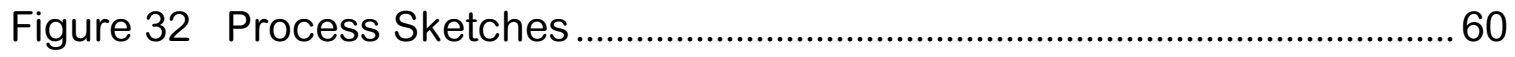

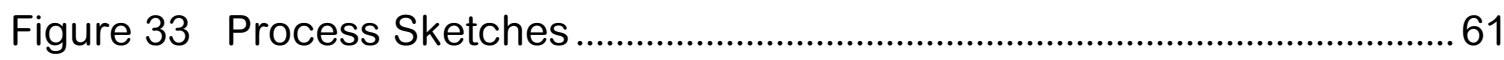

Figure 34 Construction of Shredding Machine.................................................... 62

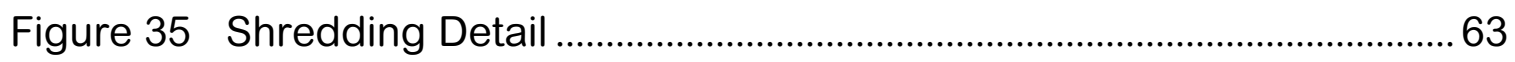

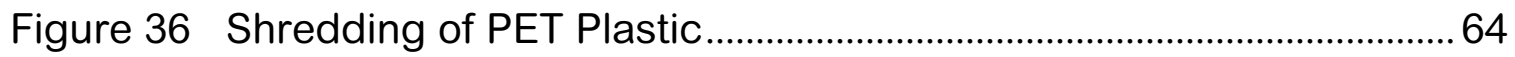

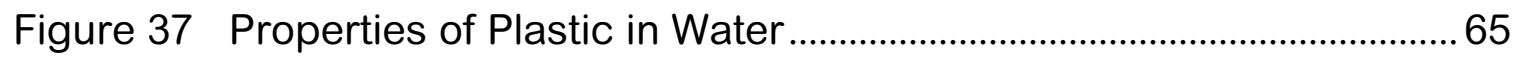

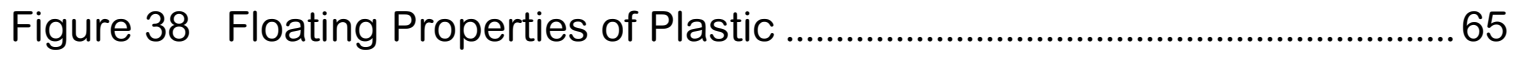

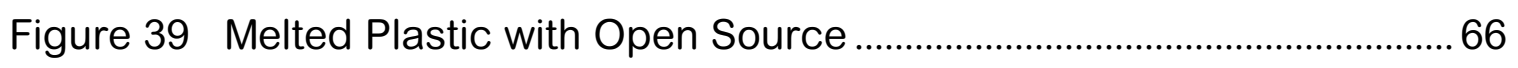

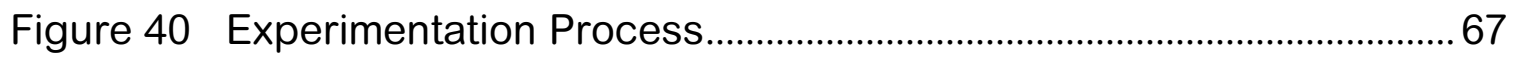

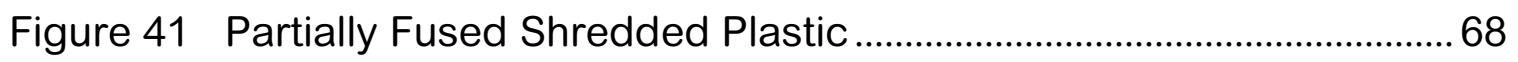

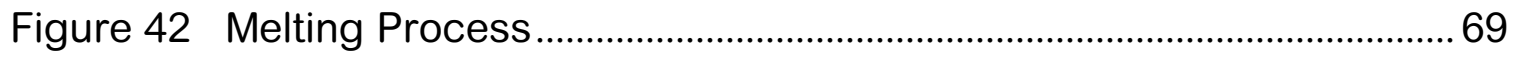

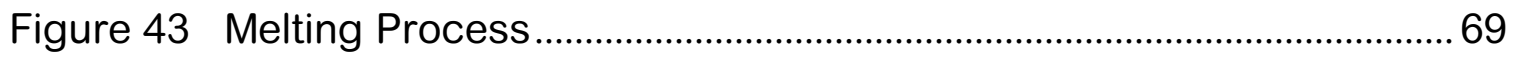

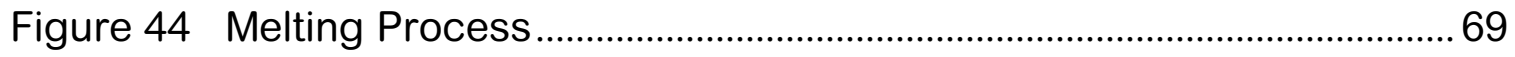




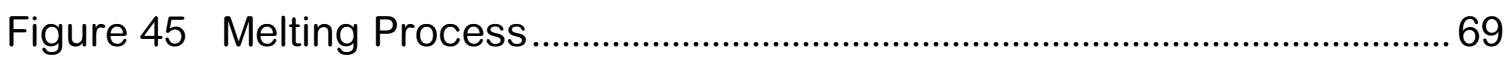

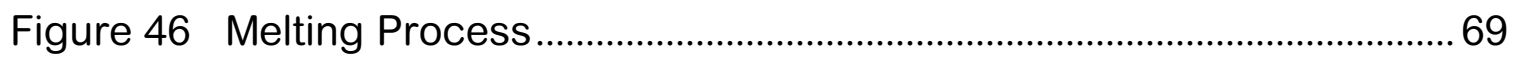

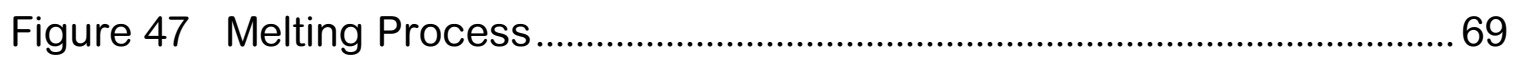

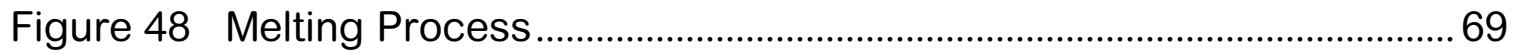

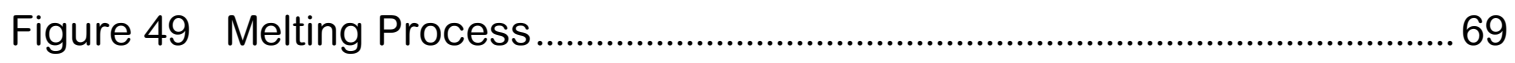

Figure 50 Plastic Shedding, Melting, Compressing, and Forming Process ... 70

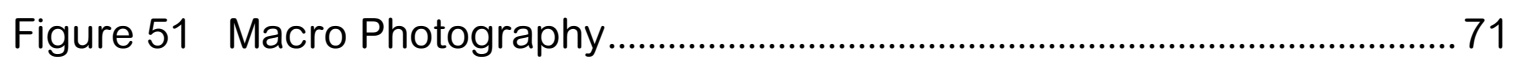

Figure 52 Macro Photography..........................................................................

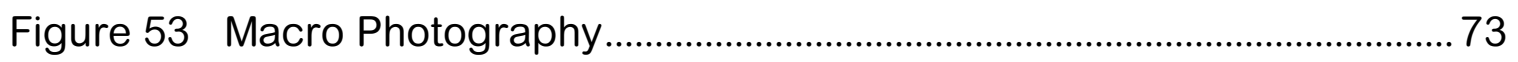

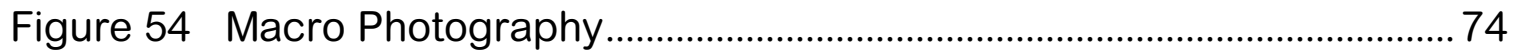

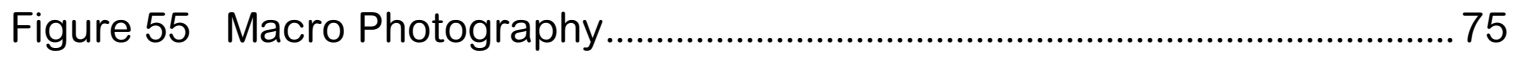

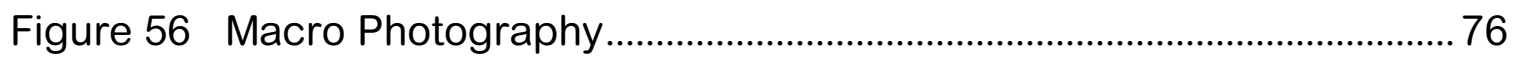

Figure 57 Macro Photography......................................................................... 77

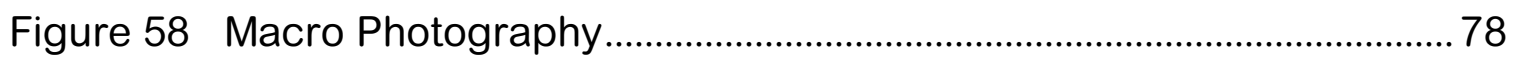

Figure 59 Mechanical and Plastic Parts ........................................................... 79

Figure 60 Plastic Eating Machine Above and Below Water................................. 80

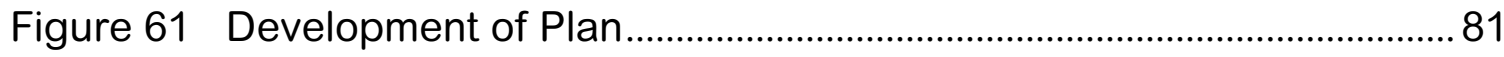

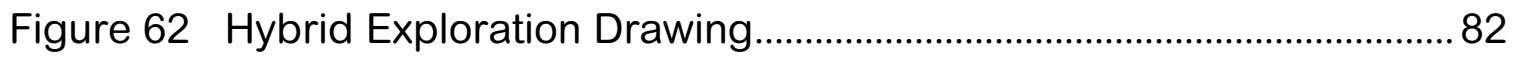

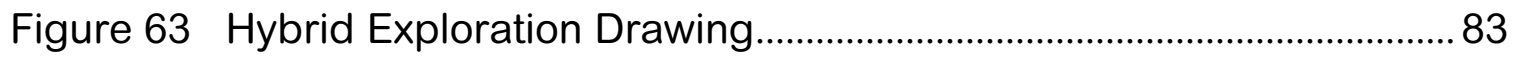

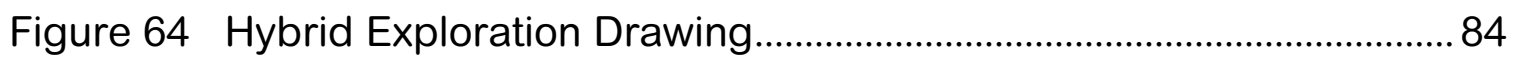

Figure 65 Hybrid Exploration Drawing................................................................ 85

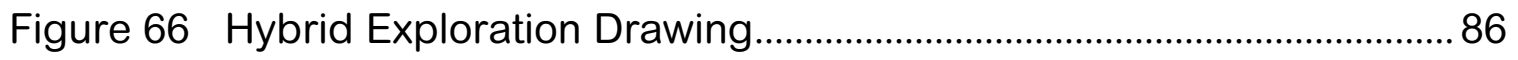

Figure 67 Comparison of the Fabricated Object to the Found Object .............87 


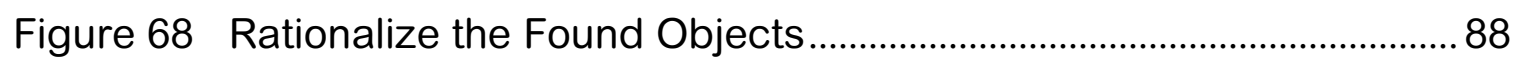

Figure 69 Fabricated Object Integrated with the Found Object ........................89

Figure 70 The Importance of Hand drawing …………….................................90

Figure 71 Establishing a Base.......................................................................... 91

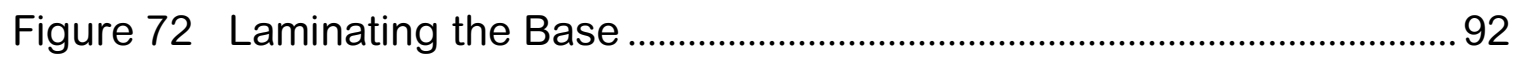

Figure 73 Pouring of PET Plastic Over Physical Model .......................................93

Figure 74 The Belly of the Machine and Scale ........................................................94

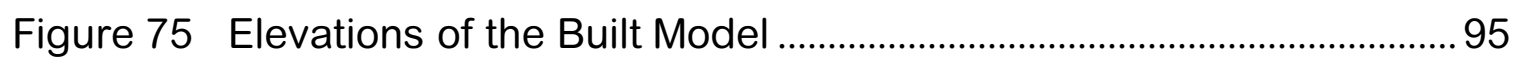

Figure 76 Elevations of the Built Model .................................................................

Figure 77 Angled Perspective of Machine......................................................... 97

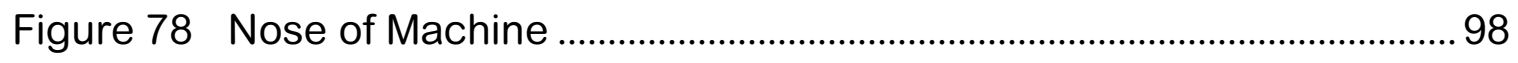

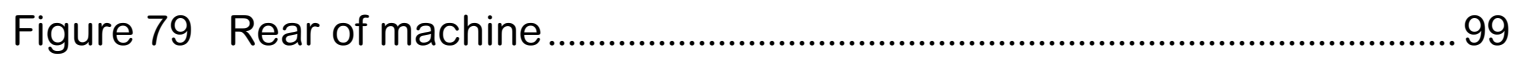

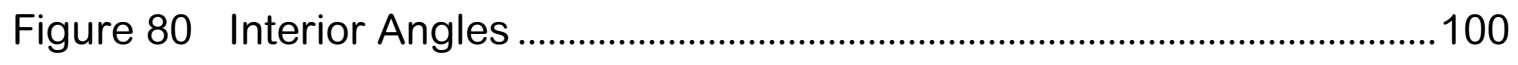

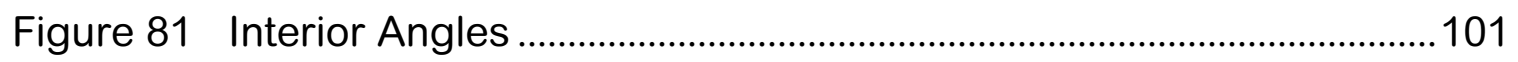

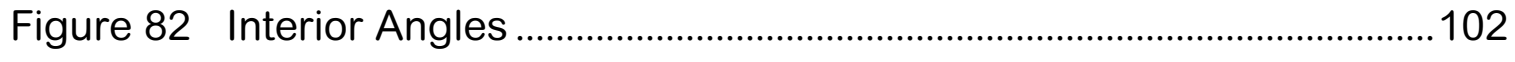

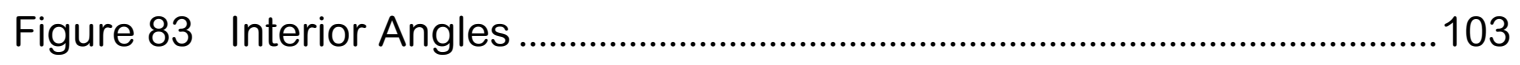

Figure 84 Concept Sketch of Plastic and Oil .................................................108 


\section{Chapter: Introduction}

The removal of plastic waste from our freshwater lakes plays an integral role in preserving aquatic ecosystems. Remediation of plastic waste is essential to prevent further damage to our environments. Once removed, however, most plastic items end up in landfills.

This proposal will study how plastic waste can be harvested from water, developed into new materials for building, and how novel uses of this repurposed material might begin to reduce landfill dispersion. Repurposed plastic will be used to create 'plastic eating' machines (PEPs) that will passively roam bodies of water, remediating microplastics and other plastic waste from our ecosystems. This process will provide infrastructural elements for scientists to study plastic waste, before, during, and after it has entered our ecosystems. It will consist of a speculative design developed from ecological issues in Canada's freshwater eco-systems. The method of Research by Design will be used for further development and exploration of hypothetical prototypes that contribute to a narrative that depicts plastic free water. A deconstructive process of mechanical parts will stimulate creative thought by establishing an architecture and imagining technology to rehabilitate aquatic ecosystems. It is important for this proposal to reinvent the notion of plastic as a multiuse product, while providing awareness of the environmental impact plastic waste has on freshwater ecosystems. The scope of this research will be limited to plastic waste in Canada's Great Lakes, specifically in the Detroit River (Figure 1), which has been designated as an Area of Concern by the government of Canada. Despite this initial narrow focus, the aim of this research is that it will be transferable to other locations.

A goal of the thesis is to establish an environment that will facilitate collaboration between multidisciplinary research. It is expected for these groups to challenge norms and to ask critical questions regarding the issues 
of plastic packaging, waste, and dispersion. How can a relationship between architecture and plastic packaging be developed? How can weaving, lamination and shredding of repurposed plastic, in combination with vacuum forming and CNC fabrication be used to create new ways of thinking and making with waste? How can the notion of recycling be changed twofold? Firstly, we must understand recycling as it currently is-a wasteful process. Secondly, we must recognize the proposed purpose of 'recycling' set out in this thesis-recycling economically for long term use-as justified as it removes the plastic from the cycle of consumerism permanently. The plastic will be used via machines to remediate the plastic problem—plastic eating plastic. 


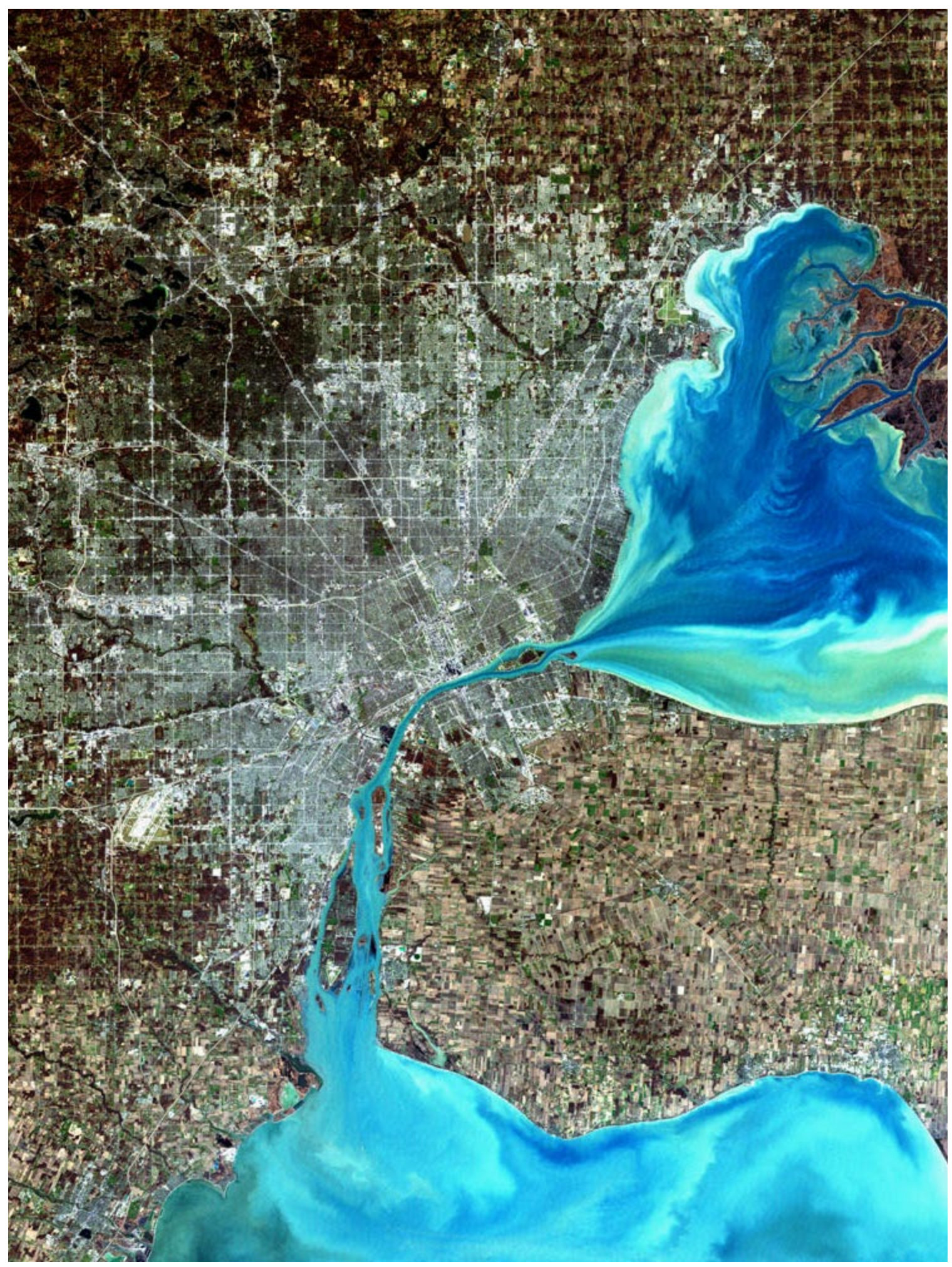

Figure 1. The Detroit River - A part of the Great Lakes system as it connects Lake St. Clair with Lake Erie. Image by Ron Beck, USGS Land Processes Data Center, Satellite Systems Branch 


\section{Chapter: History}

\subsection{The Evolution of Plastic}

In 1907 Belgian chemist Leo Baekeland developed the first synthetic polymer, Bakelite. This material had thousands of uses, meaning it could be "molded, extruded, foamed, stamped, [or] vacuum formed" (1). ${ }^{1}$ These first plastics were considered thermosets, meaning the objects remained hard, infusible, and insoluble if heat were reapplied to its surface (5). ${ }^{2}$ Between 1910 and 1940 "visible uses of plastic in consumer goods remained limited to a few products, such as celluloid dresser sets and Bakelite radios" (1). Between the years 1939 and 1941 thermoplastics were studied by JT Dickson and Rex Whinfield, ${ }^{4}$ which led to one of the most common plastics used today, Polyethylene Terephthalate (PET), commonly used for disposable water bottles. It was not until the 1940s that synthetic polymers embarked on a period of explosive experimentation, eventually leading to the mass production of everyday plastic items (1973). ${ }^{5}$ During the Second World War the United States used plastics to manufacture military equipment such as aircraft cockpit covers and mortar fuses, contributing to nearly 818 million pounds of plastic produced between 1940 and 1945 (1). ${ }^{6}$ It was during this time that plastic began to influence the lives of many baby boomers (1), ${ }^{7}$ perpetuating its use as we know it today.

As the production of plastic packaging has steadily increased since 1964, it is important to acknowledge both the wasteful nature of the systems that manage plastic waste, and the design of plastic packaging. In 2013 , only $14 \%$

\footnotetext{
${ }^{1}$ Meikle, Jeffrey L. American Plastic: A Cultural History. New Brunswick, N.J.: Rutgers University Press, 1995. eBook Collection (EBSCOhost). Web. 2 Jan. 2017.

2 Ibid.

3 lbid.

4 "What are Plastics?" Plastics Historical Society. http://plastiquarian.com (Date Accessed: Jan, 03 2017).

${ }^{5}$ Thompson, Richard C., Shanna H. Swan, Charles J. Moore, and Frederick S. vom Saal. 2009. Our plastic age. Philosophical Transactions of the Royal Society B: Biological Sciences 364 (1526): 1973-6.

${ }^{6}$ Meikle, Jeffrey L. American Plastic: A Cultural History. New Brunswick, N.J.: Rutgers University Press, 1995. eBook Collection (EBSCOhost). Web. 2 Jan. 2017.

7 Ibid.
} 
of plastics were collected for recycling, of which $4 \%$ were lost to process, and $8 \%$ lost to collection and transportation (26). ${ }^{8}$ Uncollected plastic packaging has a more shocking narrative where $14 \%$ was lost to incineration and/or energy recovery, $40 \%$ was found in landfills, and finally, 32\% returned to water as leakage (26). ${ }^{9}$ It is obvious that the evolution of plastics has spun out of control, creating major waste management problems.

The plastic industry has come a long way since the 1940s. To put this plastic production into perspective, in 1941 "global production [of plastic] was less than a million tonnes per annum" (364). ${ }^{10}$ By 2014, plastic production had reached 311 million tonnes, of which 26\% represented plastic packaging (24). ${ }^{11}$ Production of plastic packaging is only continuing to increase, and is expected to quadruple to 318 million tonnes of packaging alone by 2050 (24). ${ }^{12}$ For industry, this is extremely profitable. Seventy-eight million tonnes of plastic packaging was introduced to market in 2013, with a total value of 260 billion U.S. dollars (24). ${ }^{13}$

\subsection{Perception of Plastic in Building}

By 1954 the Building Research Institution (BRI) held its first conference on plastic, titled Plastics in Building (92). ${ }^{14}$ The attendants consisted of 500 early polymer scientists, engineers, architects, and academia, eventually leading to the formation of discussion groups where they could converse publicly about the research and experience they had with plastics (89). ${ }^{15}$ These conferences were located in Washington, DC consisting of the BRI, the US National

\footnotetext{
8 World Economic Forum, Ellen MacArthur Foundation and McKinsey \& Company. 2016. The New Plastics Economy - Rethinking the future of plastics. Accessed January 3, 2017. http://www.ellenmacarthurfoundation.org/publications. 9 Ibid.

10 Thompson, Richard C., Shanna H. Swan, Charles J. Moore, and Frederick S. vom Saal. 2009. Our plastic age. Philosophical Transactions of the Royal Society B: Biological Sciences 364 (1526): 1973-6.

11 World Economic Forum, Ellen MacArthur Foundation and McKinsey \& Company. 2016. The New Plastics Economy

- Rethinking the future of plastics. Accessed January 3, 2017. http://www.ellenmacarthurfoundation.org/publications

12 Ibid.

13 Ibid.

14 Faircloth, Billie. 2015. Plastics now: On architecture's relationship to a continuously emerging material. Abingdon, Oxon;New York, NY;: Routledge.

15 Ibid.
} 
Academy of Sciences (NAS), the National Research Council (NRC), the US Society of Plastics Industry, and the US Manufacturing Chemists' Association (94). ${ }^{16}$ By 1955 the BRI formed the Plastic Study Group (PSG), however, in 1961 this group transitioned into the BRI Planning Committee on Plastics in Building $(92,96) .{ }^{17}$ This group shifted from "product experimentation toward product standardization" $(98)^{18}$ which provided awareness of how plastics "should and could be used" (96). ${ }^{19}$ However, at the time, some architects remained skeptical of plastic as a new building material. Associate Professor Frederick J. McGarry of Building, Engineering, and Construction of Massachusetts Institute of Technology once stated, "we have fallen blindly in love with the word "plastics"' (98). ${ }^{20}$

"We believe that in plastics we can find answers to all our problems. Our major difficulty is scale - the transition between little things and big, structural things. The impetus is there - manufacturers like the building market - architects like the physical properties. But let's be more candid - let's tell architects not to make the units too large, as yet. Let's back off for a while and express plasticity ["capacity for being molded or altered, the ability to retain a shape attained by pressure deformation." ${ }^{21}$ ] in terms of flat sandwich panels and workable things until we can control additional uses more adequately. The plastics industry just hasn't the experience and equipment for the large units that the architect desires" (11). ${ }^{22}$

Within this 22-year period (1954-1976), "a selection of 17 conferences yielded roughly 180 papers" (94). ${ }^{23}$ With the potential emergence of a new building material these discussions were essential for giving architects, designers, and the scientific community the confidence to work with plastic as a building

\footnotetext{
16 Faircloth, Billie. 2015. Plastics now: On architecture's relationship to a continuously emerging material. Abingdon, Oxon;New York, NY;: Routledge.

17 Ibid.

18 Ibid.

${ }^{19}$ Faircloth, Billie. 2015. Plastics now: On architecture's relationship to a continuously emerging material. Abingdon, Oxon;New York, NY;: Routledge.

20 Ibid.

${ }^{21}$ Merriam-Webster's Collegiate Dictionary. 11th ed. Springfield, MA: Merriam-Webster, 2003.

22 Building Research Institute, Plastics Study Group of the Building Research Institute, Report of a meeting at the Illinois Institute of Technology (Washington, DC: NAS-NRC, 1957), 11.

${ }^{23}$ Faircloth, Billie. 2015. Plastics now: On architecture's relationship to a continuously emerging material. Abingdon, Oxon;New York, NY;: Routledge.
} 
material. However, experimenting with plastics has halted since this period. There has simply been a "lack of consensus regarding the value of extending working and describing activities beyond the discrete boundaries of the chemical industry to the architectural industry" (116). ${ }^{24}$ This disconnect must realign in order for the above-mentioned rehabilitation facilities to succeed. Architects and chemists must work together to rethink plastic uses.

"Architects need descriptions of plastics in order to tacitly work them.

Chemists and manufacturers still need to work them in order to describe them" (115). ${ }^{25}$

To facilitate discussions and research, this project proposes not only to reestablish conversation between multidisciplinary groups, but also to redirect its research focus to the current information surrounding plastics in relation to the environment. For example, groups such as: the American Chemistry Council, Plasticity Forums, the Great Canadian Shoreline Cleanup, and Civic Technologies for Monitoring Marine Plastics will contribute expertise that will help analyze the effects of plastic waste on our environment and in light of these issues reevaluate the pros, cons, and ultimate uses of plastic. The speculative cleaning machines proposed in this thesis would serve as the location to provoke these discussions. The machines would help to create an architecture, which supports the cleanup of water as well as facilitate primary multiple disciplinary scientific research.

\footnotetext{
${ }^{24}$ Faircloth, Billie. 2015. Plastics now: On architecture's relationship to a continuously emerging material. Abingdon, Oxon;New York, NY;: Routledge.

25 Ibid.
} 


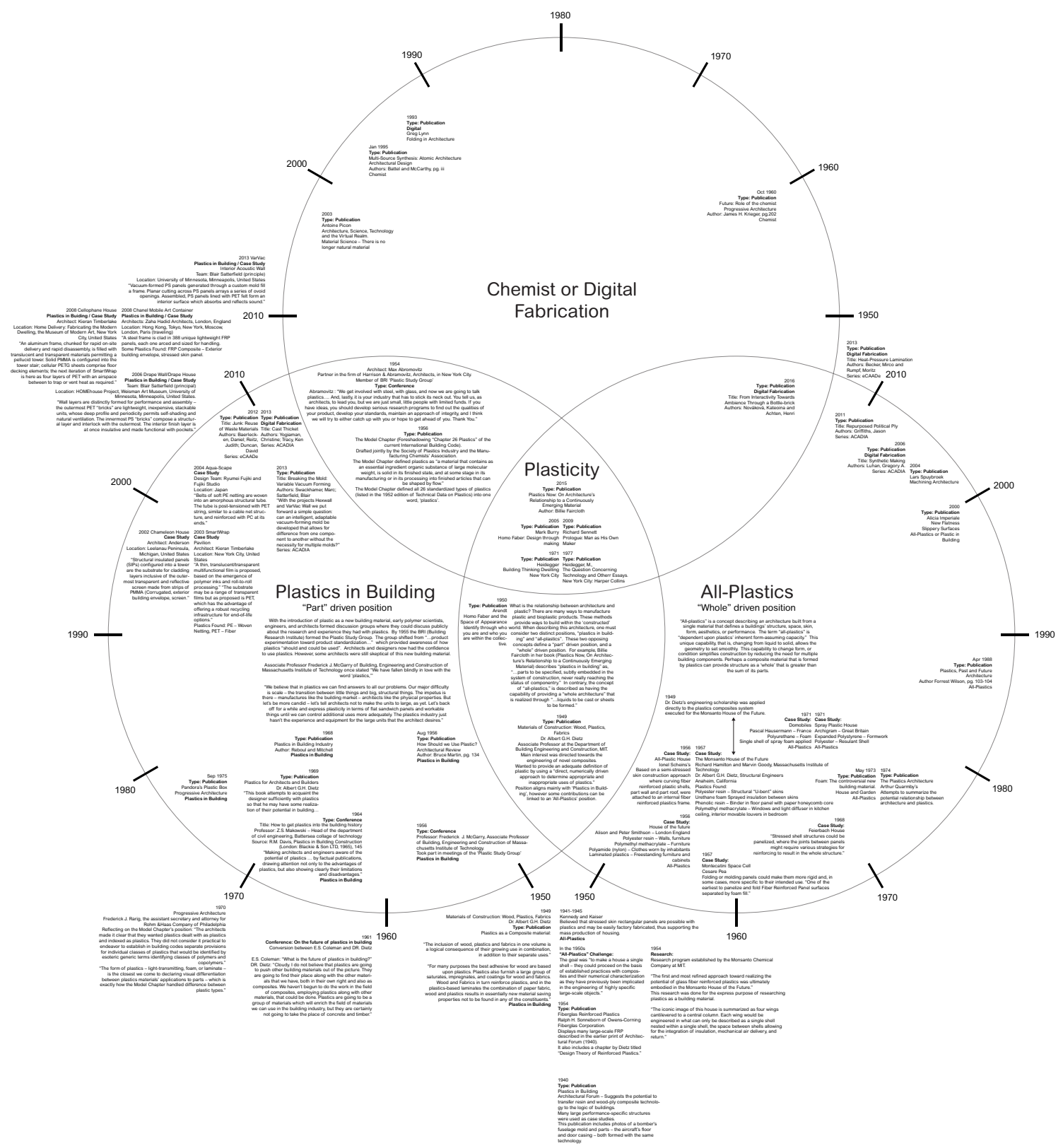

Figure 2. Mind Map - A critical thinking exercise situating / linking authors, chemists, architects, and engineers through time.

(Plastic) 


\section{Chapter: Defining Plastics}

There are many types of plastics. Specifically, they can be categorized as polymers, synthetic polymers, natural polymers, and bioplastics $(58) \cdot{ }^{26}$ These plastics have "high molecular weight, meaning each molecule can have thousands of atoms bound together." ${ }^{27}$ Once these atoms begin to group they are called monomers, which are then combined through a chemical process called polymerization to create polymers or plastics. ${ }^{28}$ Both biomass and fossil fuel carbon atoms are used to create monomers. Fossil fuels such as petroleum, coal, and natural gas all contain high levels of hydrocarbon which can be extracted and used as groups of atoms that create monomers. ${ }^{29}$ These sources of finite hydrocarbons create polymer and synthetic plastics. Biomass hydrocarbons, a renewable resource, are primarily derived from plants or organisms that feed on plants (53). ${ }^{30}$ Both biomass-derived and organismderived monomers can be used for industrial processes of natural polymers and bioplastics (58). ${ }^{31}$ The addition of plasticizers are used in industry, manufacturing activity as a whole, specifically here: the plastic industry, to improve physical properties of the product. While this is good for industry, these plasticizers are extremely detrimental to the environment, as will be evidenced below.

\footnotetext{
${ }^{26}$ Faircloth, Billie. 2015. Plastics now: On architecture's relationship to a continuously emerging material. Abingdon, Oxon;New York, NY;: Routledge.

27 "Plastics." How Plastics Are Made. Accessed February 21, 2017. https://plastics.americanchemistry.com/HowPlastics-Are-Made/.

28 Ibid.

29 Ibid.

30 Faircloth, Billie. 2015. Plastics now: On architecture's relationship to a continuously emerging material. Abingdon, Oxon;New York, NY;: Routledge.

31 Ibid.
} 


\section{Chapter: Issues}

Plastics can pollute in two ways: through its chemical breakdown, and through its physical dispersion.

\subsection{Chemical Breakdown}

Chemical Breakdown acknowledges that plastics pose significantly more threat to our aquatic environments as floating microplastics than on land. Chemical additives, such as plasticizers (also referred to as monomer additives) are used in combination with polymer strands (the plastic itself) to alter physical properties, resulting in a more flexible, flame retardant, or colourful plastic (9) ${ }^{32}$ These additives are toxic and have the potential to leach out into our ecosystems and into our bodies of water. These toxins have been correlated with "infertility, recurrent miscarriages, feminization of male fetuses, early-onset puberty, early-onset menopause, obesity, diabetes, reduced brain development, cancer, and neurological disorders such as early-onset senility in adults and reduced brain development in children" (3). ${ }^{33}$

Prolonged exposure to sunlight and repeated friction along plastic surfaces will release plasticizers into a given environment, thus allowing the plastic surface to become brittle and fragment into tiny pieces (13). ${ }^{34}$ This is most problematic in bodies of water, where sun and waves can accelerate the chemical breakdown of plastic objects. Plastic polymers are problematic in water, because they not only release pre-existing plasticizers, they also absorb oily chemicals at "concentrations of up to a million times higher than the surrounding water" (14). ${ }^{35}$ These microplastics (pieces under $5 \mathrm{~mm}$ ) are small enough for most species to ingest, thus, releasing both the original

\footnotetext{
32 Liboiron, M. (2016). "Redefining pollution and action: The matter of plastics." Journal of Material Culture, 21(1): 87110.

${ }^{33} \mathrm{lbid}$.

${ }^{34}$ Ibid.

$35 \mathrm{Ibid}$.
} 
monomer additives and the newly absorbed chemicals into the animal's tissue, eventually biomagnifying, increasing in concentration, up the food chain (1975). ${ }^{36}$ Figure 3 and 4

\subsection{Dispersion}

These microplastics, along with larger plastic waste, can be found in the Great Lakes: Superior, Huron, Michigan, Ontario, and Erie which cover 246,463 square kilometers and account for one-fifth of our planet's freshwater surface (6 quadrillion gallons). ${ }^{37}$ It is imperative to preserve the world's freshwater, not only for the thousands of species that rely on the lakes' ecosystems, but also for humanity, as this resource is a necessity for our survival. Approximately 34 million people in North America live along the shoreline of the Great Lakes. These shorelines (including islands) are equal to approximately 17,700 kilometers. ${ }^{38}$ As these locations are populated by human activity, our freshwater begins to pay the price. Figure 5 represents "places which exceed the range of normal variation due to human activity, affecting species, biological communities, or ecosystems". ${ }^{39}$

\section{The Great Lakes Water Quality Agreement (GLWQA) helps coordinate}

"actions to restore and protect the chemical, physical and biological integrity of the waters of the Great Lakes". ${ }^{40}$ Under this agreement, the Government of Canada has identified 17 Areas of Concern (AOC), five of which are "shared binationally". ${ }^{41}$ The objective of this agreement is to "restore beneficial uses of

\footnotetext{
${ }^{36}$ Thompson, Richard C., Shanna H. Swan, Charles J. Moore, and Frederick S. vom Saal. 2009. Our plastic age. Philosophical Transactions of the Royal Society B: Biological Sciences 364 (1526): 1973-6.

37 Zimmerman, Kim Ann. "Great Facts About the Five Great Lakes." LiveScience. May 3, 2013. http://www.livescience.com/29312-great-lakes.html.

38 "About the Great Lakes." Michigan Sea Grant. March 07, 2016. Accessed January 04, 2017. http://www.miseagrant.umich.edu/explore/about-the-great-lakes/.

39 Walker, Nick. "Pollution in the Great Lakes." Canadian Geographic. June 13, 2016. Accessed January 04, 2017. https://www.canadiangeographic.ca/article/pollution-great-lakes.

40 "What is the Great Lakes Water Quality Agreement?" Government of Canada, Environment and Climate Change Canada. July 12, 2013. Accessed January 04, 2017. http://www.ec.gc.ca/grandslacsgreatlakes/default.asp?lang=En\&n=45B79BF9-1.

41 "Great Lakes Areas of Concern." Government of Canada, Environment and Climate Change Canada, Ontario Region, Strategic Integration Division, Restoration Programs. April 30, 2015. Accessed January 04, 2017.

http://www.ec.gc.ca/raps-pas/default.asp?lang=En\&n=A290294A-1.
} 
the ecosystem by cleaning up severely contaminated and degraded locations around the Great Lakes". ${ }^{42}$ These guidelines will determine site specific locations for PEPs. As a starting point, Repackaging Packaging specifically focuses on the Detroit River, which has been designated as an AOC. The Detroit River is a part of the Great Lakes system as it connects Lake St. Clair with Lake Erie. As monitored by the Canadian Government, studies have shown that dense levels of "industrialization, urbanization and agricultural land use activities along the shores and within the tributaries of the Detroit River" have resulted in high levels of water pollution and degraded ecosystems. ${ }^{43}$ Habitat restoration, rehabilitation of coastal wetlands, construction of fish spawning habitats and shoreline naturalization projects are now the priority for remediation of the area. ${ }^{44}$ The Detroit River geographically separates Canada from the United States with the border situated directly down the middle of the river (see Figure 7 and 8). This site provides great opportunity for both nations to execute remediation efforts together. Its narrow width allows for infrastructure to establish a significant presence before roaming into open water.

Over 3,500 species of plants and animals, including more than 170 species of fish are affected throughout areas of the Great Lakes. ${ }^{45}$ The physical aspects of plastic dispersion are evidenced by plastic waste creating tributary damming, thus threatening fish species by blocking routes between spawning, nursery, and overwintering habitats. ${ }^{46}$ Figure 6 illustrates areas of the Great Lakes in which plastic dams are beginning to impede the flow of

\footnotetext{
42 "Areas of Concern." Government of Canada, Environment and Climate Change Canada. July 12, 2013. Accessed January 04, 2017. http://www.ec.gc.ca/grandslacs-greatlakes/default.asp?lang=En\&n=0F3E456F-1.

43 "Detroit River Area of Concern." Government of Canada, Environment and Climate Change Canada, Ontario Region, Strategic Integration Division, Restoration Programs. December 23, 2014. Accessed January $04,2017$. http://www.ec.gc.ca/raps-pas/default.asp?lang=En\&n=4EF278D1-1.

44 Ibid.

45 “About the Great Lakes.” Michigan Sea Grant. March 07, 2016. Accessed January 04, 2017. http://www.miseagrant.umich.edu/explore/about-the-great-lakes/.

46 Walker, Nick. "Pollution in the Great Lakes." Canadian Geographic. June 13, 2016. Accessed January $04,2017$. https://www.canadiangeographic.ca/article/pollution-great-lakes.
} 
water, nutrients and sediment. ${ }^{47}$ This human footprint is increasingly compromising our freshwater supply.

Many sources of litter such as: fishing, shipping, dumping, medical, personal hygiene, natural disasters, and recreational activities have a negative impact on the environment. Litter associated with recreational activities, include (but are not limited to): cigarette butts, food wrappers, bottle caps, beverage bottles, beverage cans, and other plastic and foam. ${ }^{48}$ Organizations such as the Great Canadian Shoreline Cleanup attempt to restore freshwater shorelines to a more natural and ecofriendly state. In 2015 approximately 59,000 registrants removed a total of 957,213 items, cleaning $3,211 \mathrm{~km}$ of Canadian shoreline. ${ }^{49}$ Nearly 181,000 items were made from plastic, which includes approximately 38,000 plastic bottles..$^{50}$ In Lake Ontario, 19,000 plastic bottles were collected. ${ }^{51}$ While it is generally important to collect these plastics, it is more important to consider the timeline in which they are collected. They must be removed from the water before they can disintegrate into microplastics. Once thought to take hundreds of years to break down, current research posits it takes as little as one year for plastic to begin leaching toxic chemicals into the water ${ }^{52}$ Furthermore, how these collected plastics are disposed is equally important to consider.

Recycling has become a profitable industry. One could argue that more product is sold if it is labeled as recyclable, thus benefiting industry more than the environment (11). ${ }^{53}$ Recycling has become an "industrial process that produces waste, uses energy, requires virgin materials [that is "free of

\footnotetext{
${ }^{47}$ Walker, Nick. "Pollution in the Great Lakes." Canadian Geographic. June 13, 2016. Accessed January $04,2017$. https://www.canadiangeographic.ca/article/pollution-great-lakes.

48 "Facts \& Figures." Great Canadian Shoreline Cleanup. Accessed January 04, 2017. http://www.shorelinecleanup.ca/en/content/facts-figures.

49 lbid.

50 Ibid.

51 Ibid.

52 "Plastic Breaks Down in Ocean, After All -- And Fast." National Geographic. Accessed January 04, 2017. http://news.nationalgeographic.com/news/2009/08/090820-plastic-decomposes-oceans-seas.html.

53 Liboiron, M. (2013). "Modern Waste as Strategy," Lo Squaderno: Explorations in Space and Society, 29: 9-12.
} 
impurity or stain," ${ }^{54}$ ] and often results in down-cycling, [the act of recycling a material by mixing it with a less valuable or non-recyclable material]" (56-60). ${ }^{55}$ This is a less than ideal solution when mediating between environment and plastic waste. Municipalities assume responsibility for the collection of disposable products, entirely alleviating responsibility from industry. For real change to occur, responsibility must shift back to industry (the source). If industry, for example, was taxed based on amount of plastic product they produced, one of two things would happen: production of plastic would either decrease at its source, or funding for remediation and scientific research would increase.

There is a disconnect between the industry's output of plastic products and their accountability towards plastic waste. It is simply cheaper and more profitable for industry to manufacture disposable plastic than it is for them to invest in reusable plastics. The origin of these perspectives is well summarized by the comments of Lloyd Stouffer, editor of Modern Packaging Inc., made during the SPI Conference in New York (1956):

It [is] time for the plastics industry to stop thinking about "reuse" packages and concentrate on single use. For the package that is used once and thrown away, like a tin can or a paper carton, represents not a one-shot market for a few thousand units, but an everyday recurring market measured by the billions of units. Your future in packaging, I said, does indeed lie in the trash can. (1) ${ }^{56}$

For industries, profit is the bottom line. Stouffer further discussed during the SPI Annual National Plastics Conference in Chicago:

It is a measure of your progress in packaging in the last seven years that [my 1956] remark will no longer raise any eye-brows. You are filling

\footnotetext{
54 Merriam-Webster's Collegiate Dictionary. 11th ed. Springfield, MA: Merriam-Webster, 2003.

55 (McDonough and Braungart 2002: 56-60)

56 Stouffer, Lloyd. "Plastic s Packaging: Today and Tomorrow." 1963 National Plastics Conference, November 19 , 1963, 1-3.
} 
the trash cans, the rubbish dumps and the incinerators with literally billions of plastics bottles, plastics jugs, plastics tubes, blisters and skin packs, plastics bags and films and sheet packages--and now, even plastics cans. The happy day has arrived when nobody any longer considers the plastics package too good to throw away. $(1)^{57}$

Although this quote may seem antiquated, recall these numbers: in 2013, only $14 \%$ of plastics were collected for recycling, of which $4 \%$ were lost to process, and $8 \%$ lost to collection and transportation (26). ${ }^{58}$ This left a meager $2 \%$ of world plastics that were truly recycled. The "happy day" that Stouffer was so excited to see arrive is here.

57 Stouffer, Lloyd. "Plastic s Packaging: Today and Tomorrow." 1963 National Plastics Conference, November 19, 1963, 1-3.

58 World Economic Forum, Ellen MacArthur Foundation and McKinsey \& Company. 2016. The New Plastics Economy - Rethinking the future of plastics. Accessed January 3, 2017. http://www.ellenmacarthurfoundation.org/publications. 


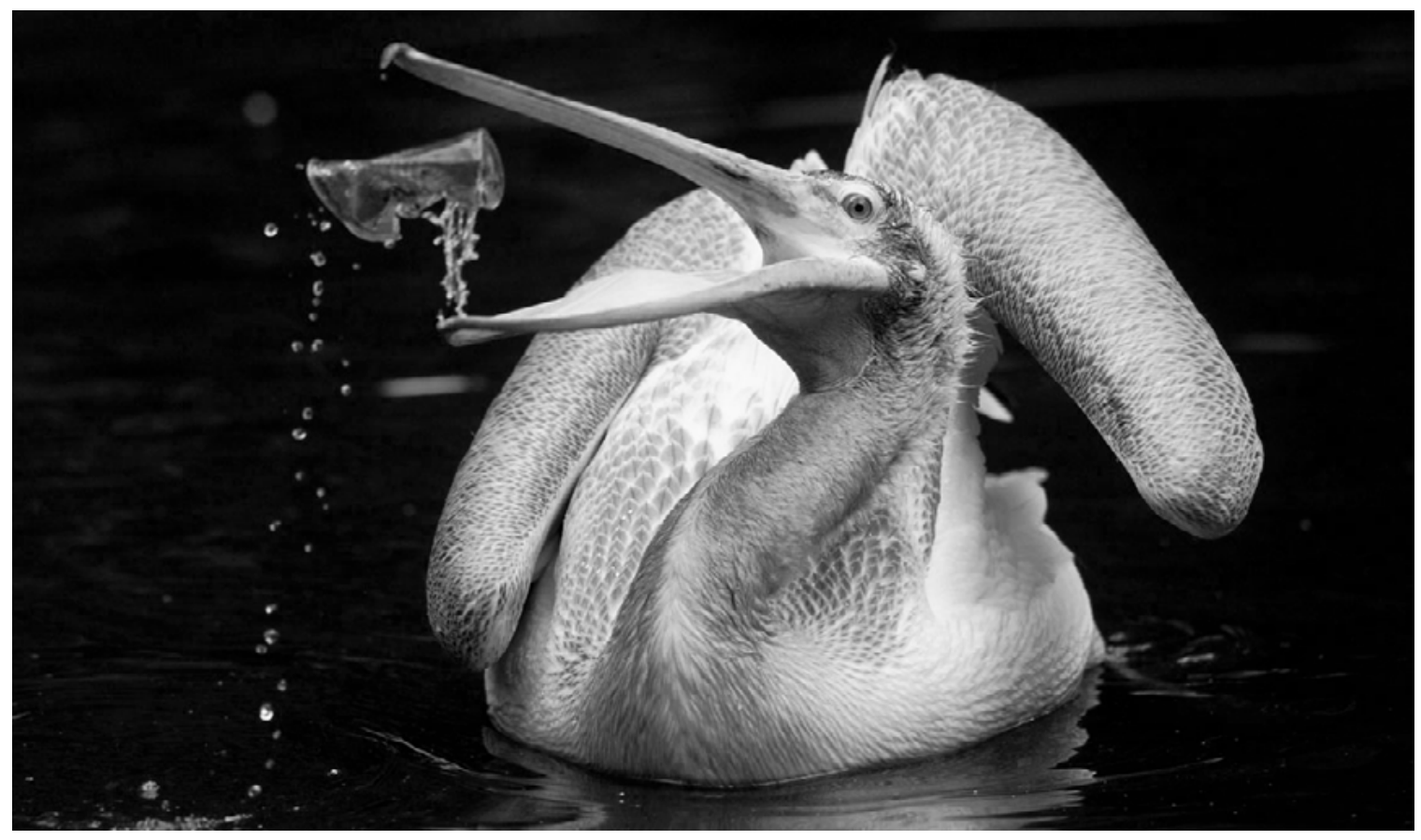

Figure. 3 Cizek, Michal. Bird eating a plastic cup. Digital image. Getty Images. Accessed January 3, 2017. https://s.w-X.co/birdplastic.jpg.

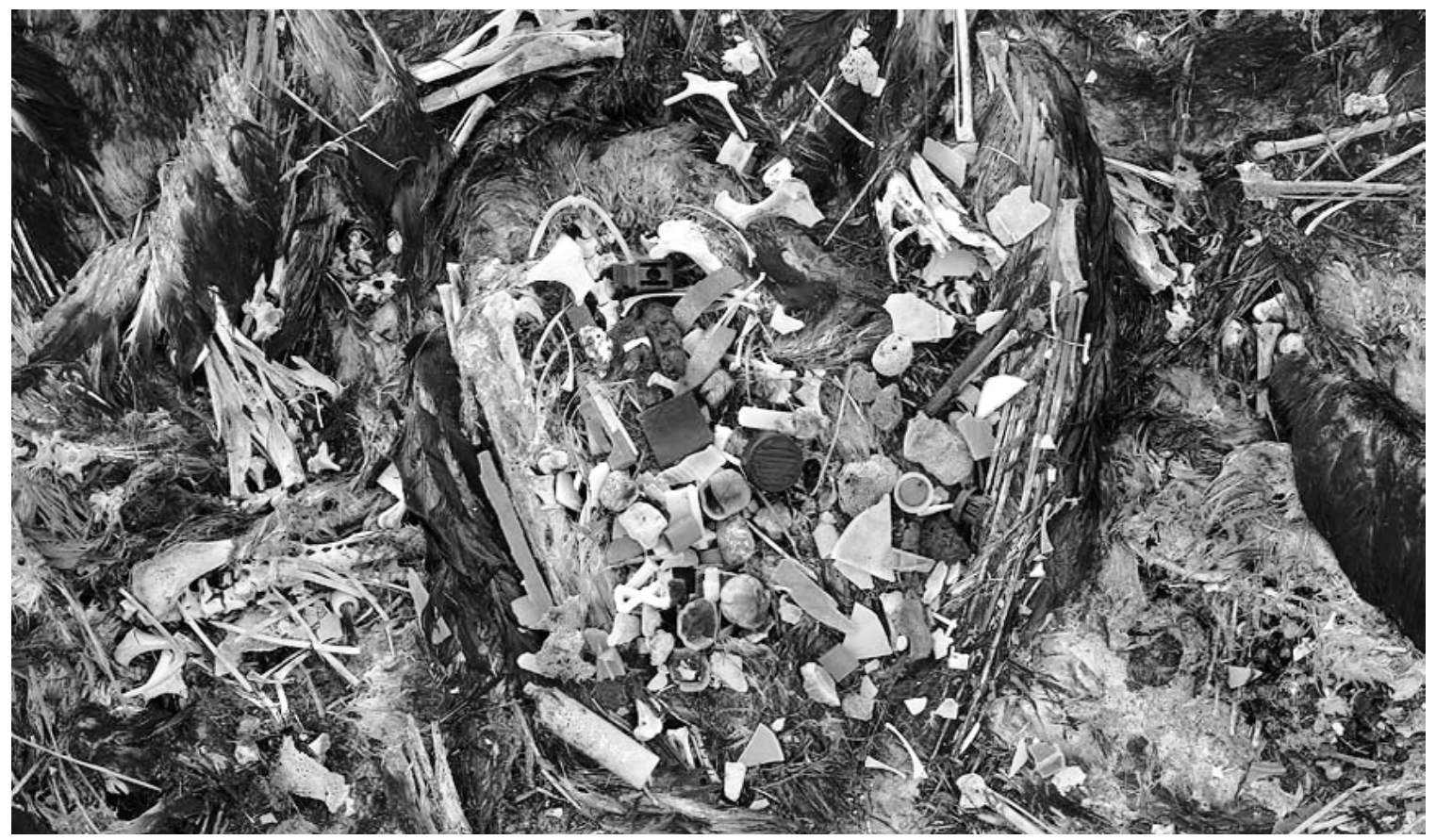

Figure 4. Jordan, Chris. Bird with plastic in it. Digital image. Nature Trust. Accessed January 3, 2017. http://www.naturetrust. $\mathrm{nb} . c a / \mathrm{wp} / \mathrm{blog} /$ the-charlotte-isles-cleanup/. 


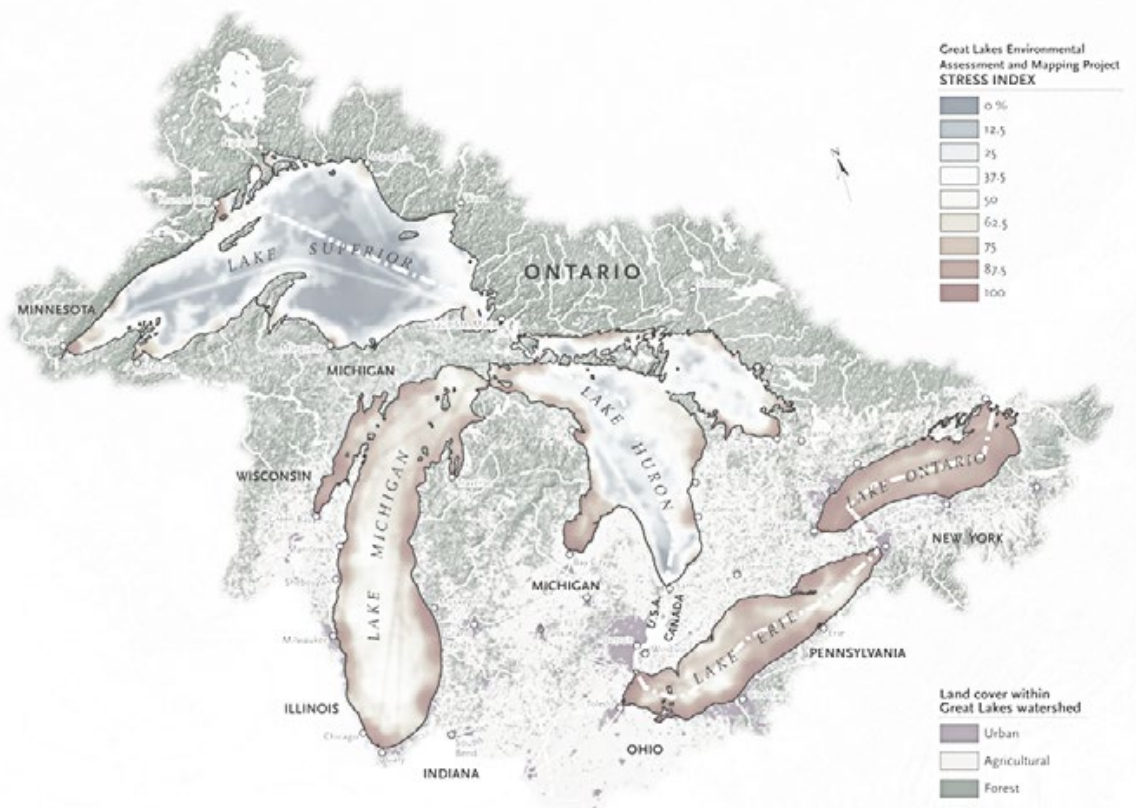

Figure 5. Map: Chris Brackley/Canadian Geographic

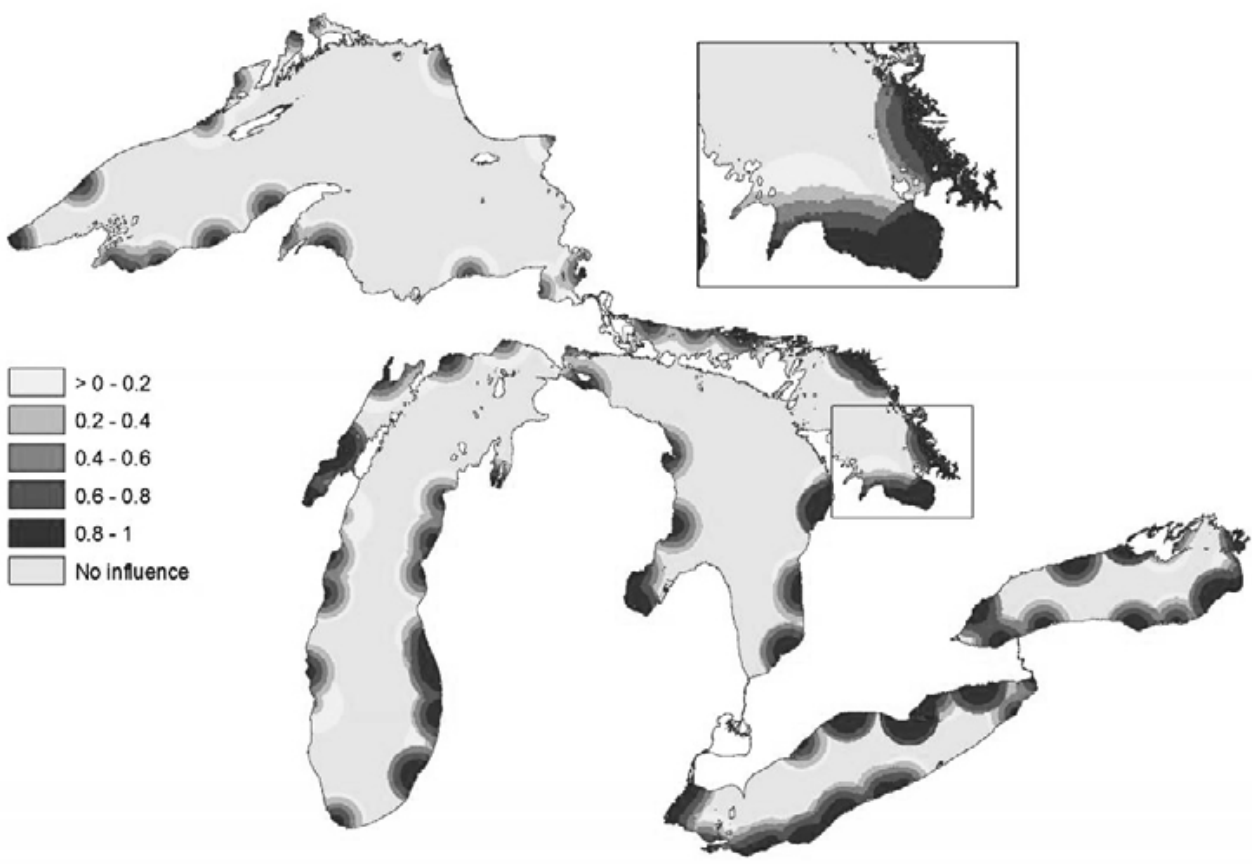

Figure 6. GLEAM Great Lakes Environmental Assessment and Mapping Project 


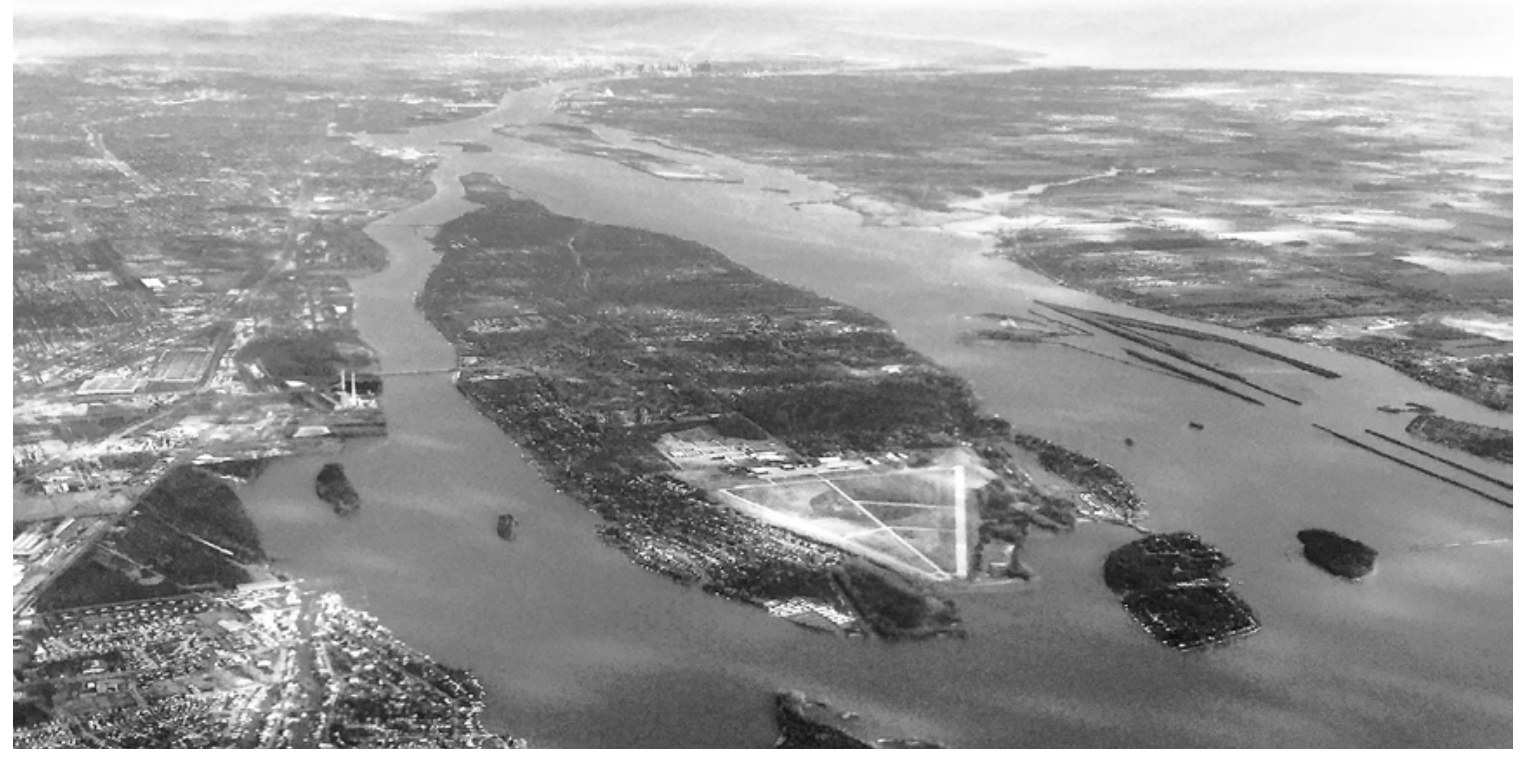

Figure 7. Aerial view of Grosse lle in the Detroit River from the south, as viewed from an aircraft shortly after takeoff from Detroit Metropolitan Airport. Grosse Ile Municipal Airport can be seen at the southern end of the island. Tim Kiser, January 7, 2016.

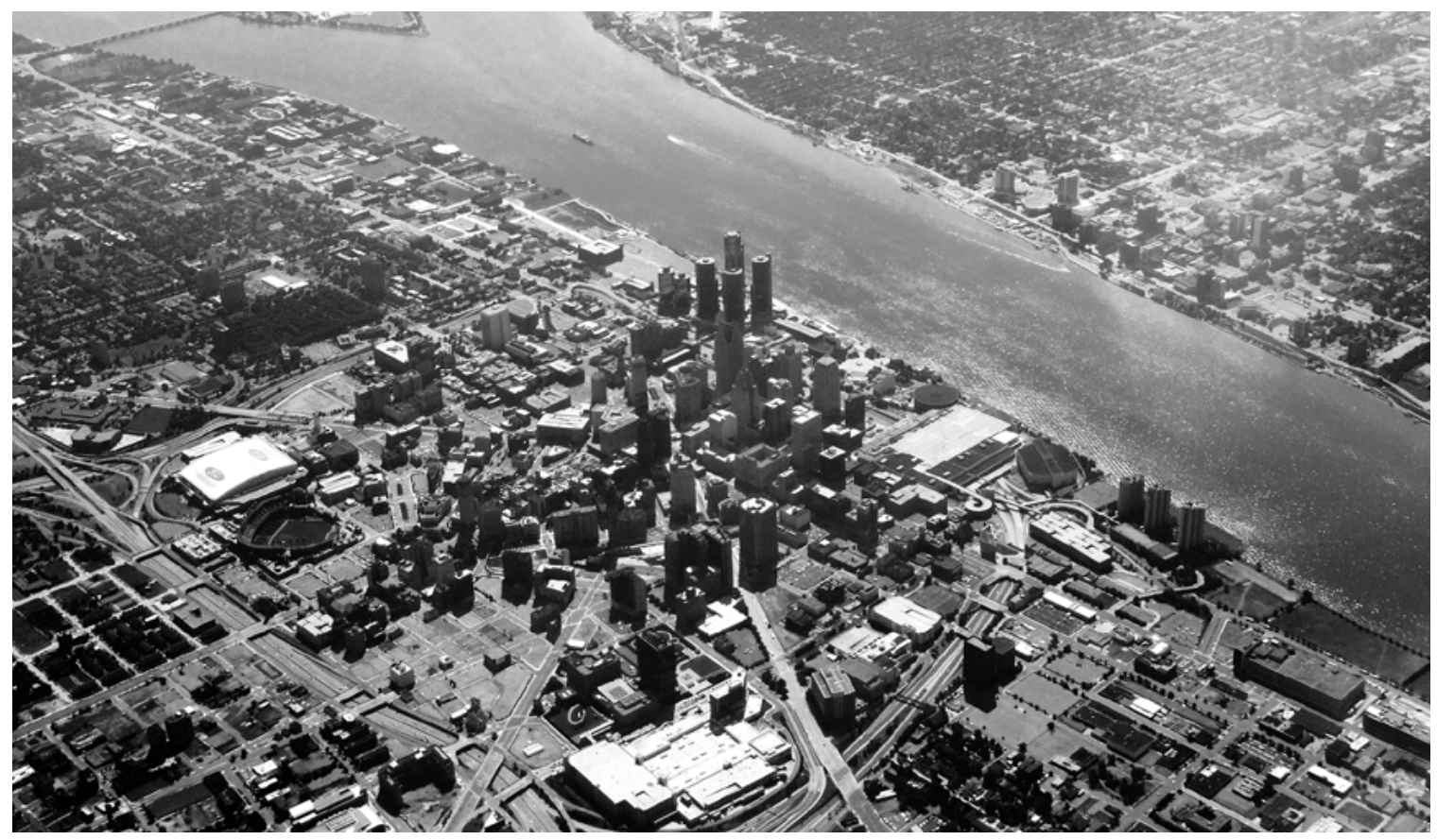

Figure 8. The Detroit River geographically separates Canada from the United States with the border situated directly down the middle of the river. Image above is by Barbara Eckstein, licensed by Creative Commons. 


\section{Chapter: Proposal of Project}

The process of recycling can be viewed negatively as it perpetuates the cycle of plastic. Recycling as we know it simply reintroduces plastic back into the rotation of products available. These will then eventually end up in the same wasteful position in landfills or as microplastics. This proposal will utilize a different type of 'recycling', where the plastic is 'recycled' into an entirely different product to be used long term. The plastic will be taken out of the cycle of waste and utilized as a part of the 'plastic eating' machines in order to eliminate itself (plastic waste) from our aquatic ecosystems. PEPs will roam independently through waterways 'ingesting' plastic material as it is encountered. Within the machine, the plastic will be repurposed into parts that will form new 'plastic eating' machines, or repair old ones. The more plastic that is removed in this fashion, the less will be available to return to this wasteful position in the water or landfills. In this scenario, the 'recycled' material is used and has a positive purpose-to diminish its environmental impact. As long as this final 'recycling' process is used to remove the plastic from the position of overall waste, then recycling is acceptable for the purpose of this project.

After the 'plastic eating' machines collect plastic waste from the Great Lakes, instead of transporting it to a recycling facility where energy waste occurs, the proposed machines will 'recycle' the waste into building material using methods such as melting, 3D printing, shredding, laminating or weaving. These large machines would also provide a locale for scientists to research and develop other positive improvements to the ecosystem around the machine.

Plastics are continuing to enter our environments each day, creating a systemic problem within our culture of consumerism. We have become complacent with the profitable, and wasteful ideology of the plastic industries. 
The wasteful and convenient nature of packaging has rendered habits within our culture that must be changed. It is essential to establish an understanding of plastic pollutants and the effects they have within our ecosystems. Without this understanding, we are potentially damaging our planet beyond repair. The research group, Civic Laboratory for Environmental Action Research (CLEAR) is developing technological tools which monitor the state of plastic pollution (38). ${ }^{59}$ By quantifying the amount of plastic entering aquatic ecosystems, scientists can better understand how plastic pollutants continue to damage these ecosystems. This research is essential for allowing effective intervention within the realm of plastic pollution (43). ${ }^{60}$ These programs will be developed further on the proposed machines and will gather primary data to be discussed and analyzed within interdisciplinary communities of scientists, designers, architects and more. The intention is to enable these groups the opportunity to make significant progress in understanding how to eliminate plastic pollution.

In many areas, rocky landscapes and extreme weather can present challenges for scientists when attempting to collect data. Technology can play a significant role when establishing architectural systems that act and interact within extreme environments. The proposed research centers (PEPs) will allow scientists to deal with unpredictable storm conditions, thus allowing both data collection and plastic remediation to continue all year round. During winter months, the research centers will be equipped with stabilizing engines which counter, or adjust to ice movement (Figure 9 and 10). However, creating technologies that only remove plastics from our ecosystems perhaps isn't the solution in eliminating the pollutant. Max Liboiron argues that:

these devices do not address the root of marine plastic pollution and can even divert money and attention away from deceasing, mitigating,

\footnotetext{
59 Liboiron, M. (2016). "Civic Technologies for Monitoring Marine Plastics," Journal of Ocean Technology 11(2): 36-45. $60 \mathrm{lbid}$.
} 
and slowing the creation of plastic disposables in the first place. Marine plastics are a stock and flow problem, where plastics flow from land into the oceans and accumulate there as stock. Technologies that make big claims to "clean up" marine plastics deal with the stock, but not the flow, or source, of plastics. $(44)^{61}$

This thesis argues that, it is important for these interventions and processes to not only clean up plastic, but also to make industry re-think how plastic waste is currently defined, designed, created, and circulated (12). ${ }^{62}$ Only by influencing the 'flow' of plastic can there be significant remediation of plastic 'stock'. The technologies being referenced above differ from the proposed in that the proposed 'plastic eating' machines remove the plastic 'stock' from the 'flow' permanently. In the proposed scenario, the problem of 'stock' is not ignored, as it is collected and used as a solution to remediate more plastic, 'plastic eating plastic', reducing a cycle of waste. In this scenario, the 'flow' of plastic is also not overlooked as PEPs facilitate scientific research that attempts to reduce the production of plastic at its source.

As plastic remains in water it will continue to fragment into smaller and smaller pieces. Research has proven that microplastics (in natural conditions) will take centuries to biodegrade, "capable of being broken [...] by the action of living things," ${ }^{3}$ thus existing within 'deep time', a "[geological timescale] that far outstrip[s] the timescales of species" (44). ${ }^{64}$ The notion of 'deep time' is evidenced in the formation of plastic rocks, known as plastiglomerates. ${ }^{65}$ Plastic has been embedded and fused to dense rock material, ${ }^{66}$ essentially fossilizing and locking it in 'deep time'. Scientists have also found vast amounts of plastic particles frozen in Arctic sea ice, leading to experts estimating that, "under current melting trends, more than 1 trillion pieces of

\footnotetext{
61 Liboiron, M. (2016). "Civic Technologies for Monitoring Marine Plastics," Journal of Ocean Technology 11(2): 36-45.

62 Liboiron, M. (2013). "Modern Waste as Strategy," Lo Squaderno: Explorations in Space and Society, 29: 9-12.

${ }^{63}$ Oxford University Press. The Oxford American College Dictionary. Published G.P. Putnam's Sons, 2002.

64 Liboiron, M. (2016). "Civic Technologies for Monitoring Marine Plastics," Journal of Ocean Technology 11(2): 36-45.

${ }^{65}$ Chen, Angus. "Rocks Made of Plastic Found on Hawaiian Beach." Science | AAAS. January 12, 2016. Accessed

March 28, 2017. http://www.sciencemag.org/news/2014/06/rocks-made-plastic-found-hawaiian-beach.

${ }^{66} \mathrm{Ibid}$.
} 
plastic could be released in the next decade." "If technologies only focus on the issues of 'stock' we are essentially "moving pollution around in space while it endures over time" (44) ${ }^{68}$ This proposal will aim to provide framework within which scientists, artists, and architects can combine expertise to solve both the 'flow' and 'stock' problems of plastic waste. This proposal acknowledges that recycled plastic is not a desirable raw material for profit, however, underlines the significance for reducing the production and dispersion of virgin plastics. Something must be done with plastic waste.

${ }^{67}$ Hand, Eric. "Trillions of Plastic Pieces May Be Trapped in Arctic Ice." Science | AAAS. January 12, 2016. Accessed March 28, 2017. http://www.sciencemag.org/news/2014/05/trillions-plastic-pieces-may-be-trapped-arctic-ice.

68 Liboiron, M. (2016). "Civic Technologies for Monitoring Marine Plastics," Journal of Ocean Technology 11(2): 36-45. 


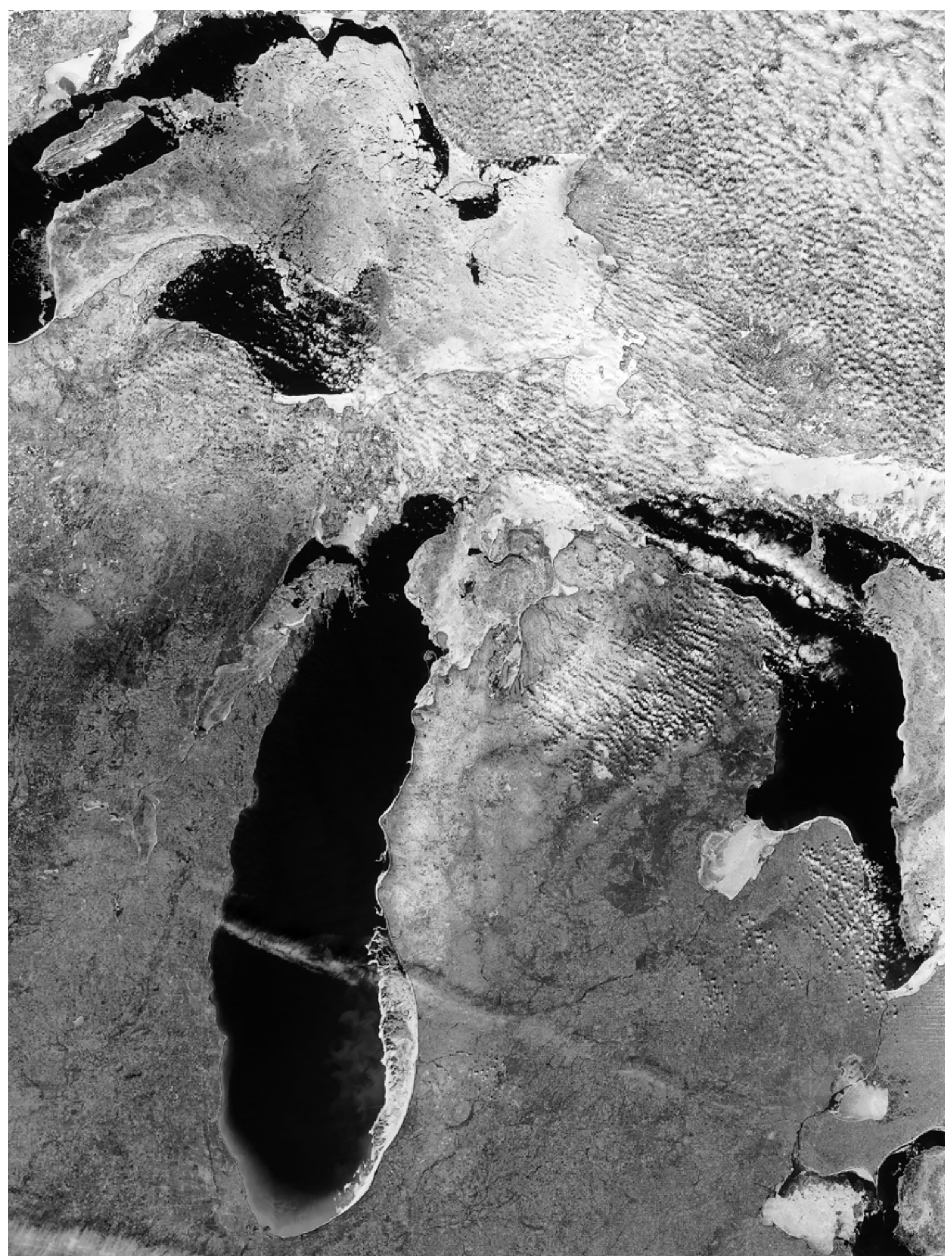

Figure 9. Schmaltz, Jeff. A Great Freeze Over the Great Lakes. Satellite image of ice formation on all five Great Lakes. Digital Image. NASA. February 19, 2014. 


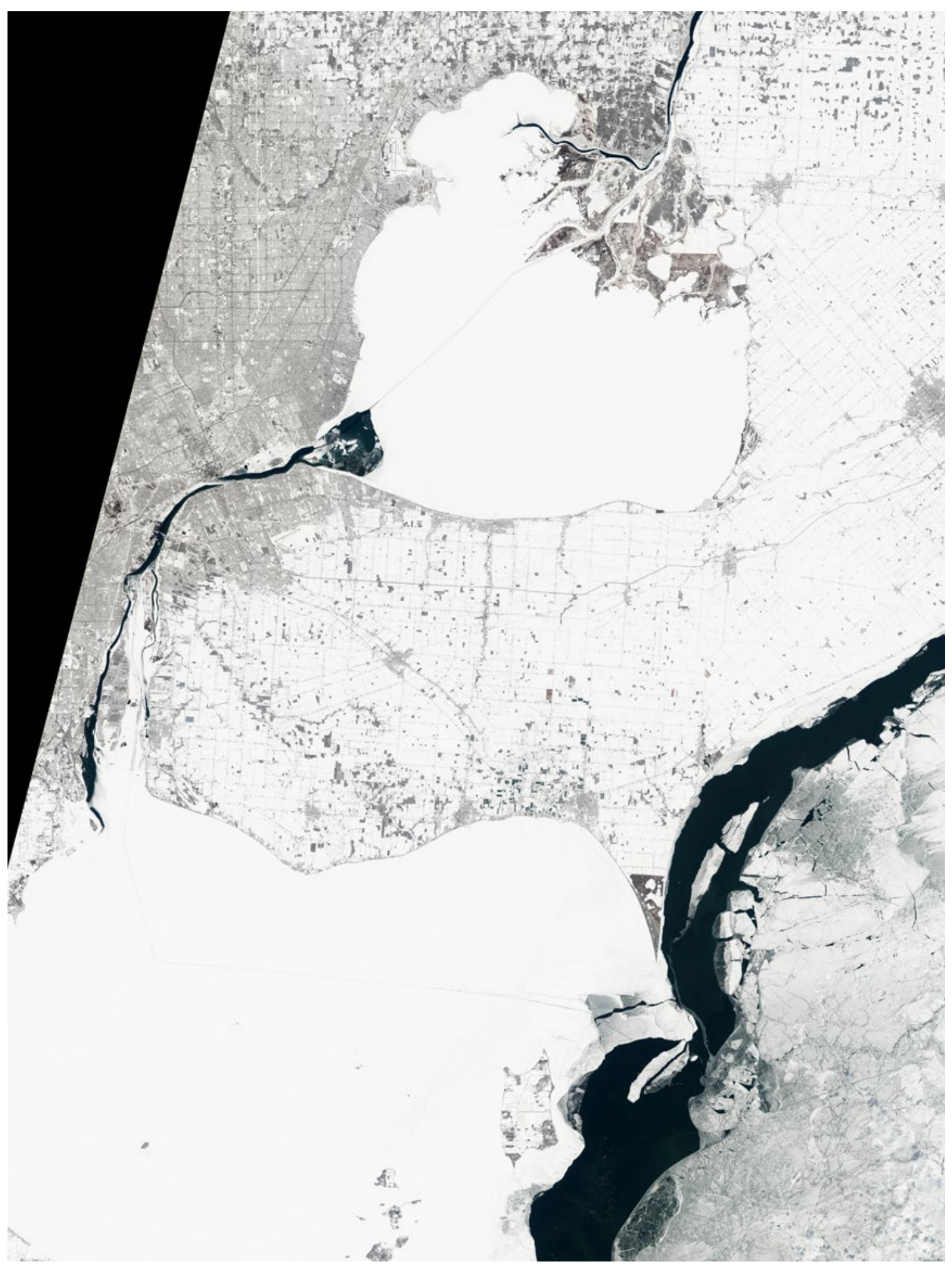

Figure 10. NASA Worldview (2015, November) Lake Erie and Detroit River. 
Through intensive research, parallels surfaced between existing organizations and principles being outlined in this paper. After analysing the similarities, these common goals can be regarded as a virtue.

Parley is an organization which encourages designers, academics, and leaders to come together to "raise awareness for the beauty and fragility of our oceans." ${ }^{69}$ The intentions of Parley align with the underlying focus of this thesis as it attempts to unite multidisciplinary groups to collaborate on projects that can transform our oceans back to their natural state.

The organization aims to "save marine wildlife by cleaning up shorelines [...] oceans and [cutting] into the production of new, virgin plastic through closedloop recycling systems." ${ }^{70}$ This mitigates the "stock" issue of plastic pollution and further, Parley reduces the "flow" of plastic by operating "an extensive research and development program to invent alternatives [to plastic] and to establish new industry standards." ${ }^{11}$

With regards to "stock", much attention has been placed on the reuse of ocean plastics. Parley has teamed up with clothing companies such as Adidas to develop products made from ocean plastics. The intention behind the reuse initiative is not only to reduce the pollutant from bodies of water, but to reduce the consumption of natural resources such as the fossil fuels needed to create virgin plastics. ${ }^{72}$ These companies are beginning to envision plastic pollution as a source to create reusable products. At first glance, these attempts to reduce the footprint of plastic waste seem to be a step in the right direction.

69 "Parley for the Oceans." Parley. Accessed March 07, 2017. http://www.parley.tv/\#fortheoceans.
70 Ibid.
71 Ibid.
72 "Parley for the Oceans." Parley. Accessed March 07, 2017. http://www.parley.tv/\#fortheoceans. 
By 2017 Adidas aims to produce "1 million pairs of [...] sneakers from more than 11 million plastic bottles. Eventually, [striving] to eliminate virgin plastic from its supply chain [and] expand its plastic cultivation to much more of its product line." ${ }^{\text {73 }}$ Adidas has also "released a line of swimwear made entirely from used fishing nets and debris intercepted in coastal areas." ${ }^{74}$ Fishing nets can be converted into "upcycled yarn that has all the same properties as traditional nylon, without the environmental footprint." ${ }^{75}$

Although this proves that with research and development new products can be made from collected waste, it may unintentionally provide false hope as a long-term solution for remediating plastic from water. Products will only find their way back into our ecosystems and landfills once more unless they are purposed as multi-use products for long term use outside of the consumer cycle, such as structurally reinforced plastic panels and other components of plastic eating machines. In these cases, if the plastics do break down they are enclosed in a closed loop environment where they can easily be altered or changed and are never reintroduced into the natural environment. Again, to eliminate the problem of plastic, industry must re-think the product at its origins - from its purpose to end-of-life consequences.

Through many conferences organizations such as Parley have been able to synchronize diverse thinking, thus unifying a common goal. Marco Spier, founder of Psyop, a creative design and animation studio discusses how "inspiration is the spark that ignites technology [and how] science fiction can change the world." ${ }^{16}$ Through visual storytelling, Spier hopes to spread awareness and "catalyze solutions for the oceans." 77 These solutions begin to manifest through the research of Miranda Wang. As a student of biochemistry

\footnotetext{
73 McCarthy, Joe. "Adidas Shoes Made from Ocean Plastic Are Finally Here." Global Citizen. Accessed March 06, 2017. https://www.globalcitizen.org/en/content/adidas-shoes-made-from-ocean-plastic-are-finally-h/.

74 Ibid.

75 Ibid.

76 Spier, Marco. "Talks." Parley. Accessed March 06, 2017. http://www.parley.tv/talks/\#parley-talks1.

77 Ibid.
} 
at the University of Pennsylvania, she is "isolating and characterizing plasticdegrading bacteria from the natural environment. She continues to engage in developing new methods of bioremediation through synthetic biology." Many conventional methods cannot remediate microplastics - professionals believe that synthetic biology can provide a solution to this problem. A team of students from the University College in London (UCL), have "[synthesised] a new strain of bacteria, capable of detecting, aggregating, and buoying [...] elusive microplastics." ${ }^{79}$ Their vision is to create large synthetic plastic islands.

This thesis will consider all supporting principles as justification for an architecture that not only serves as inspirational technology to rehabilitate aquatic ecosystems, but also to provide spaces in which scientific thought, and multidisciplinary collaboration, can occur (Figure 25).

\footnotetext{
${ }^{78}$ Wang, Miranda. "Talks." Parley. Accessed March 06, 2017. http://www.parley.tv/talks/\#parley-talks1. 79 "Plastic Republic." UCL Biochemical Engineering. July 08, 2016. Accessed March 06, 2017. https://www.ucl.ac.uk/biochemeng/about/iGEM/tabs/2012.
} 


\subsection{Project Strategy}

\section{Step 1}

Reduce-Plastic in packaging must be minimized by the industry.

Step 2

Tax Industries-By taxing industries on the content they are creating they will either produce less product or raise funds for remediation of the pollutant.

Step 3

Construction-These funds raised by companies following new taxation will allow for construction of roaming 'plastic-eating' machines that simultaneously function as scientific research centers.

Step 4

Collection-The machines begin their work of gathering material to be sorted, cleaned, and converted into usable material.

Step 5

Maintenance-Repairs will be done on the machines/research centers as storms, currents and time take their toll.

Step 6

Use-The 'recycled' plastic is used onsite to repair and improve the research centers over time including sails, rain screens and new parts. 


\subsection{Project Outline}

\subsubsection{Immediate Goal}

To investigate the limitations and capabilities of thermoplastics as building material. To capture the attention of individuals, and to facilitate conversation that re-thinks plastic waste.

\subsubsection{Long Term Goal}

Plastic Free Water-Influence policy makers within the plastic industry to rethink plastic packaging.

\subsubsection{Purpose}

Plastic Remediation - This approach underlines not only the desire to remove plastic from our water, but more importantly, emphasizes the need to reduce, and eventually, eliminate plastic production. For this project, disposable plastic exists within the closed looped system of plastic-eating-plastic.

Multidisciplinary Collaboration-PEPs will provide opportunity for researchers to develop equipment that remediates the plastic pollutant, collects data, and allows researchers to better understand the issues of plastic waste. As supported by organizations such as Parley and Civic Technologies, a multidisciplinary platform will establish plastic free water.

Mapping and Monitoring of Aquatic Ecosystems- "Monitoring [aquatic ecosystems] represents an important step towards quantifying spatial and temporal trends of [...] plastic." (1975) ${ }^{80}$ Continued mapping of aquatic

\footnotetext{
80 Thompson, Richard C., Shanna H. Swan, Charles J. Moore, and Frederick S. vom Saal. 2009. Our plastic age. Philosophical Transactions of the Royal Society B: Biological Sciences 364 (1526): 1973-6.
} 
ecosystems will provide researchers the information needed to counteract plastics that are sinking, floating, or migrating within bodies of water.

Inspiration-This concept aims to create awareness of our plastic problem, while stimulating creative action within the realms of science and design.

\subsubsection{Tasks: Support of Ocean and Great Lake Preservation}

Restoration:

Remediation of Great Lakes, shorelines, ocean gyres, and deep seas through the removal of floating microplastics. Redevelopment of coastal and Great Lakes species and their habitats after this removal.

\section{Data Collection:}

Mapping, monitoring, and observation of ocean, coastal and the Great Lake systems. These ecosystem assessments and mapping for protecting ecosystem health from plastic debris will also help us to gain practical experience of our planet's water.

\section{Research Development:}

Scientific experiments relating to the collection and use of littered plastics. Conferences and meetings to discuss primary data and prototypes.

\subsubsection{Importance of Restoration Program}

It is evident that many organizations, such as those previously discussed, are proactive when it comes to preserving aquatic ecosystems. According to the U.S. Commission on Ocean Policy, research and restoration programs, such as the plastic eating machines, would not only "create jobs and support coastal economies $[\ldots]$ they would also ensure that present and future generations benefit from the ecological, economic, educational, social, cultural, spiritual, nutritional and recreational resources of our ocean, coasts 
and Great Lakes." ${ }^{81}$ The desire for these types of programs justifies the proposed architecture as a speculative design. It is intended to rethink the way in which these programs work individually and gather them into one unifying research facility, located on the plastic eating machines, and allow these organizations to interact and have social collisions that ultimately progress solutions.

Within Repackaging Packaging, the architect becomes the agent by establishing new ways to use 'recycled' material. With this intention, it is important for architects to understand the capabilities and limitations of the 'recycled' plastic. Specifically, through collaboration and experimentation, researchers will design and manufacture plastic components which will be used to operate the plastic remediation facilities. Components such as: wind and current sails (to assist in the structure's movement), trawls (to collect data samples), plastic reinforced panels (to act as rain screens), and plastic joints. Future iterations will include: submerged panelized sections that will release plastic 'locating' bacterial organisms (developed by research from UCL) that will result in the collection of stitched floating micro plastics, and eventually, customized machines will operate shredding, compression, extrusion, and plastic printing mechanisms that will assist with repair strategies for the facility. The next step will be to develop an environment that allows bacteria to attach and grow along the facility's structure. Thus, the collection of microplastics becomes a structural, as well as a remediating process. The research of Miranda Wang will be utilized as she has engineered bacteria that produce protein after breaking down the plastic waste. This protein can be used to bioremediate the ecosystem by feeding fish. Occupants of the facility will first be challenged to create bioreactors, "an apparatus in which a biological reaction or process is carried out, especially on an industrial

\footnotetext{
81 Woglom, Emily. "The Most Important Congressional Action on the Ocean You've Never Heard of." Ocean Currents. November 15, 2013. Accessed March 06, 2017. http://blog.oceanconservancy.org/2013/11/15/the-most-importantcongressional-action-on-the-ocean-youve-never-heard-of/.
} 
scale" 82 that can scale the bacteria population to sufficient numbers to produce the predetermined levels of protein necessary to sustain the onsite fish population. These processes will work in tandem with the first set of bacteria that collect and harness the plastic and the next set will use this plastic as the source to support the fish population (Figure 27).

82 Merriam-Webster's Collegiate Dictionary. 11th ed. Springfield, MA: Merriam-Webster, 2003. 


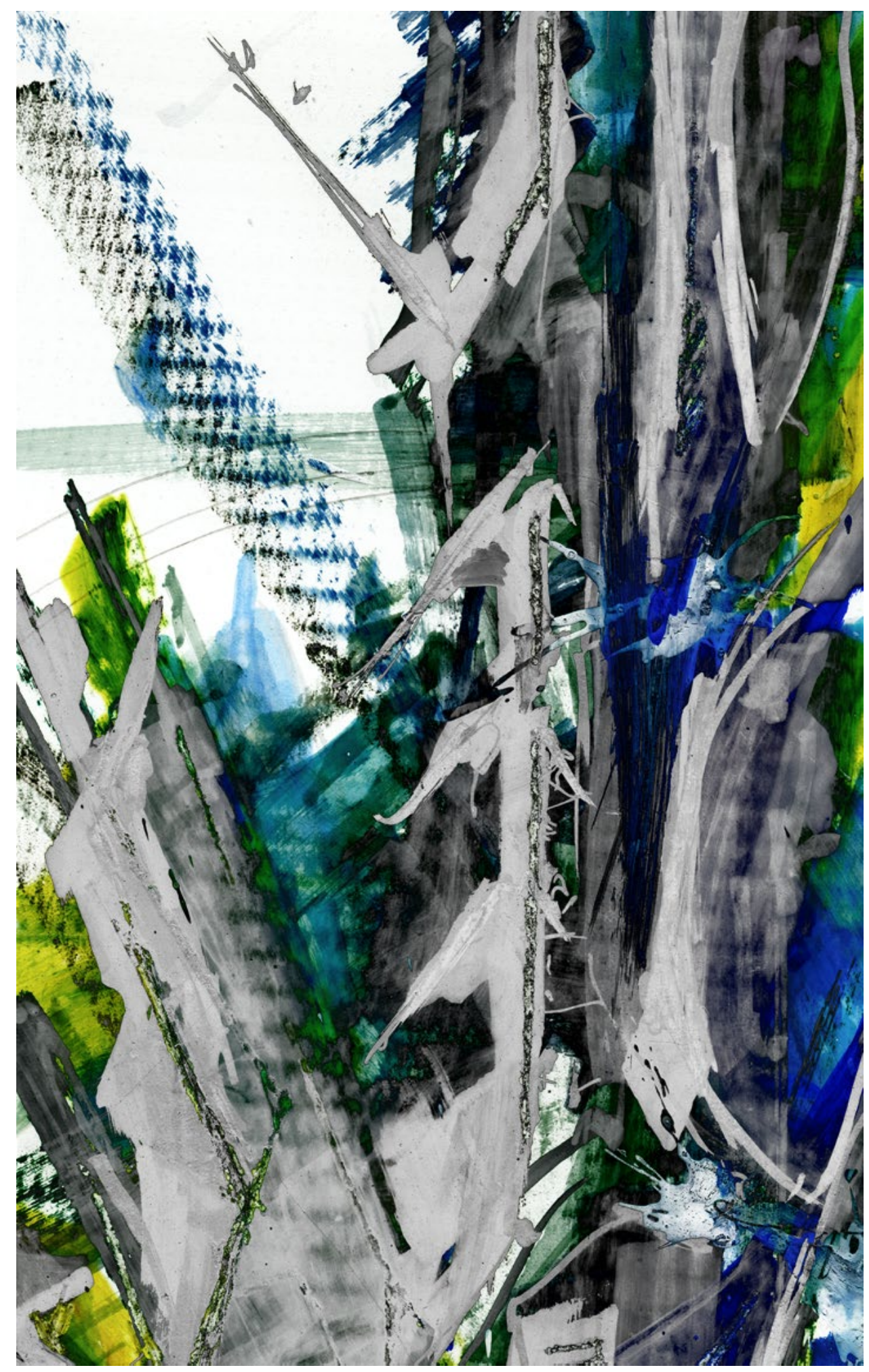

Figure 11. Process Sketch - Colour Exploration 


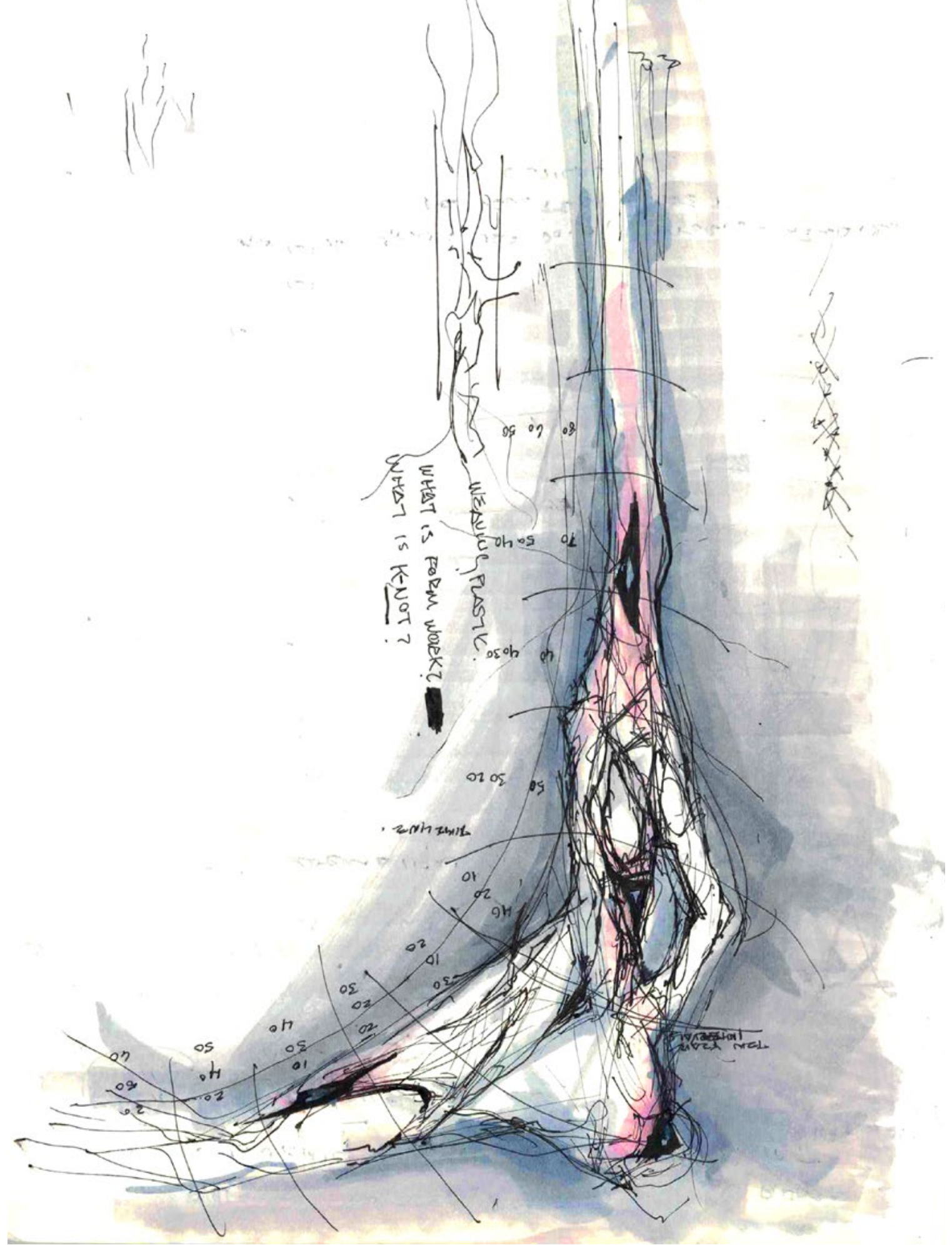

Figure 12. Process Sketch - Growth of Plastic Island (10 year intervals) 


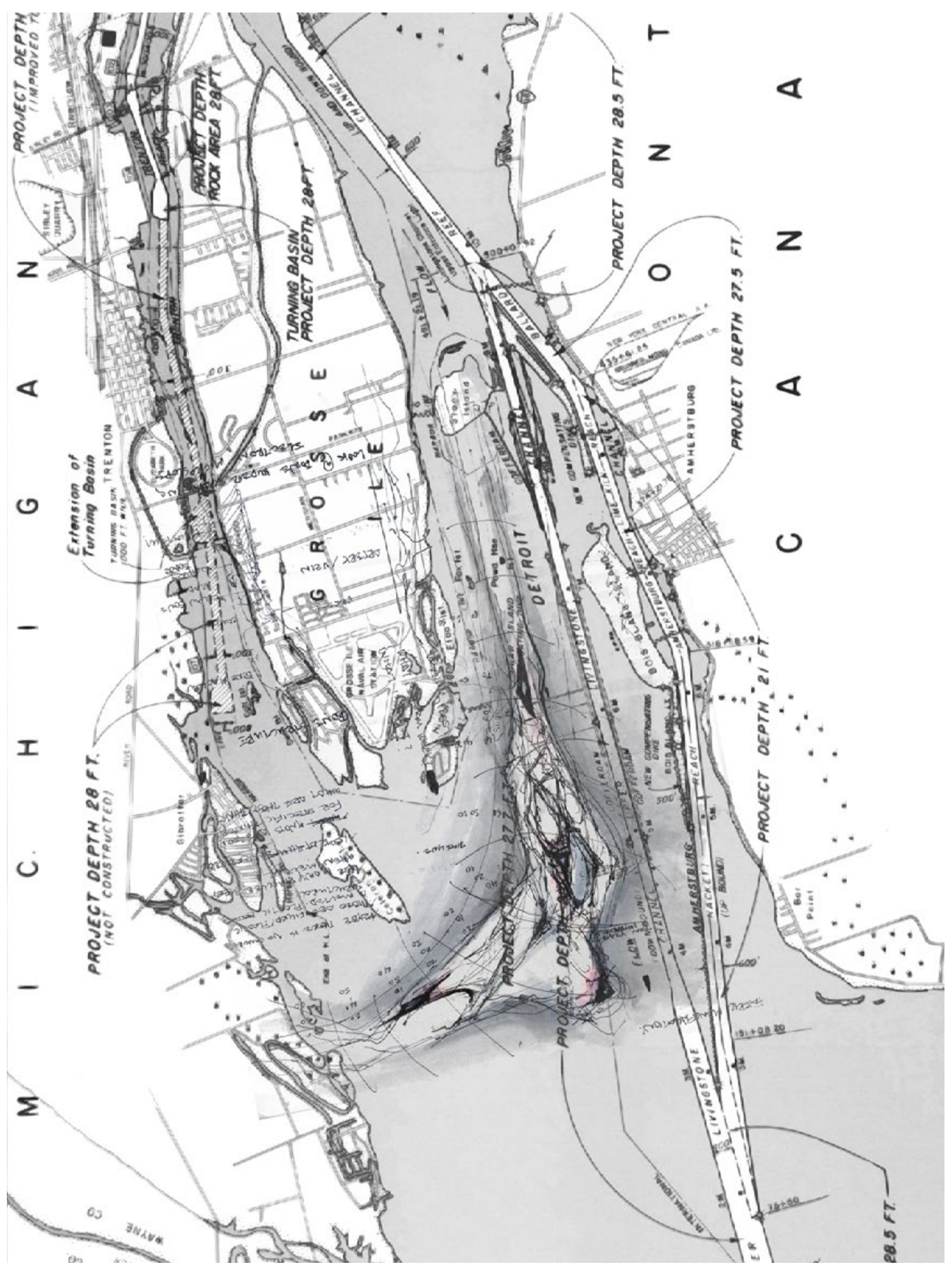

Figure 13. Concept - Growth of Docking Facilities depicted in ten year intervalsUnits may begin to link, creating mega scale infrastructure. 


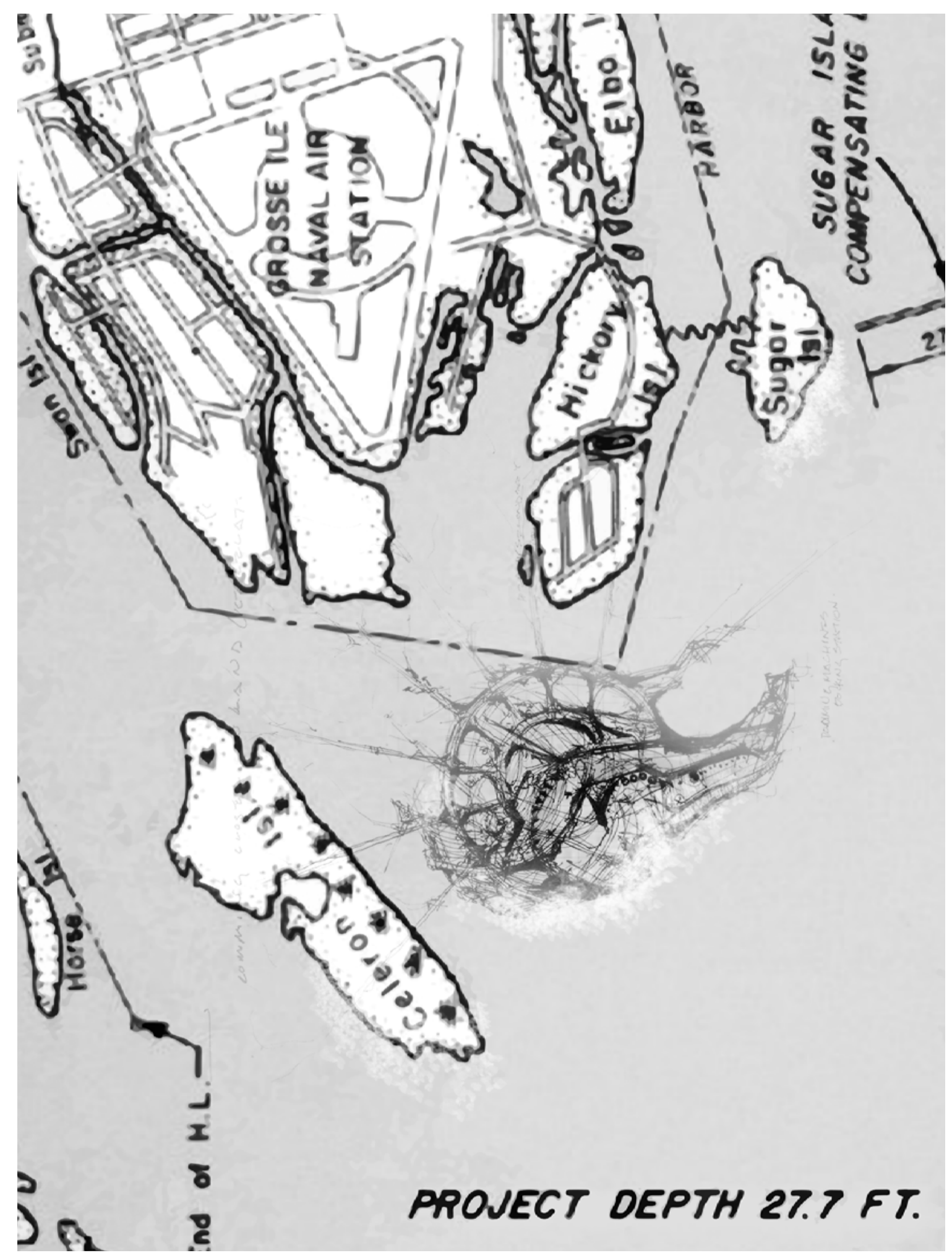

Figure 14. Concept - Docking Facility for the Roaming Plastic Eating Machines. 


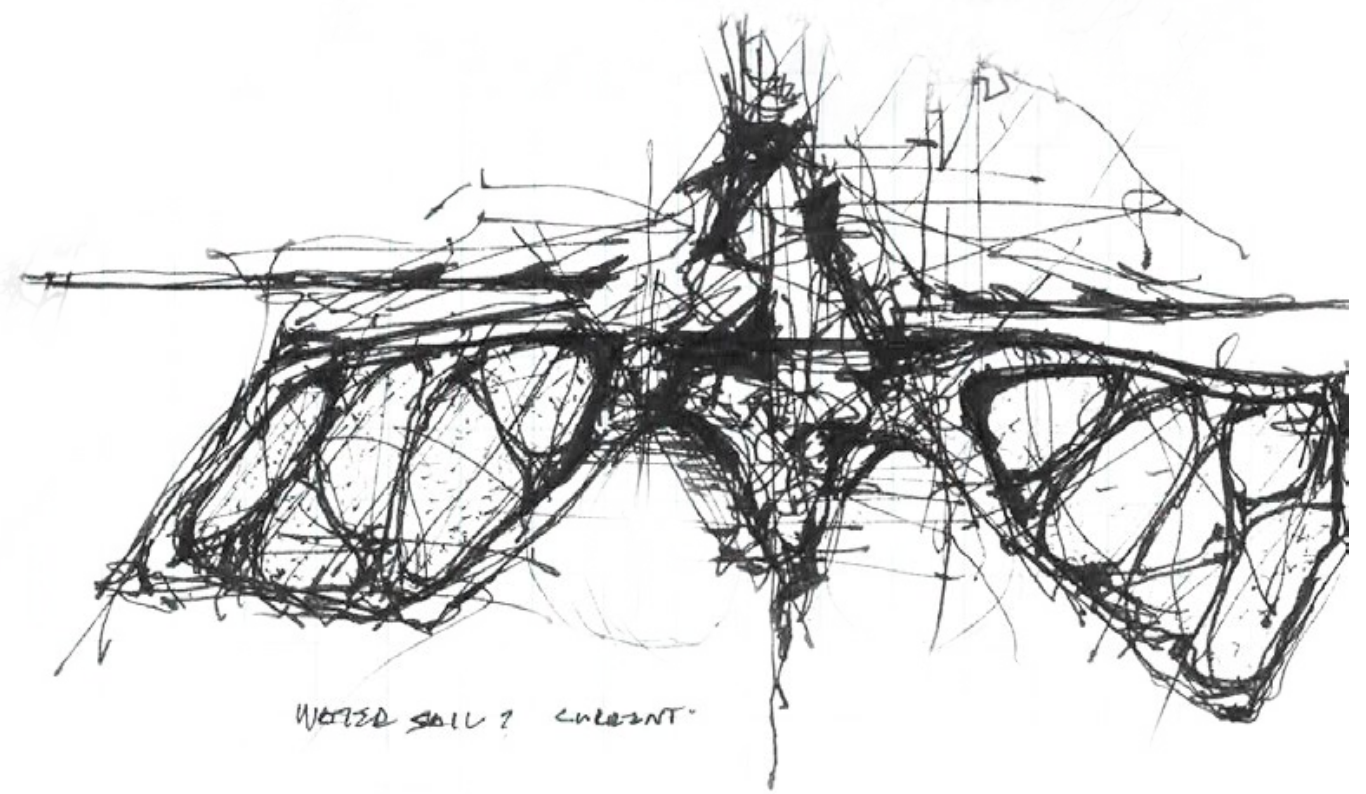

Figure 15. Cross Section of Single Scientific Research Facility.

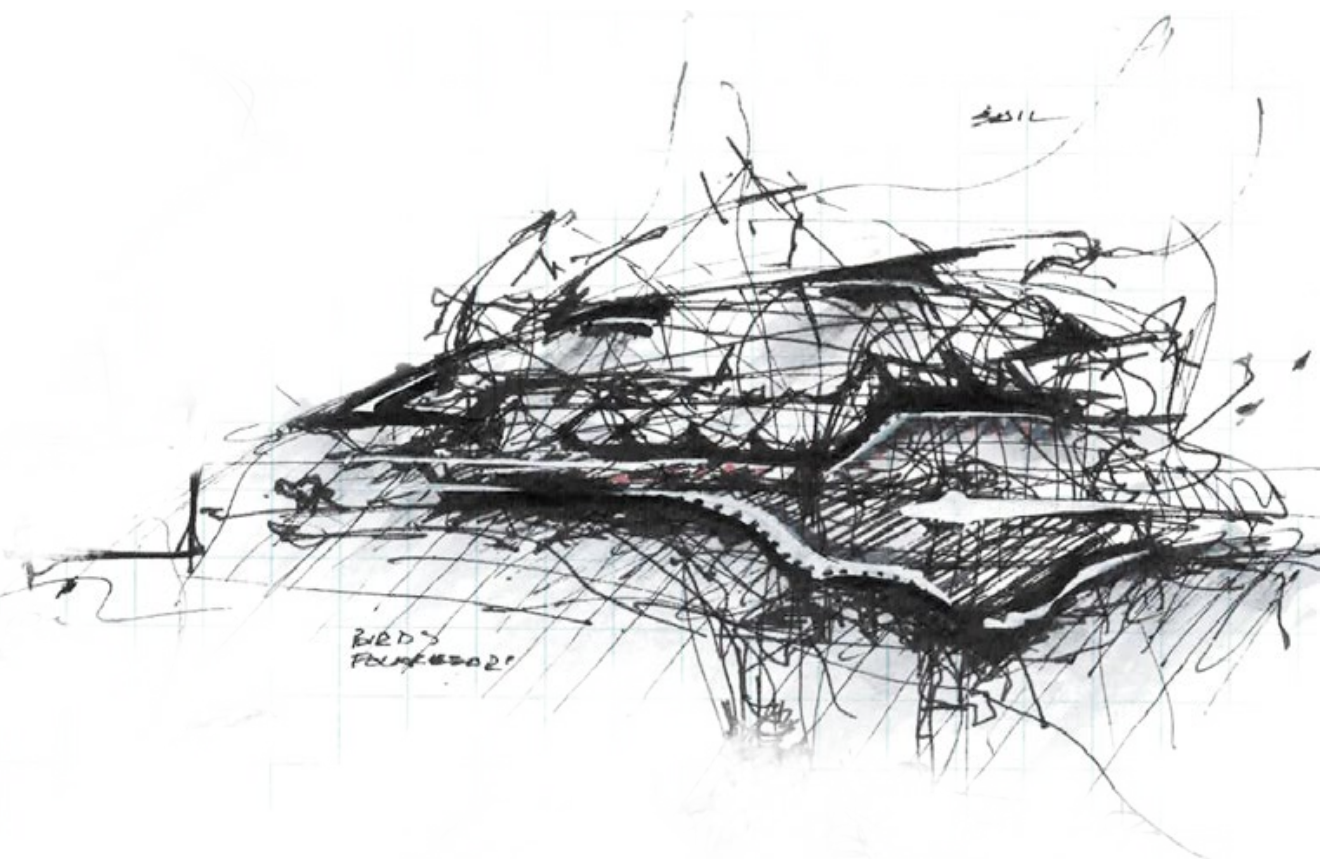

Figure 16. Concept - Longitudinal Section of Single Scientific Research Facility. 


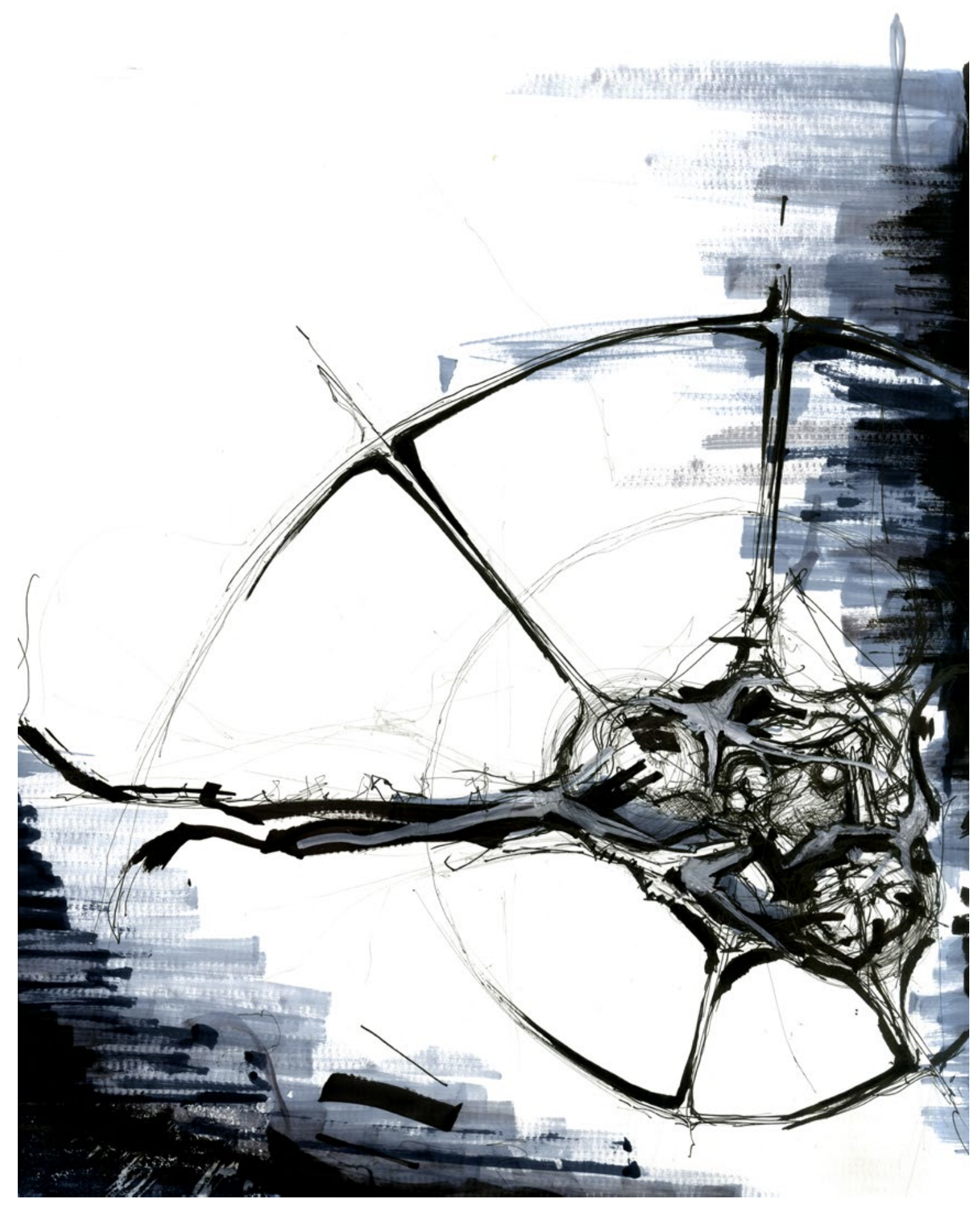

Figure 17 . Process Sketch - PEP Machine Establishing Quarantine Area (Plan) 


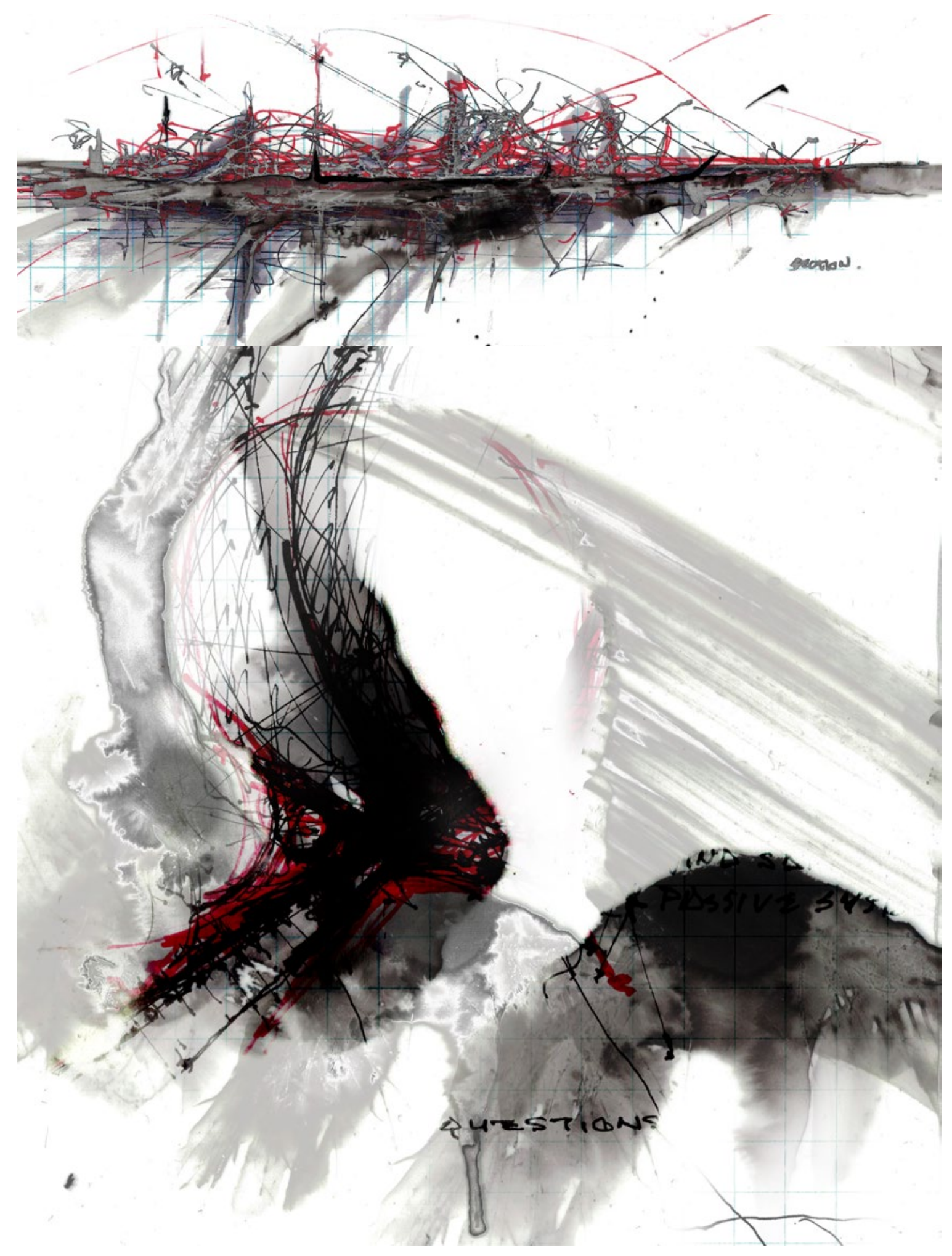

Figure 18. Process Sketch - Aerial View of Plastic Rehabilitation Zone. (Section Above) 


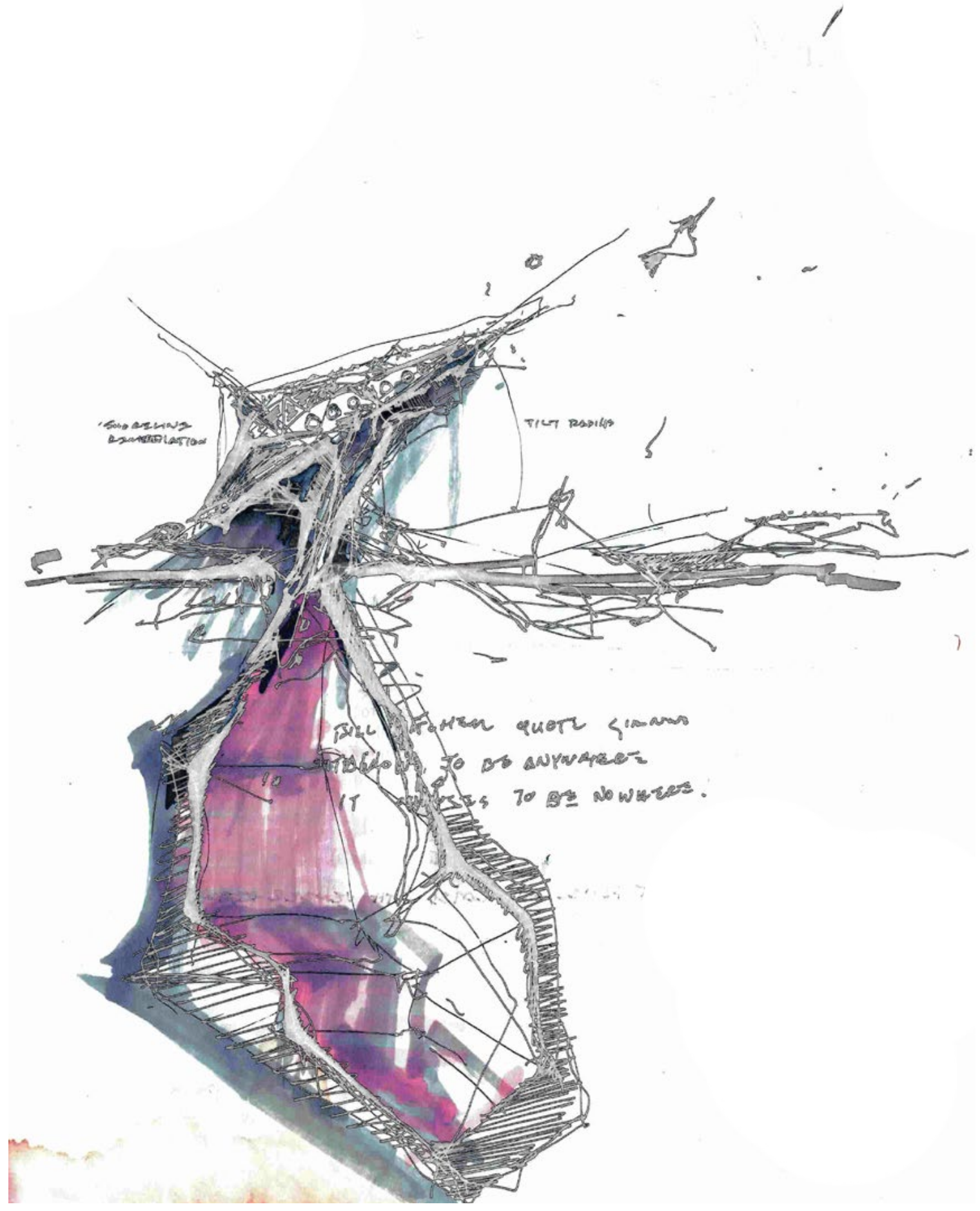

Figure 19. Concept - Plastic Eating Machine with Established Quarantined Area Below Water Surface 


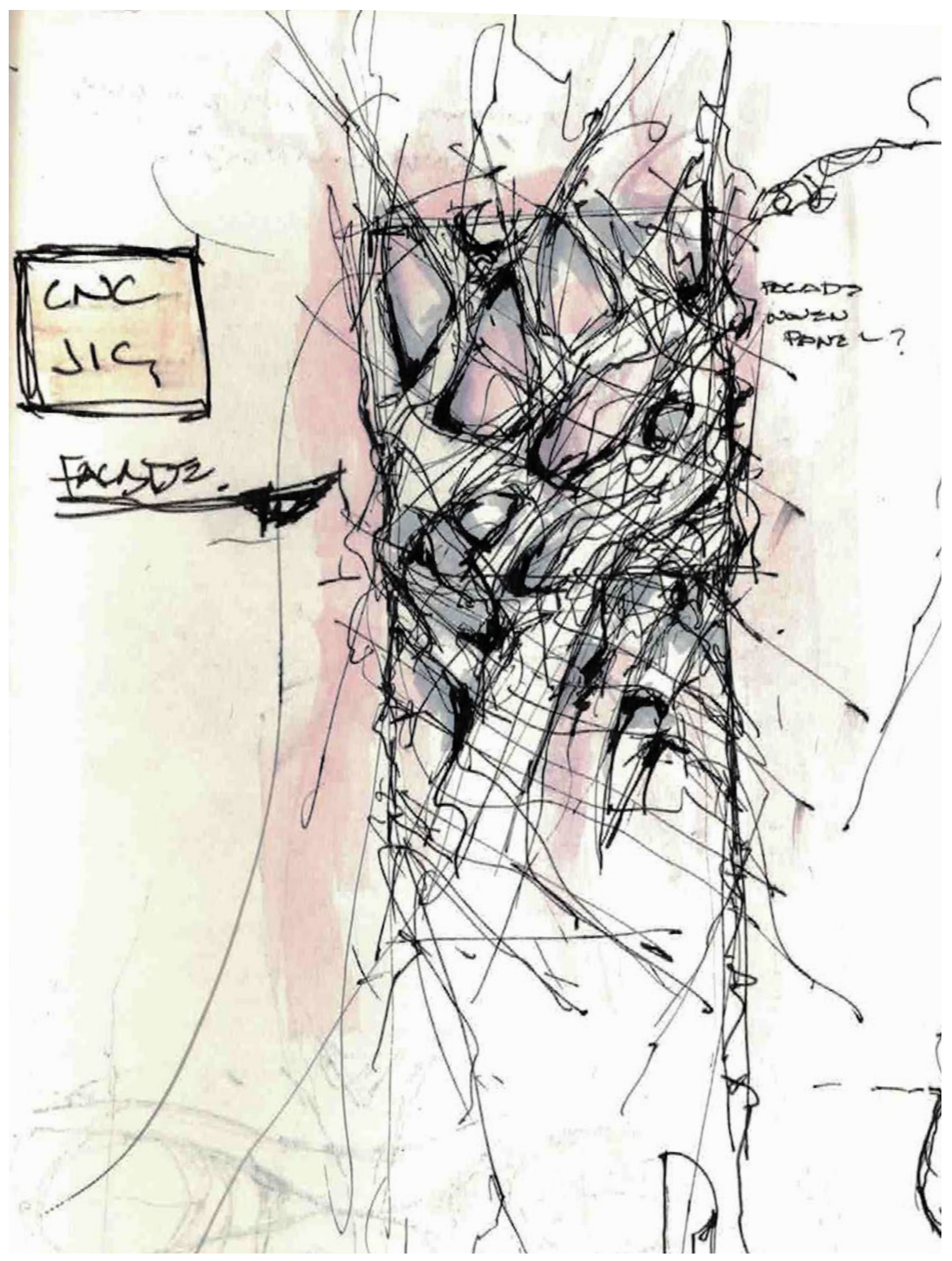

Figure 20. Concept - Bacteria and plastic growth layered on façade / plastic woven. 


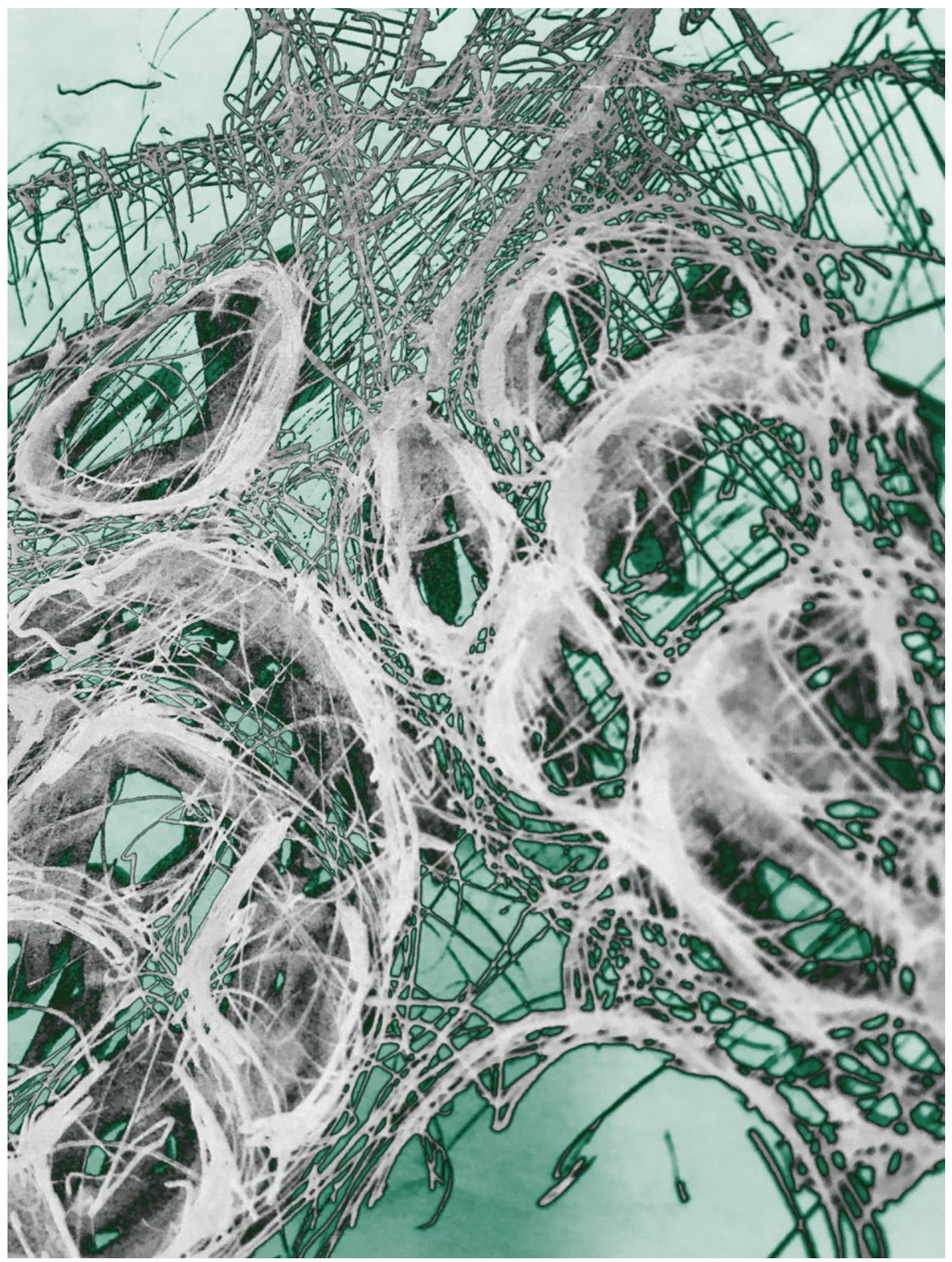

Figure 21. Concept - Plastic panelized skin. 


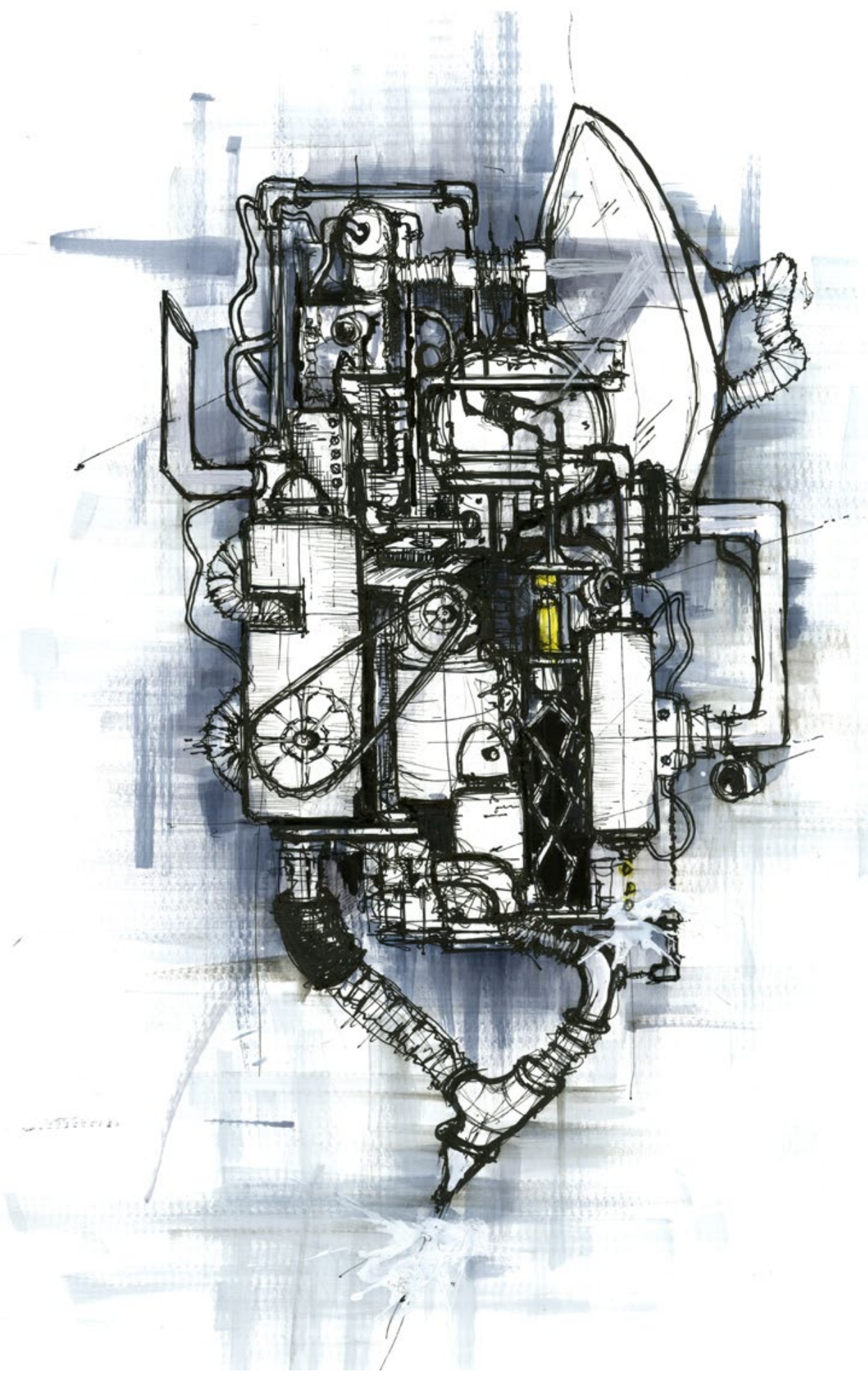

Figure 22. Concept Sketch - All in One Machine. (Bioreactor, Compressor, Shredder, Extrusion) 


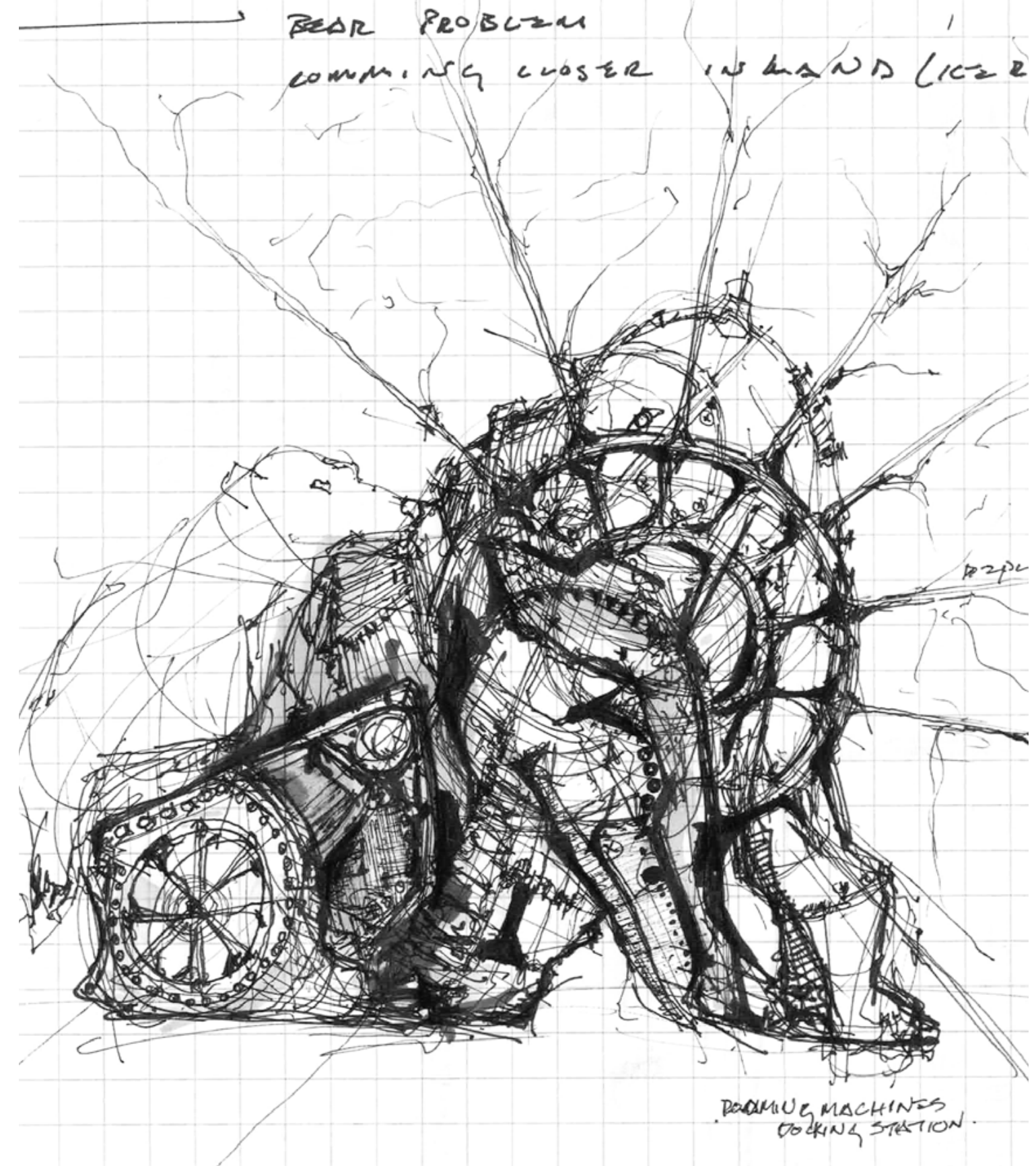

Figure 23. Concept - Process Sketches. 


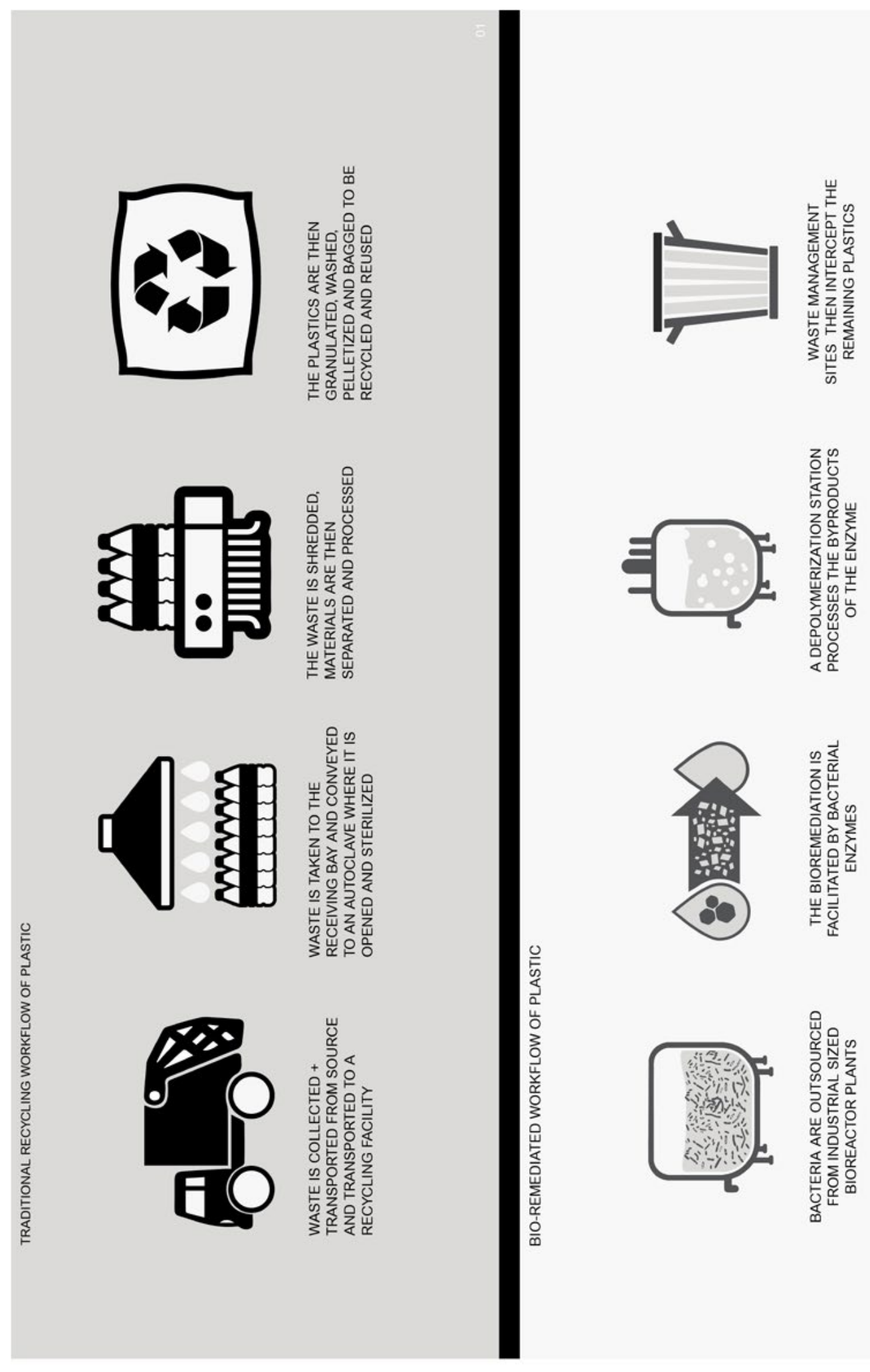

Figure 24. Traditional Recycling Process and Bioremediation Process 

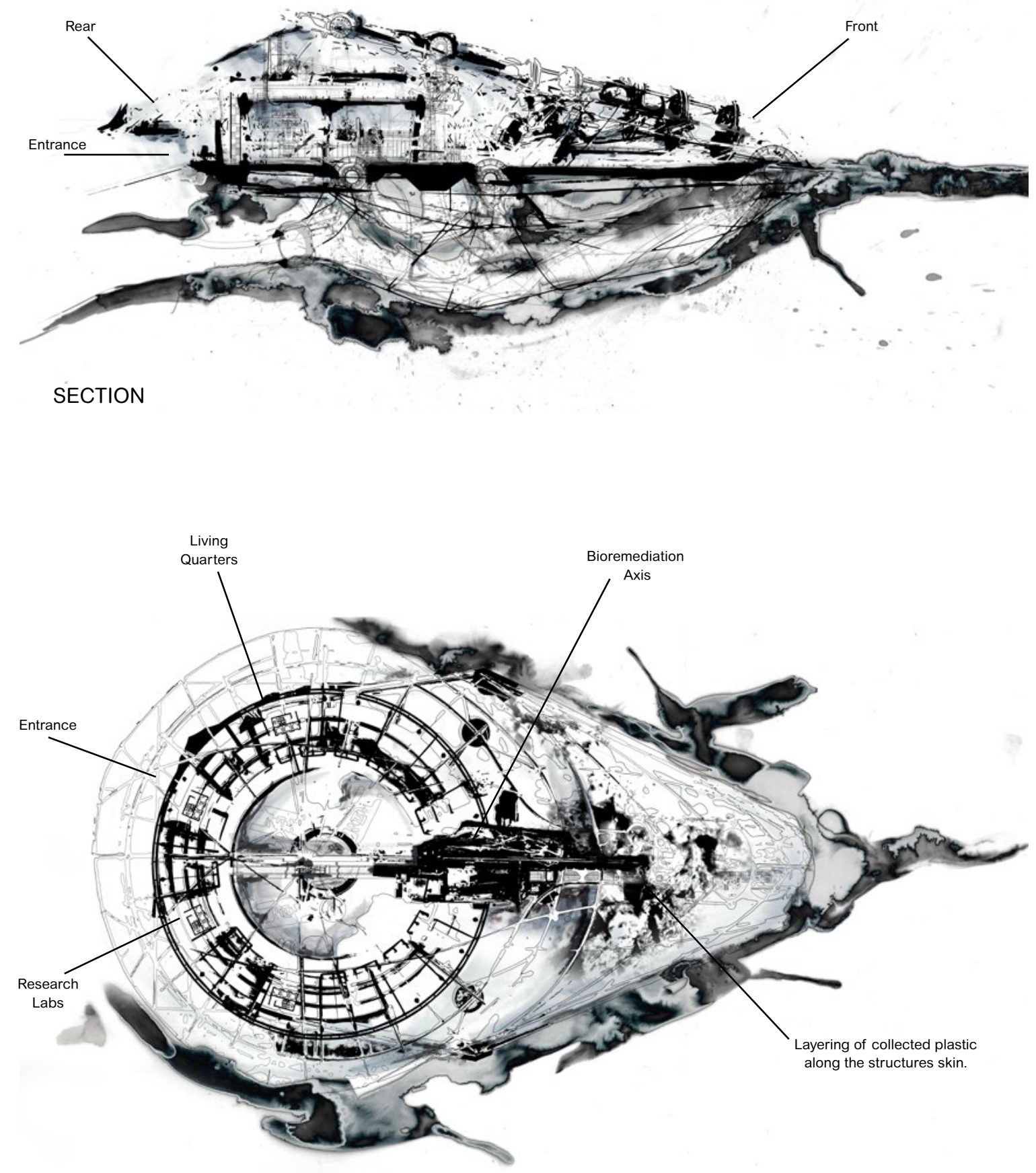

PLAN

Figure 25. Plan and Section of Research Facility - Living quarters are integrated with research labs and wrap around the bioremediation zone allowing for a 360-degree view of the initial extraction point. This spatial arrangement emphasizes the purpose of these machines - research and collaboration. Entrance into the facility is at the rear. 


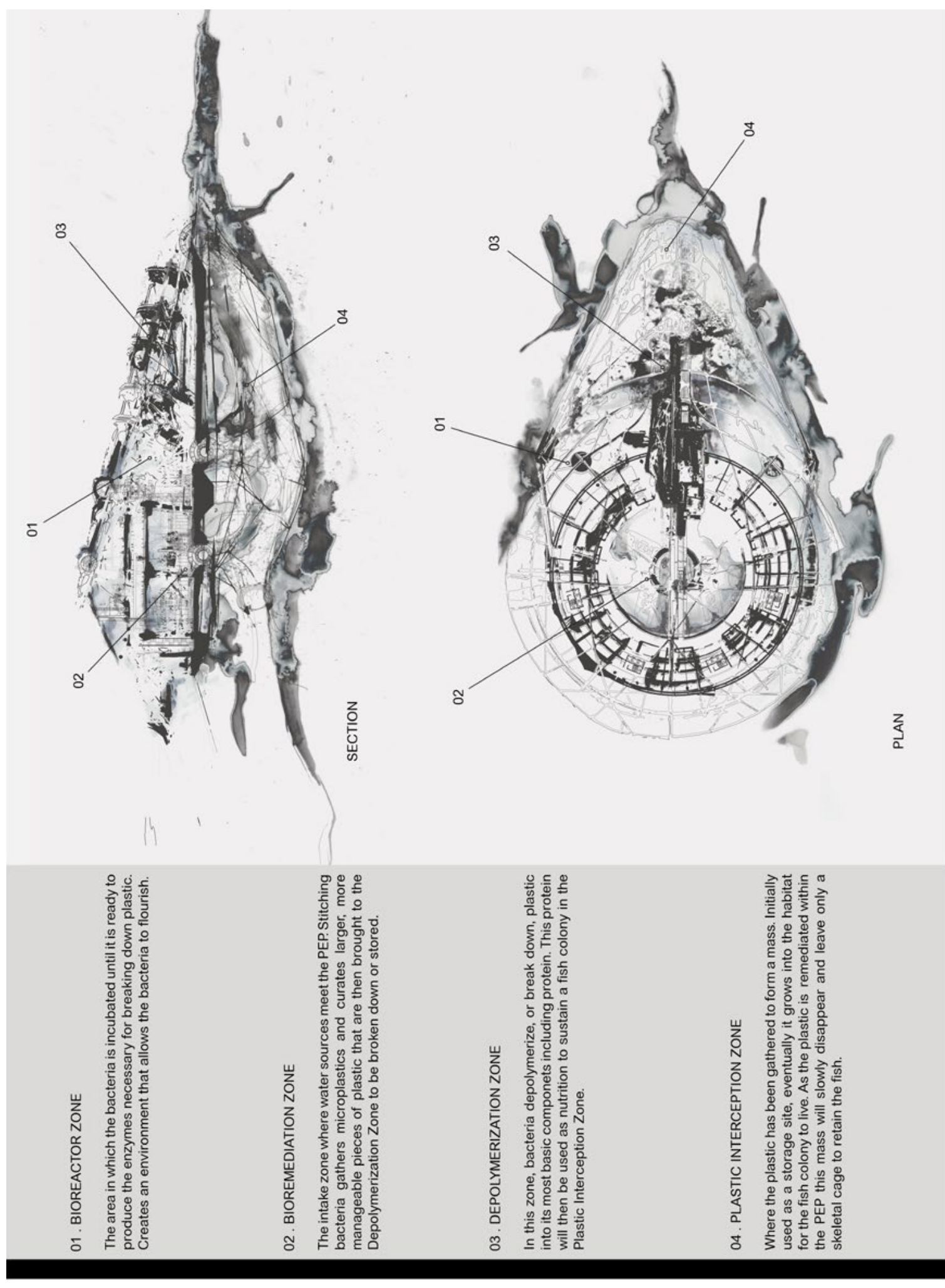

Figure 26. Identifying the Zones 

意

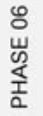
음
W
$\frac{1}{2}$
$\frac{1}{\alpha}$

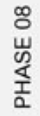
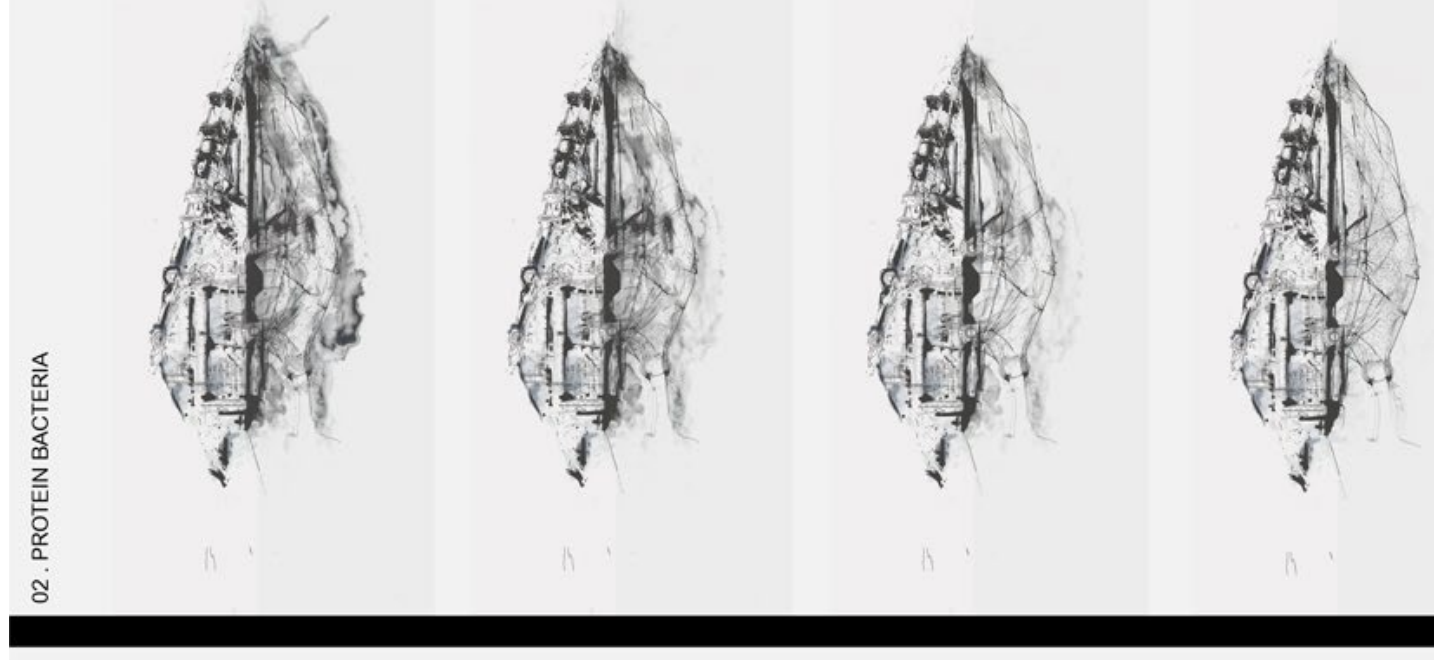

5
$\frac{5}{6}$
$\frac{1}{2}$

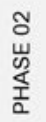

$\dddot{8}$
$\frac{1}{6}$
$\frac{1}{2}$
$\frac{1}{2}$

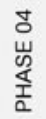
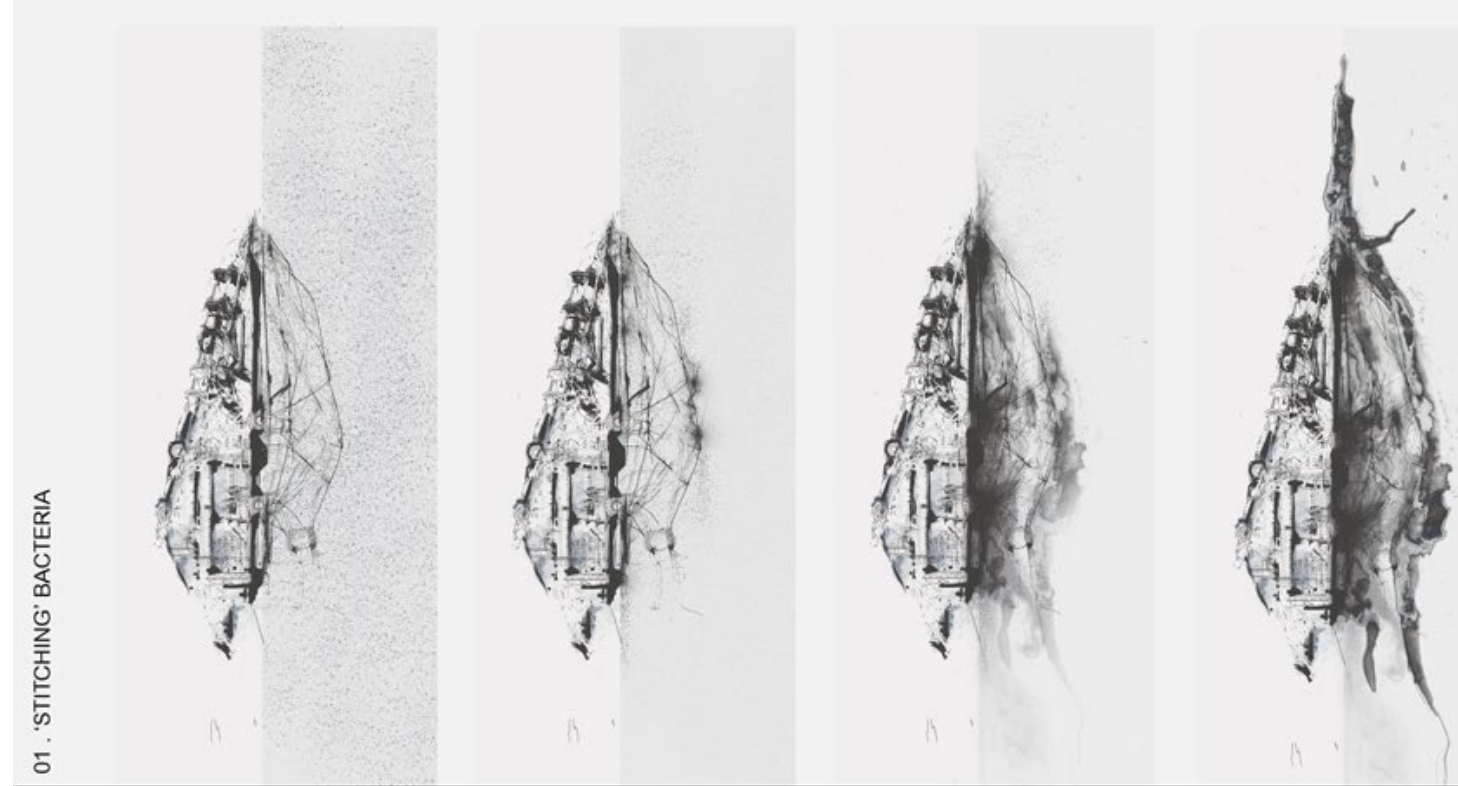

Figure 27. Integrating Multiple Bacterial Processes. Throughout phases 01 to 04 bacteria will attack surrounding microplastics and begin stitching them into larger clumps. By phase 04 , all surrounding microplastics have crystalized along the belly of the machine and can now be processed. Phases 05 to 08 will begin to convert plastics into protein that can be used to feed and repair depleted ecosystems. 


\section{Chapter: Methods}

Can there be a relationship between architecture and plastic packaging? This section sets the framework to be able to talk about what is made during this project and how to classify and describe what is being created. As well as where the research will be categorized in the architectural world.

There are many ways to use plastic and bioplastic products within architecture. When describing this architecture, one must consider two distinct positions, "plastics in building" and "all-plastics" (21). ${ }^{83}$ These two opposing concepts define a "part" driven position, and a "whole" driven position (21) ${ }^{84}$ For example, Billie Faircloth in her book Plastics Now, On Architecture's Relationship to a Continuously Emerging Material describes "plastics in building" as: "parts to be specified, subtly embedded in the system of construction, never really reaching the status of componentry" (21).$^{85}$ In contrast, the concept of "all-plastics," is described as having the capability of providing a "whole architecture" that is realized through "liquids to be cast or sheets to be formed" (21). ${ }^{86}$ These are the parameters in which this thesis will describe the proposed plastic architecture.

'All-plastics' is a concept describing an architecture built from a single material that defines a building's structure, space, skin, form, aesthetics, or performance (174) ${ }^{87}$ This concept is suited for retaining the material in its purest form in the fashion that is desired during the 'final recycling' process. The term 'all-plastics' is 'dependent upon plastics' inherent form-assuming capacity" (176). ${ }^{88}$ The unique capability of changing from liquid to solid allows

\footnotetext{
${ }^{83}$ Faircloth, Billie. 2015. Plastics now: On architecture's relationship to a continuously emerging material. Abingdon, Oxon;New York, NY;: Routledge.

$84 \mathrm{Ibid}$.

$85 \mathrm{Ibid}$.

${ }^{86} \mathrm{lbid}$.

87 Ibid.

$88 \mathrm{Ibid}$.
} 
for each cast to set smoothly (176) ${ }^{89}$ This capability to change form, or condition, simplifies construction by reducing the need for multiple building components. Perhaps a composite material, formed by plastics, can provide structure as a 'whole' that is greater than the sum of its parts.

This research will investigate how thermoplastics can be reused in the world of architecture. There are many ways to categorize plastics. When working with plastics there are two outputs to consider, thermoplastics, or thermoset plastics. When heated, thermoset plastics become permanently hardened and are extremely durable ${ }^{90}$ However, when thermoplastics are heated they will not cure into place, rather, become soft and pliable. This allows for the material to be moulded and re-moulded into shape. ${ }^{91}$ This thesis has based exploration on the properties of thermoplastics. As evidenced below, some limitations of plastic as building material have been observed through this research.

\subsection{Process}

Process: Some of the ways to manufacture plastic and bioplastic products are as follows: casting, compression moulding, contact moulding, digital fabrication, extrusion, filament winding, foam moulding, injection moulding, and laminating.

The primary method of making explored within this process has been shredding previously used Polyethylene Terephthalate (PET), High Density Polyethylene (HDPE) and Polystyrene (PS). These plastics were chosen because they are commonly available as plastic packaging. In order to shred found plastics into small enough pieces to be melted, a high caliber shredding

\footnotetext{
${ }^{89}$ Faircloth, Billie. 2015. Plastics now: On architecture's relationship to a continuously emerging material. Abingdon, Oxon;New York, NY;: Routledge.

90 "What are Plastics?" The Plastics Historical Society. Accessed February 21, 2017. http://plastiquarian.com/?page id=14296.

91 "Thermoplastics." Polymers. Accessed February 21, 2017. http://polymers.com.au/thermoplastics/.
} 
machine was built. In the initial research, it was discovered that these types of shredders do exist but that the availability of them to the public was difficult and not useful at the small scale of this project. These shredding machines are very efficient, and expensive, and exploration of this type is less efficient to the industry than simply using new plastic.

The first explorations encompassed cutting bottles into strips by hand. The idea was that each bottle should be turned into a single continuous strip. A hand operated bottle cutting mechanism was developed for this purpose (Figure 28 and 31). After using this bottle cutter many limitations were uncovered. The main limitation is bottle size in relation to resulting strip size. A small bottle results in a small thread while a larger bottle results in a much longer thread. However, both strips are finite. The problem then became attaching multi-sized strips to make one long strip that could be weaved. The weak point created at this connection emphasizes the limitations with this technique. The best way to create a stronger joint was to eliminate the connection entirely by creating one continuous strip. Firstly, the plastic needed to be shredded, then washed, and finally melted at specific temperatures. The intention was to convert the melted plastic into block material, or, to be extruded as one long continuous strip. In theory, this strip could then be weaved continuously, creating large plastic sheets as usable construction material. Furthermore, weathered and deformed material collected from bodies of water restricted the use of the bottle cutting method, thus justifying the need to shred and melt deteriorated plastics.

Two plans of action were developed. First, a paper shredder was purchased for shredding plastic. Limitations during the process were discovered, including irregular plastic shapes needing to be cut into flat sheets in order to fit into the shredder's small opening. Secondly, an affordable used paper shredder was purchased for deconstruction (Figure 34). After taking off the safety mechanism to fit more whole plastic objects, it was realized the electric 
motor was not strong enough to pull whole bottles through the cutter. This is not a limitation of the blades, but of the motor (Figure 35). To enable faster shredding without hours of prep work, this shredder could be attached to a stronger frame and to a low RPM motor. The resulting plastic was cut up into fine pieces measuring under $5 \mathrm{~mm}$, mimicking microplastics found in water (Figure 36).

Further methods explored heating and compressing the shredded PET plastic into a block material. The safe melting range for PET plastic is between 245 degrees and 265 degrees Celsius. ${ }^{92}$ The first trial indicated that one quarter cup of shredded plastic takes approx. three minutes to become moldable. Note this test proceeded with an open container and a small amount of plastic (Figure 39). The next trial investigated how the plastic would react in a closed container, and proved that the melt time would increase when using these parameters. A hollow steel pipe, measuring eight inches in height, one and one quarter inch in width, and an eighth of an inch in thickness was used for the remaining trials. In total, half a cup of plastic (five soda bottles) could fit in the pipe after it was compacted (Figure 40). This allowed for about one inch of spacing on either end of the pipe. ROXUL insulation was used to plug each gap, thus preventing any melted plastic from spilling out. The first test resulted in partially fused plastic that held together as a cylindrical form, but could still be identified as the original shredded plastic (Figure 41). During this experiment, the pipe was heated with plastic inside to the proper melting point and then left for five minutes. After several experiments, it was noted that the pipe should be heated before pouring in the shredded plastic. During the next test the plastic was heated for 40 minutes, removed from the heat source, compressed, and clamped into place. This resulted in a unified cylinder of plastic that was completely broken down from its original form. This experiment yielded a cylinder measuring approximately two and a half

\footnotetext{
92 "Precious Plastic." Home - Precious Plastic. Accessed January 07, 2017. https://preciousplastic.com/en/.
} 
inches in height and one inch in width. Once all plastic was liquefied, it could be compressed up to five and a half inches before it began to squeeze out of the plugged pipe (Figures 42 to 49). There are many variables to consider during this process. Firstly, the amount of ROXUL used at each end of the pipe must be used sparingly, as the insulating properties prevented the internal temperature from reaching the melting point consistently. Secondly, the heating element should exceed the melting range by at least ten degrees Celsius, thus assuring an internal temperature within the melting range of the plastic. Lastly, to avoid chipping, the plastic should be compressed as much as possible to eliminate any air pockets and should only be removed once fully cooled.

Much attention must be placed on safety precautions to guard against potential hazards. Firstly, the temperature of the plastic must stay within its melting zone to make sure it does not burn. If plastic is burning it begins to off-gas and releases toxic chemicals. Smoke and burning are clear indicators of off-gassing. For this reason, it is important to wear a carbon-mask when experimenting and to make sure there is good ventilation in the work area. Avoid inhaling any plastic fumes. If temperatures stay within the specific melting point, it is safe to melt and reform the plastic. Secondly, when grinding and shredding plastics, hoppers must be used to funnel plastic safely though the cutting mechanism.

\subsection{Representation - Design Methodology}

Mechanical and plastic parts that were found in printers, projectors, computers, and other consumer objects have been used in tandem with plastic packaging to create architectural models and drawings of the project (Figure 59). A futuristic network of mechanical, biological, technological, and plastic systems have been used to establish a narrative that depicts plastic free water. 
The strength of this thesis remains as speculative design enhanced by detailed hand drawings which call attention to plastic pollution in aquatic ecosystems. This project seeks to inspire the decisive action necessary to remediate the plastic problem.

A series of three deconstructive processes were used to stimulate creative thought by establishing an architecture and imagining technology to rehabilitate aquatic ecosystems. The first process was strictly an extraction of physical qualities through hand drawing. This method was instinctual as plastic and metal waste was disassembled and placed into a pile. This pile was then sketched to allow for a new understanding of the spatial qualities, textures and the interaction of light that exist between the fragmented pieces. These sketches provided a framework for the design process to develop within.

The second process utilized was to take an interesting found object, scan it, and digitally archive it. This object was then manipulated, redrawn digitally and then printed using laser cutting technology. The new objects were then assembled into a model that began to represent new spatial qualities that could be photographed or drawn again. This created a process of hybrid layering that naturally advanced the design.

The third process combined the first two processes by layering all drawings, photographs, and sketches to create a new representation that encompassed the entire project. Section and plan were extracted and finalized using this method.

Figure 60. Representation of Process 1: Sectional qualities were derived from this drawing that later informed the way the physical model was designed. (Prismacolour Markers/Warm Colours, no digital adaptation). 
Figure 61. Representation of Process 1: This drawing informed the plan of the plastic eating facility. (Prismacolour Markers/Cool Colours, no digital adaptation).

Figure 62-66. Representation of Process 3: This exploration drawing stitches existing images, fragments of the project together. No lines or colour were added except those that were previously drawn out of the found objects and sketches. Plans, sections, perspective drawings, and sketches were combined to create a spatial arrangement that is depicted as plan if viewed from far, or section, if viewed close-up. Dark colours read as cut lines if zoomed out from the image, transitioning to light colours as the cut lines if zoomed into the image. This hybrid technique weaves in and out, allowing for a sense of depth within the images' composition, reveling unpredictable moments within the drawing. A variety of new spatial arrangements can now be extracted from this drawing exercise. (Prismacolour Markers/India Ink/Graphite/Pen Ink/Sharpie Markers/Velum/Thick Matte Paper/lllustrator Line Weighting/CAD Line Work/Photography of Built Model (D90 Nikon)/Photoshop Editing).

In this way, each line (or part) has a meaning waiting to be uncovered. As these fragments are manipulated in each iteration they begin to derive new meaning. Sketching is a mode to further fragment and stitch elements of the physical world into special compositions using colour and line to represent depth. 


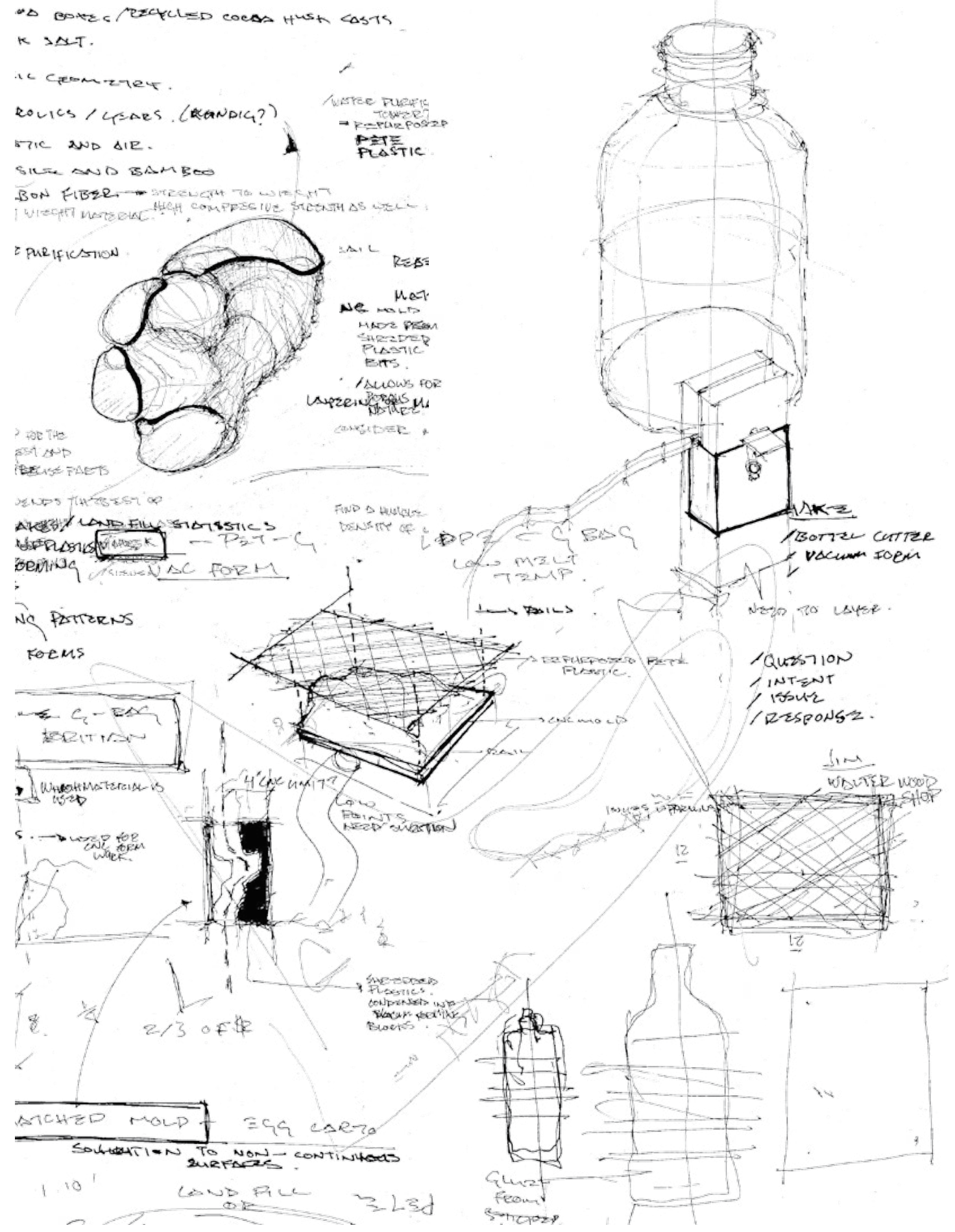

Figure 28. Process Sketches - Development of vacuum forming, bottle cutter, and compression molding. 


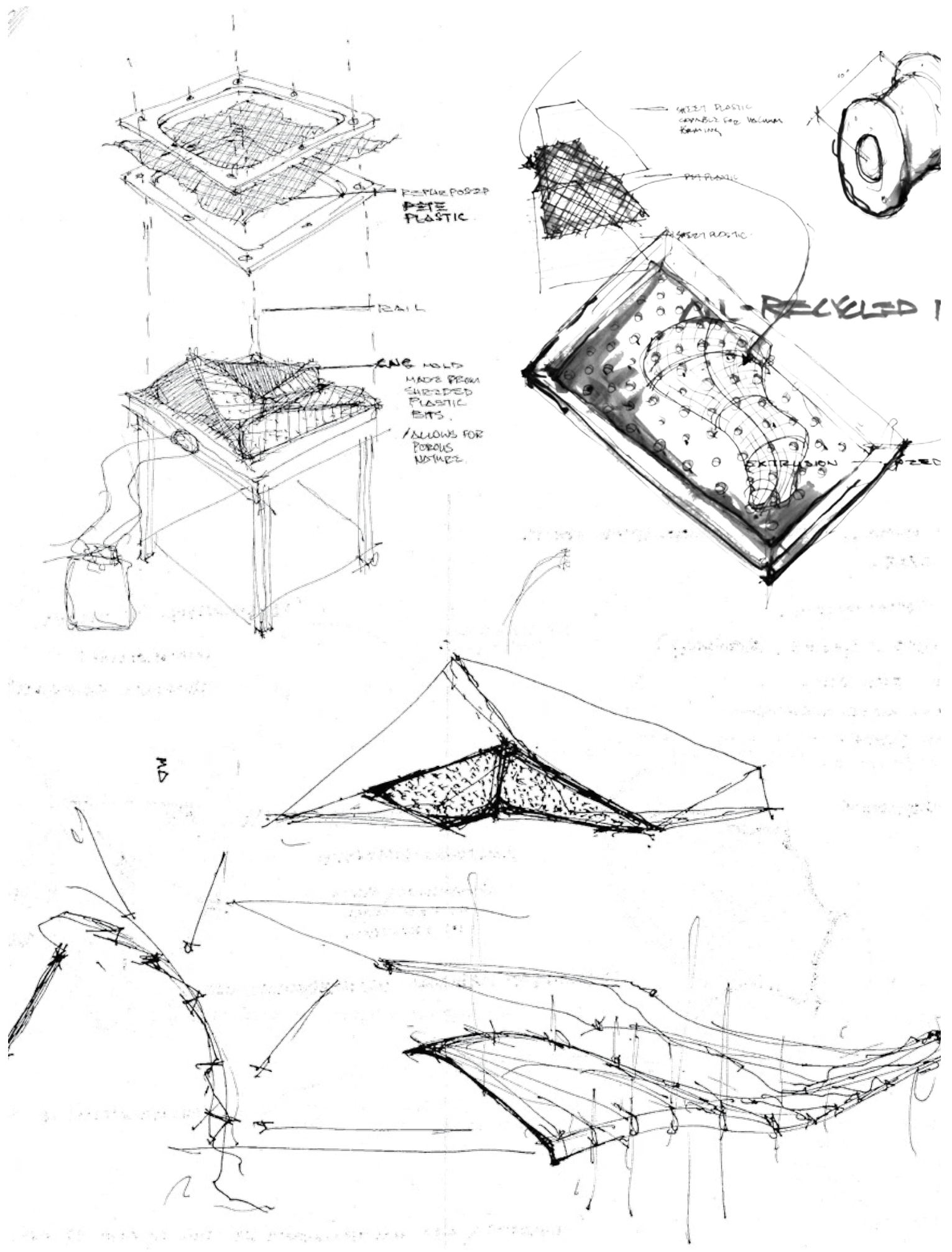

Figure 29. Process Sketches - Application of plastic material. 


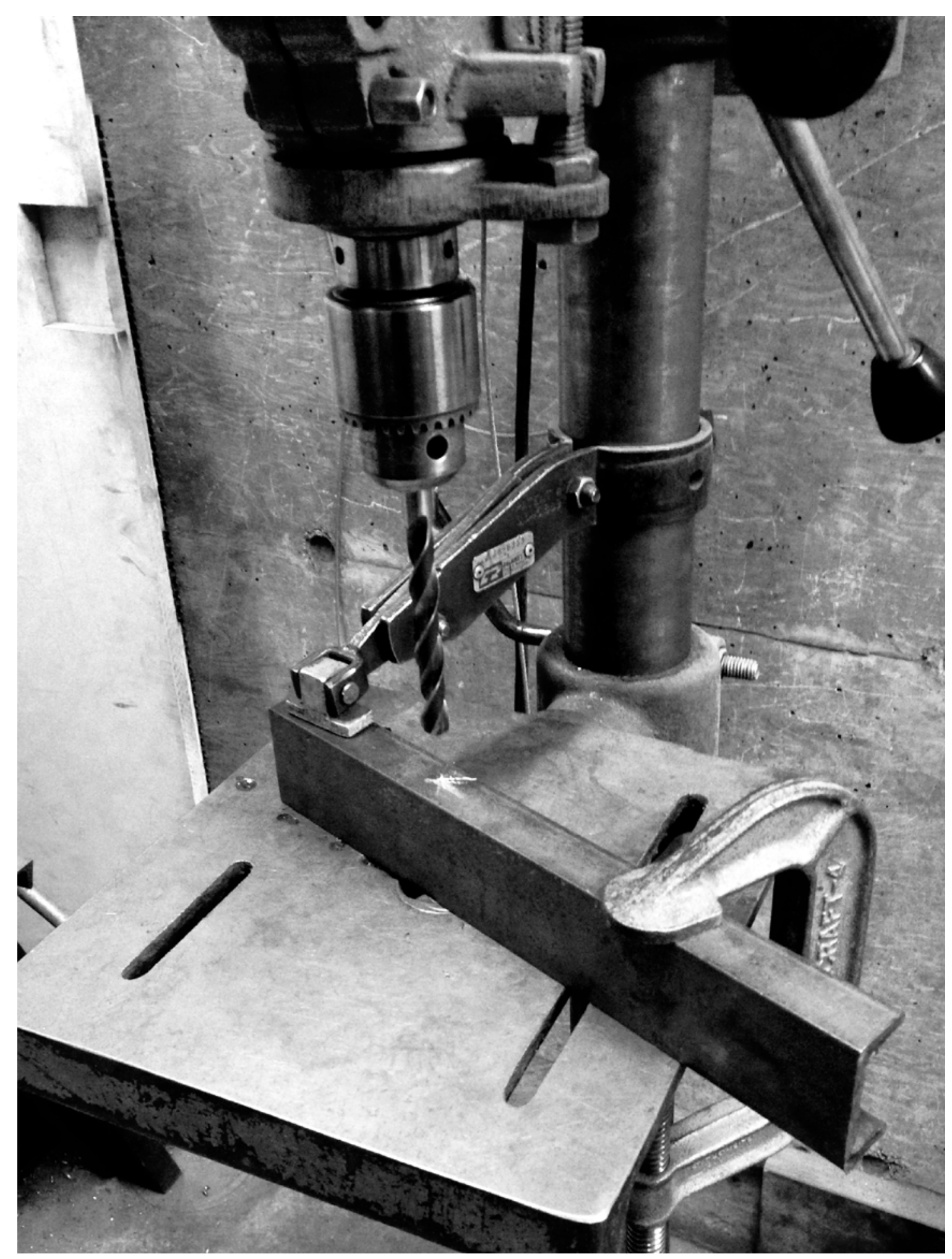

Figure 30. Process - Progression of Bottle Cutter. 


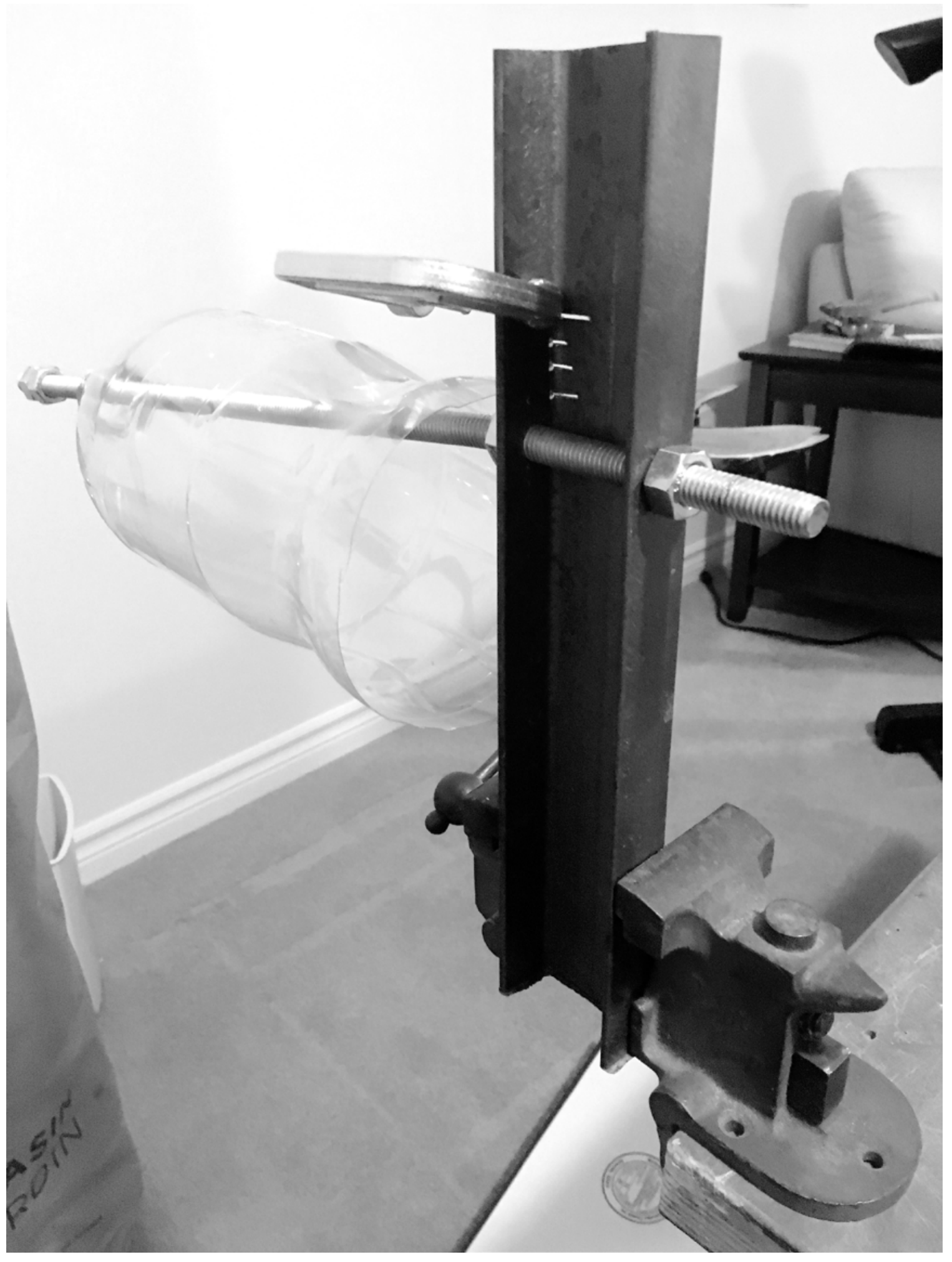

Figure 31. Process - Progression of Bottle Cutter. 


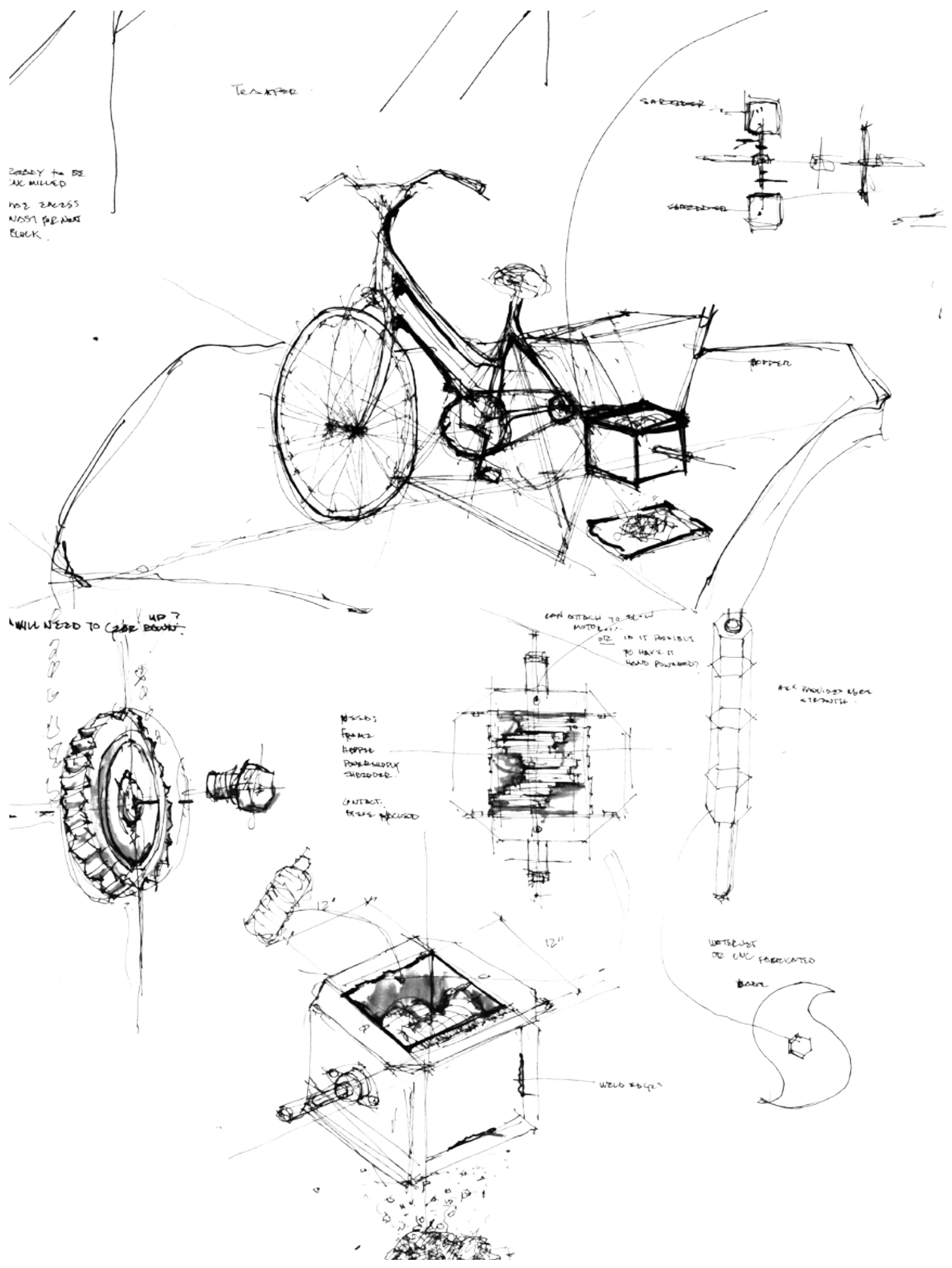

Figure 32. Process Sketches - Images derived / adapted from Precious Plastic shop drawings. "Precious Plastic." Home - Precious Plastic. Accessed January 03, 2017. https://preciousplastic.com/en/. 

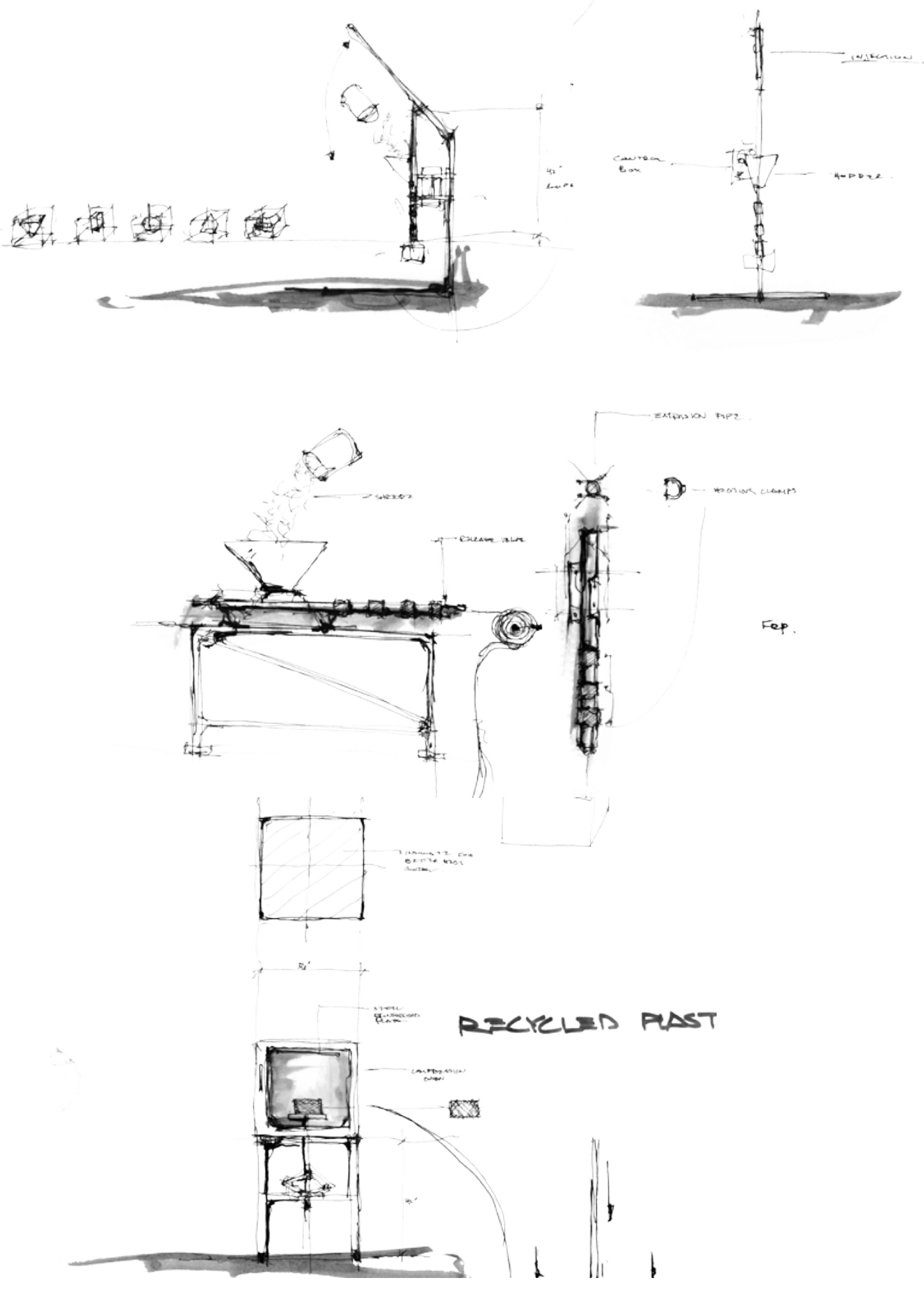

Figure 33. Process Sketches - Images derived / adapted from Precious Plastic shop drawings. "Precious Plastic." Home - Precious Plastic. Accessed January 03, 2017. https://preciousplastic.com/en/. 


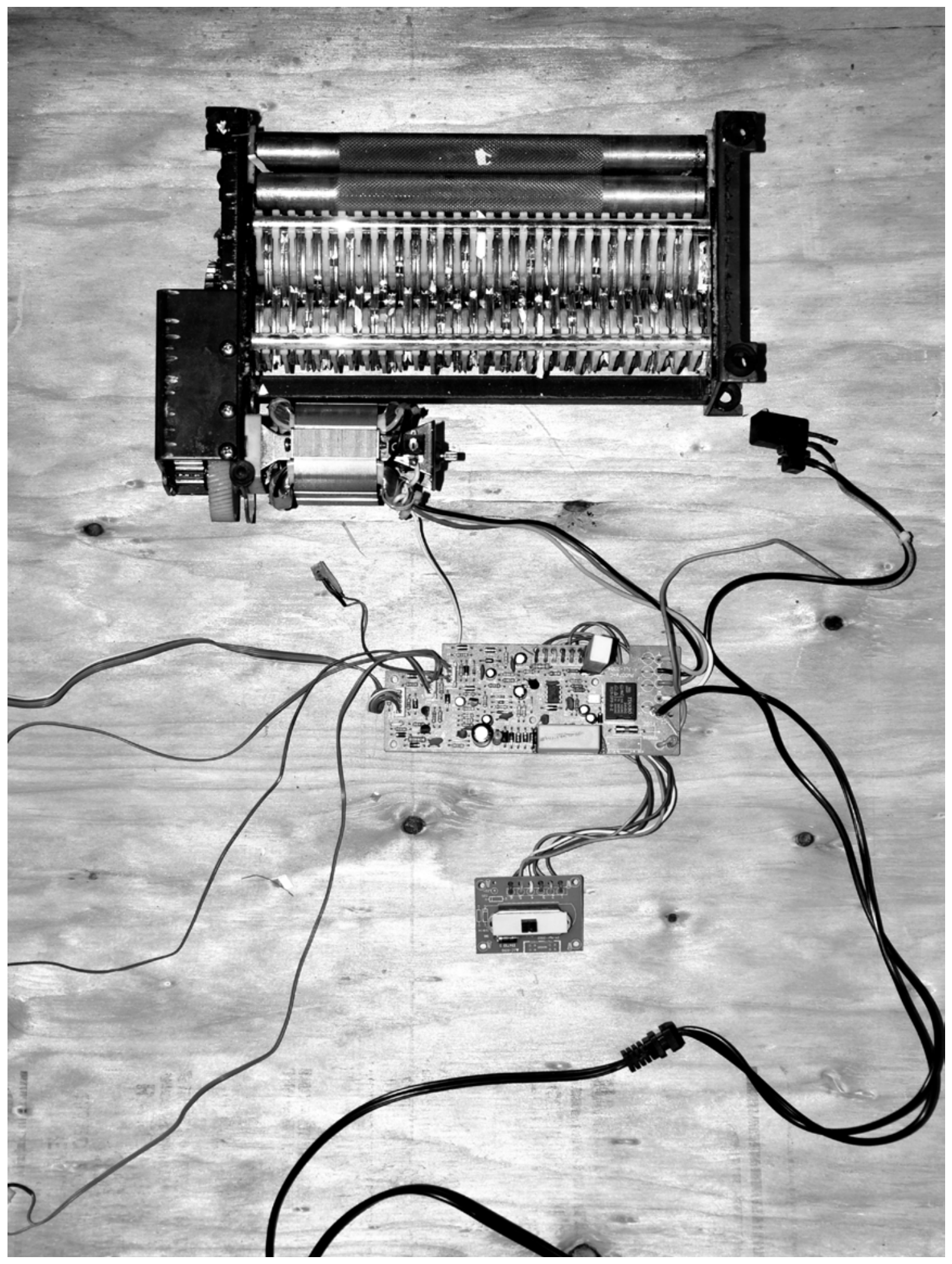

Figure 34. Process - Construction in progress of custom shredding machine. 


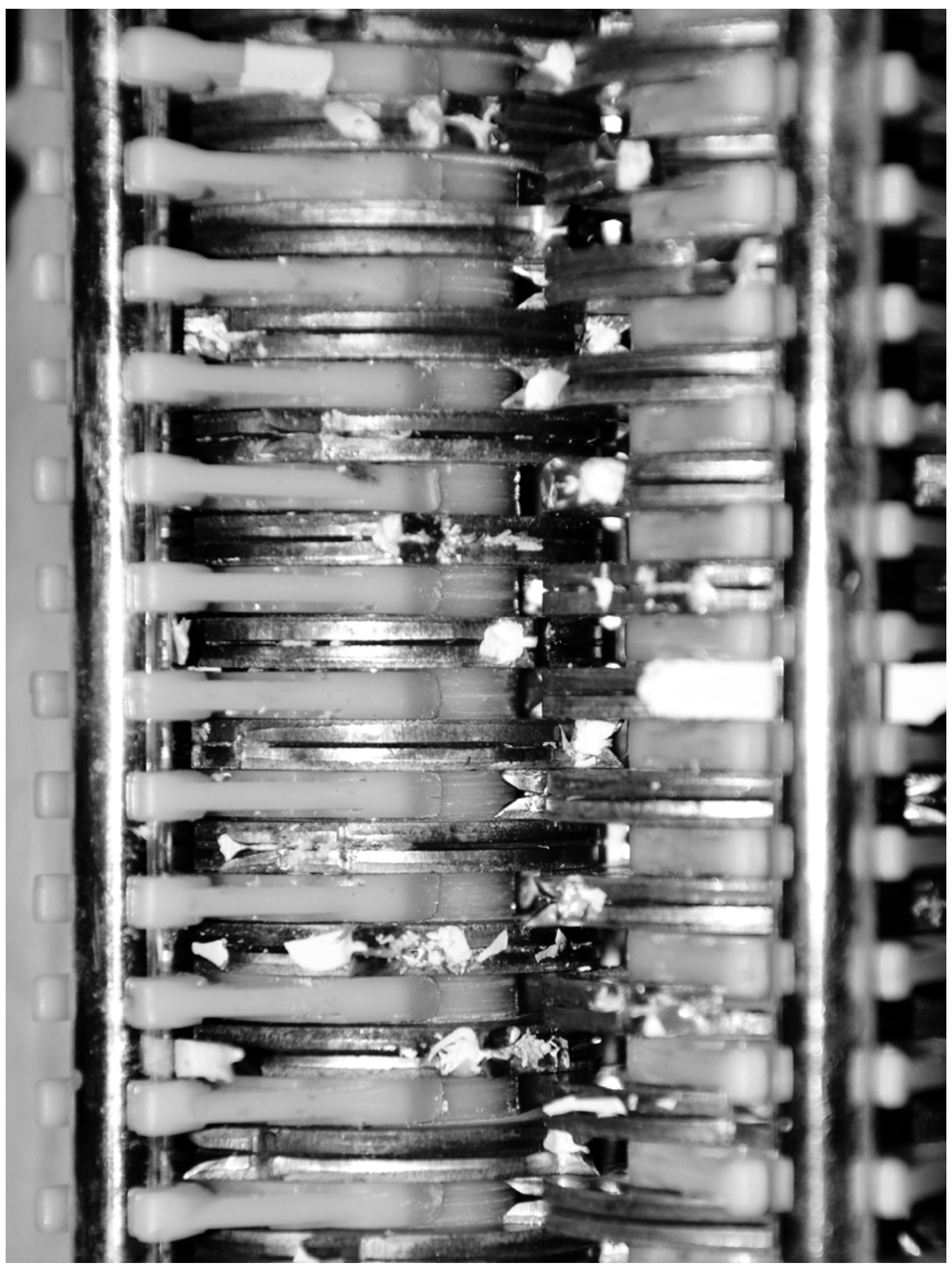

Figure 35. Process - Shredding Detail. 


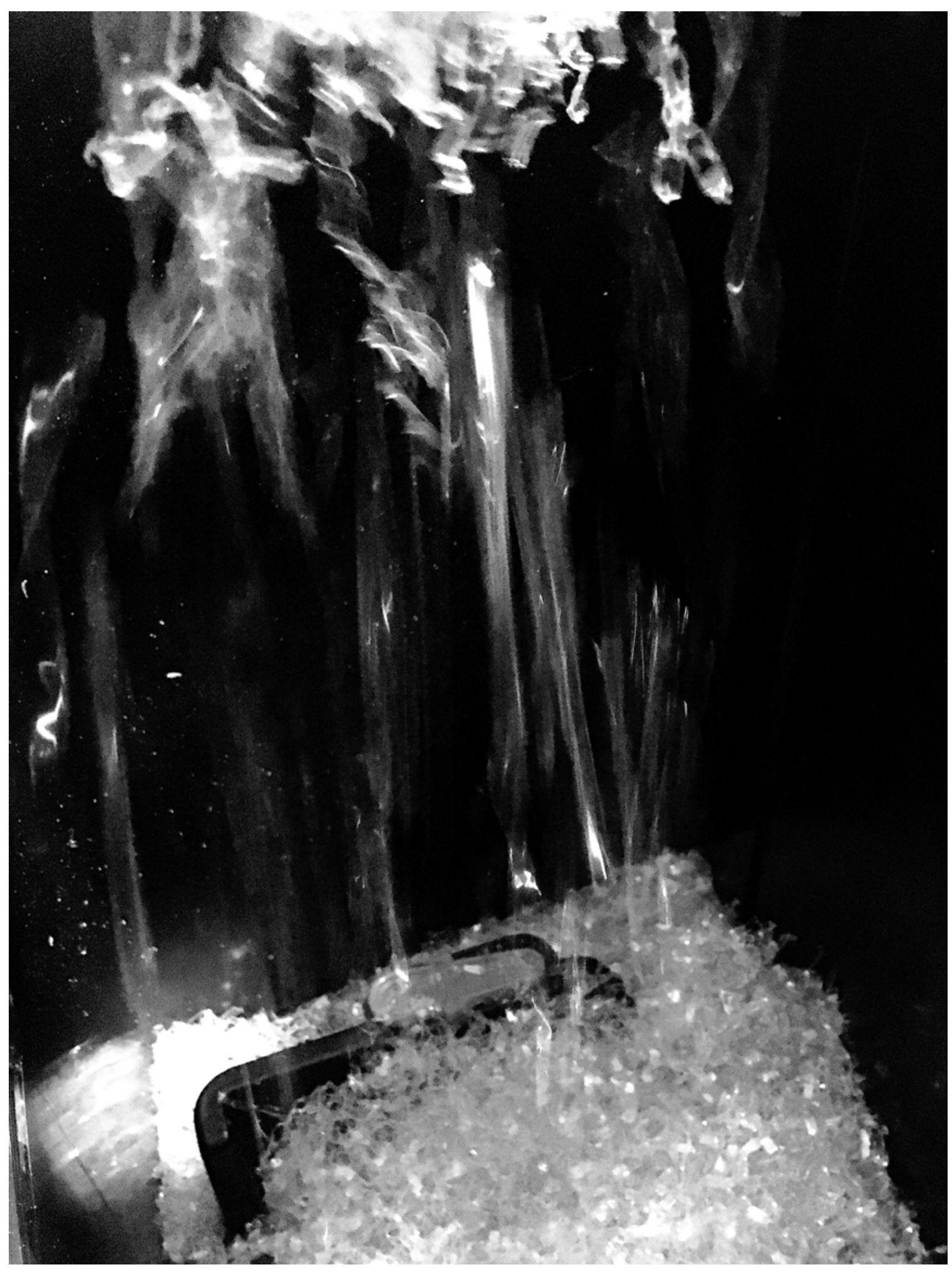

Figure 36. Process - Shredding of PETE plastic. 


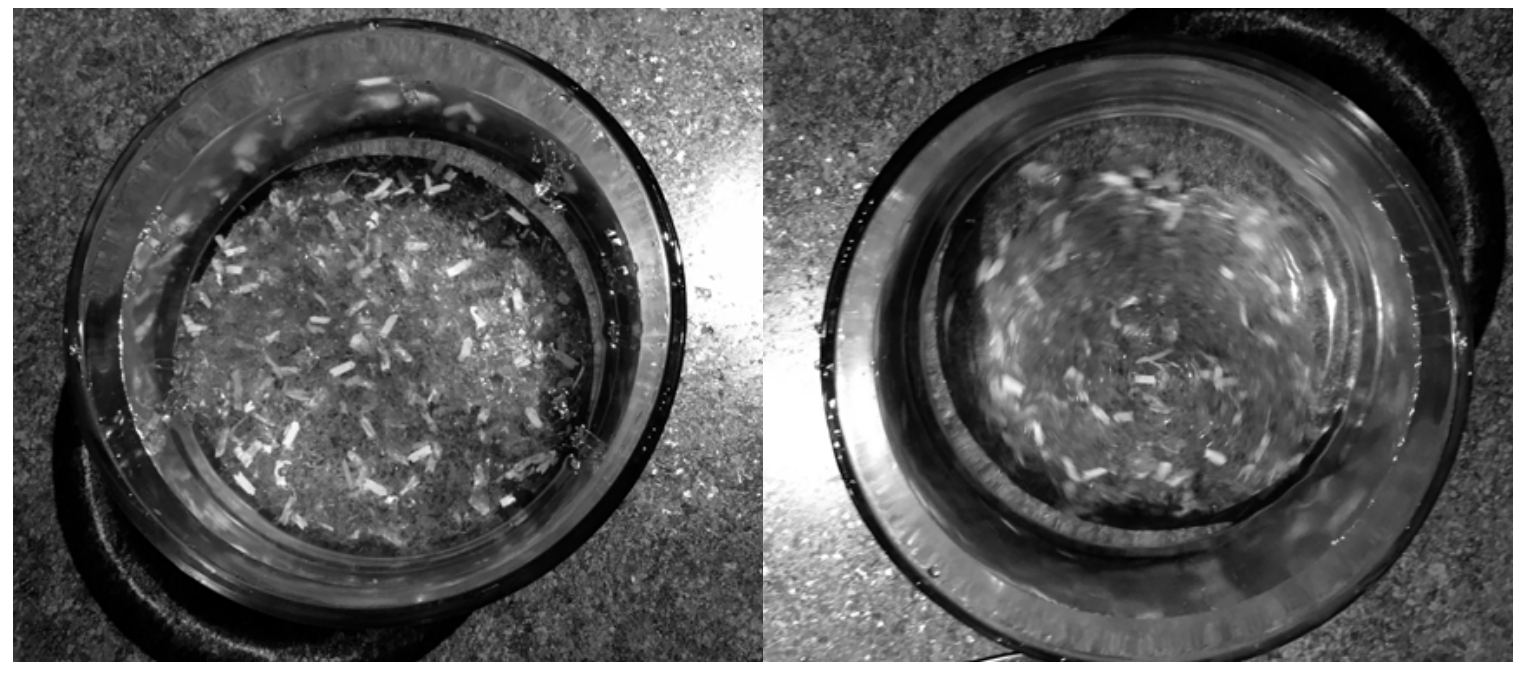

Figure 37. Process - Properties of plastic in water-Still vs. Moving.

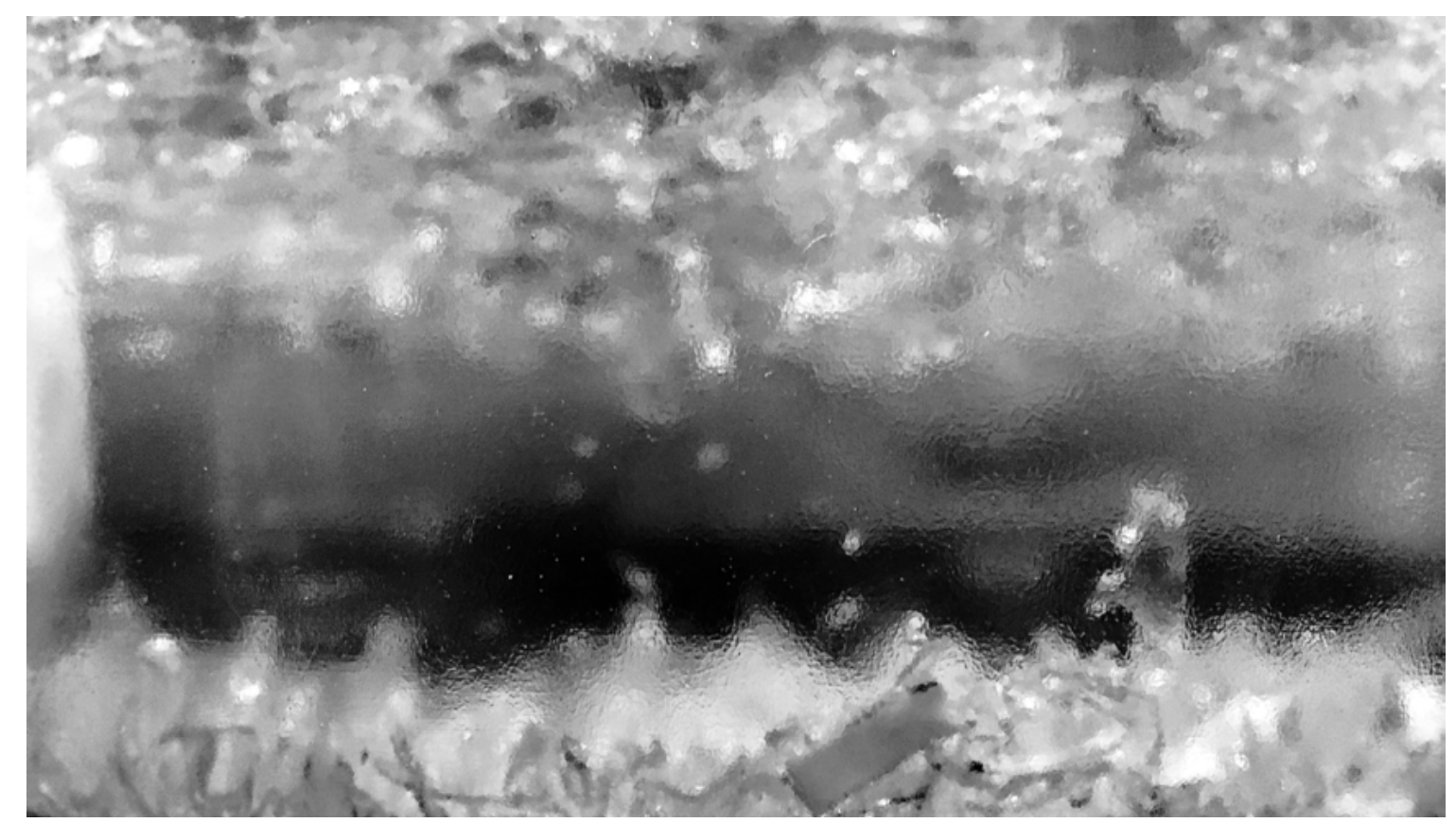

Figure 38. Process - Floating properties of plastic in water. 


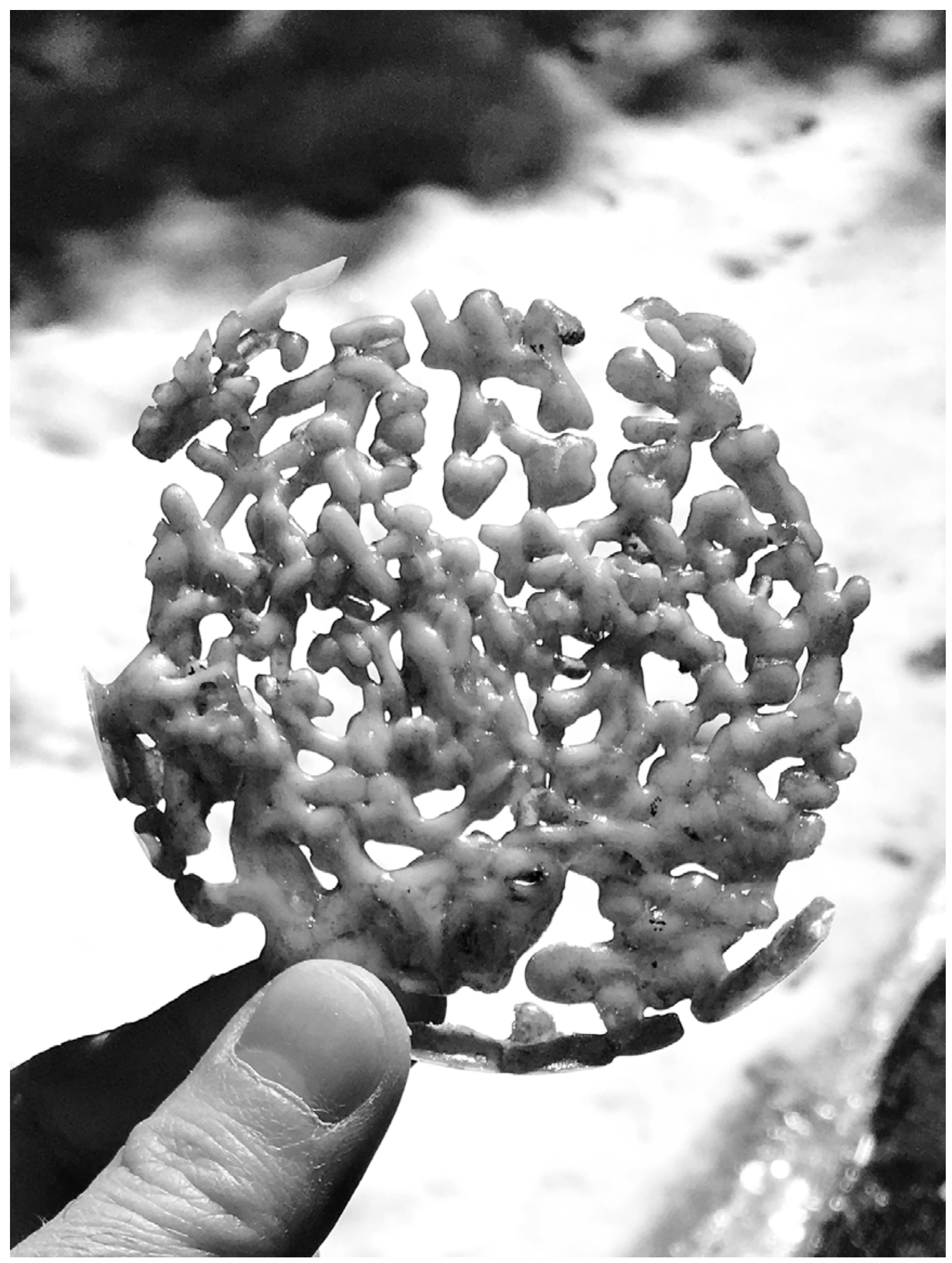

Figure 39. Process - Melted Plastic with Open Source 

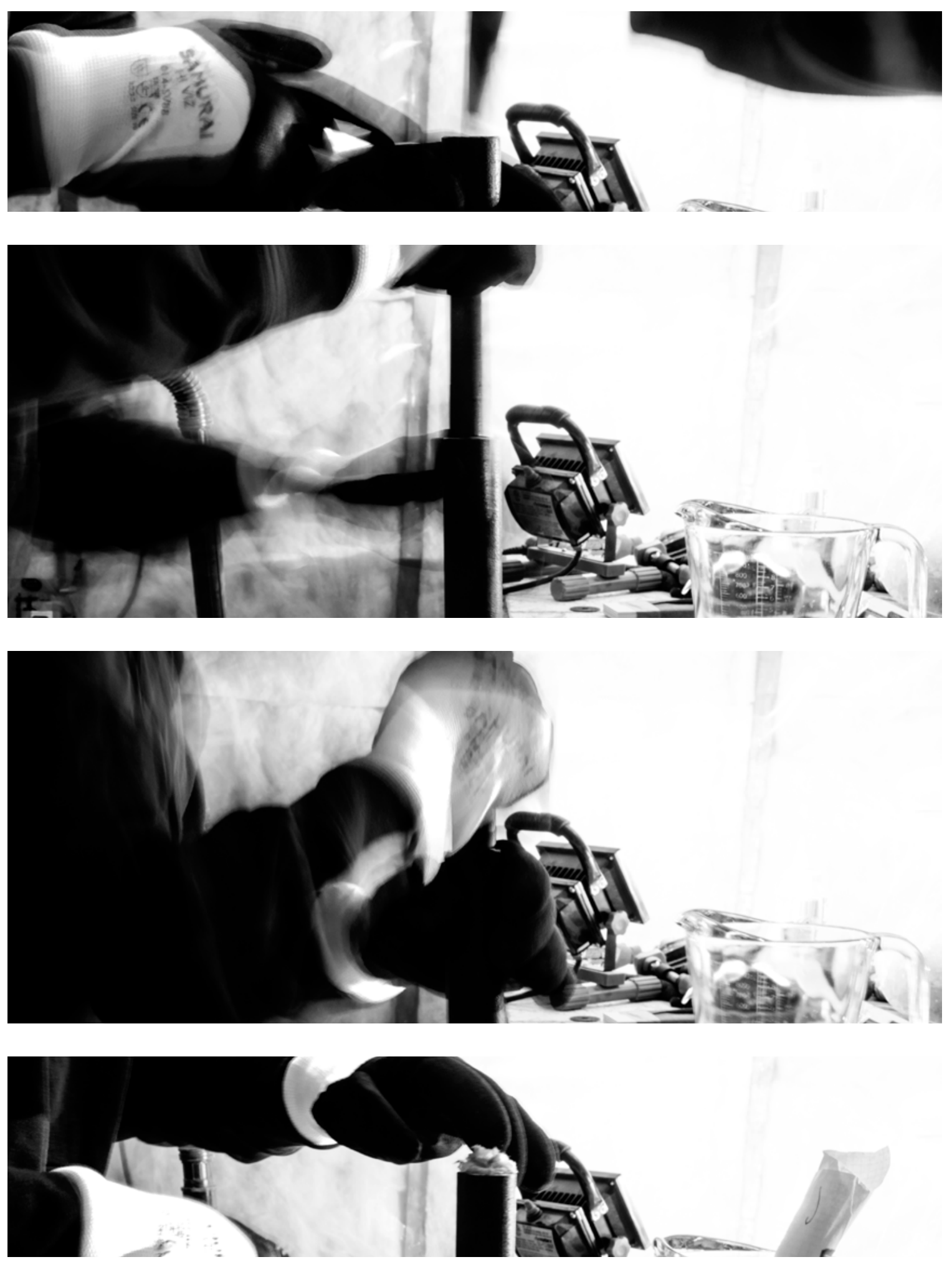

Figure 40. Experimentation Process - Inserting Plastic, Compressing Plastic, Capping Pipe with ROXUL 


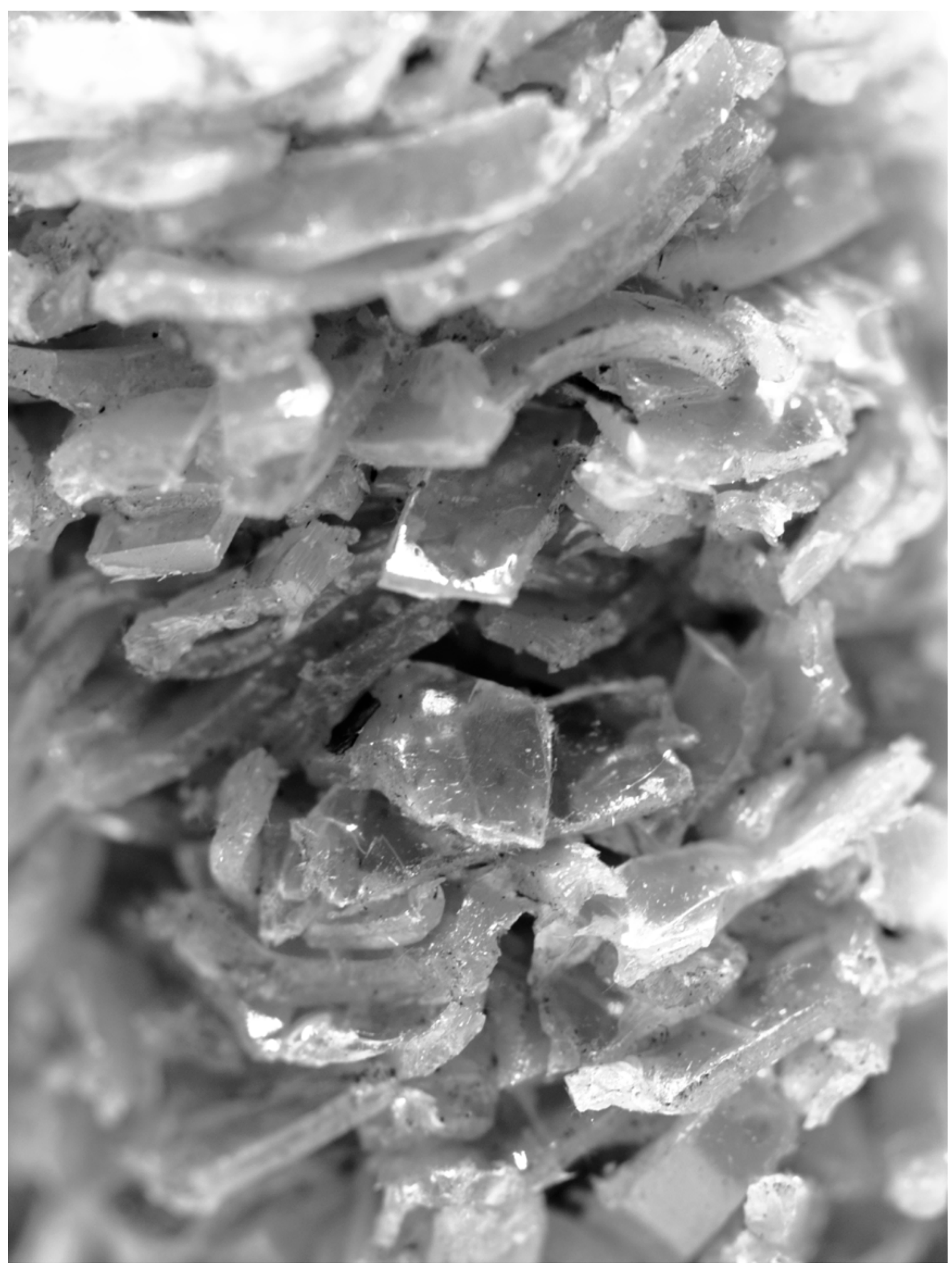

Figure 41. Melting Process - Partially Fused Shredded Plastic 


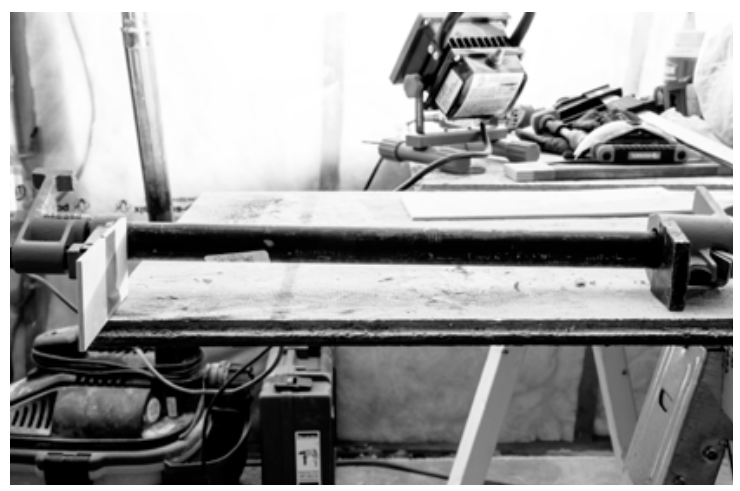

Figure 42.

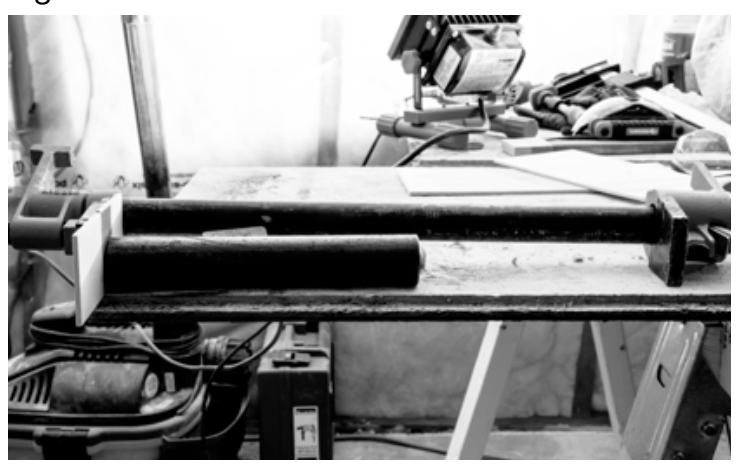

Figure 43.

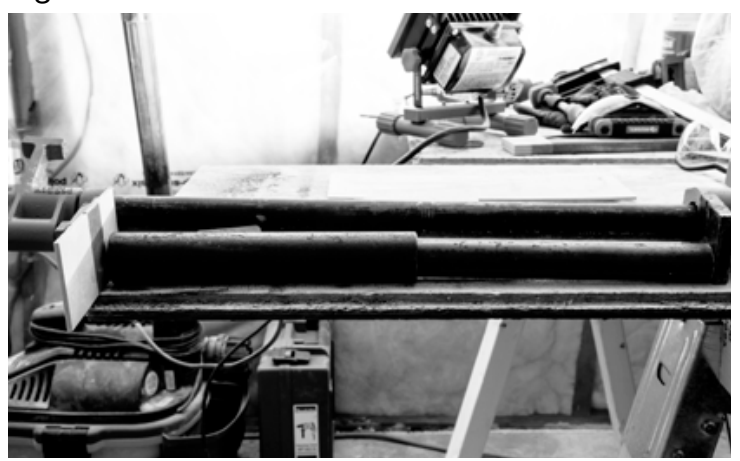

Figure 44.

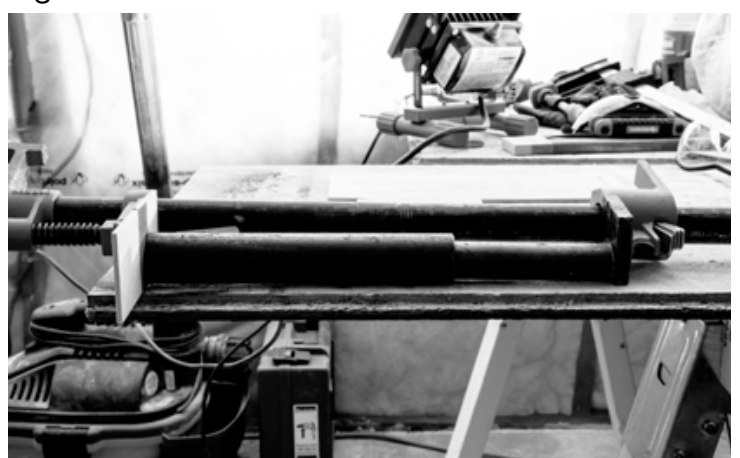

Figure 45

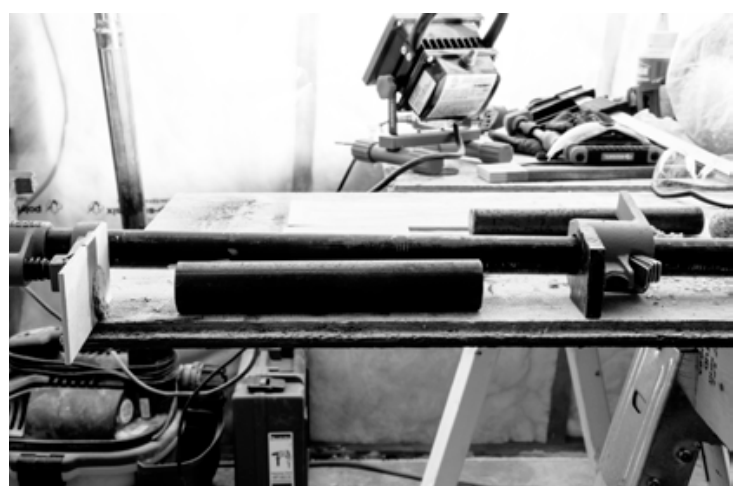

Figure 46.

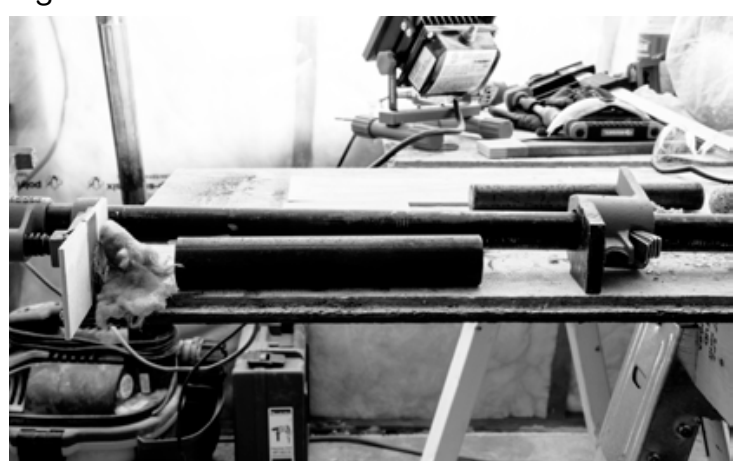

Figure 47.

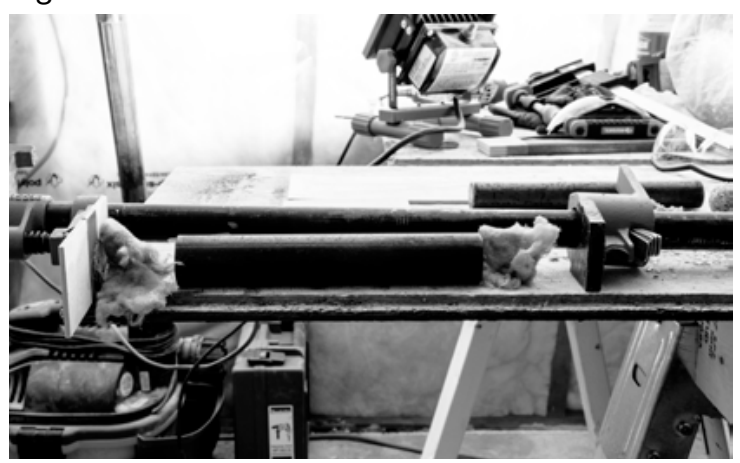

Figure 48.

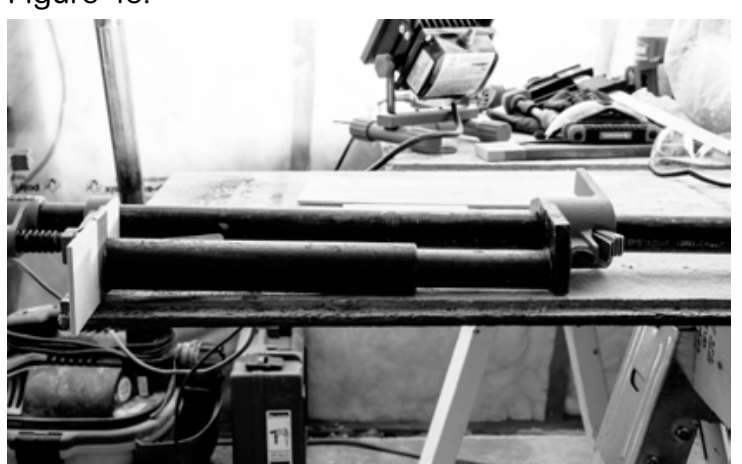

Figure 49.

Figure 42-49. Melting Process 


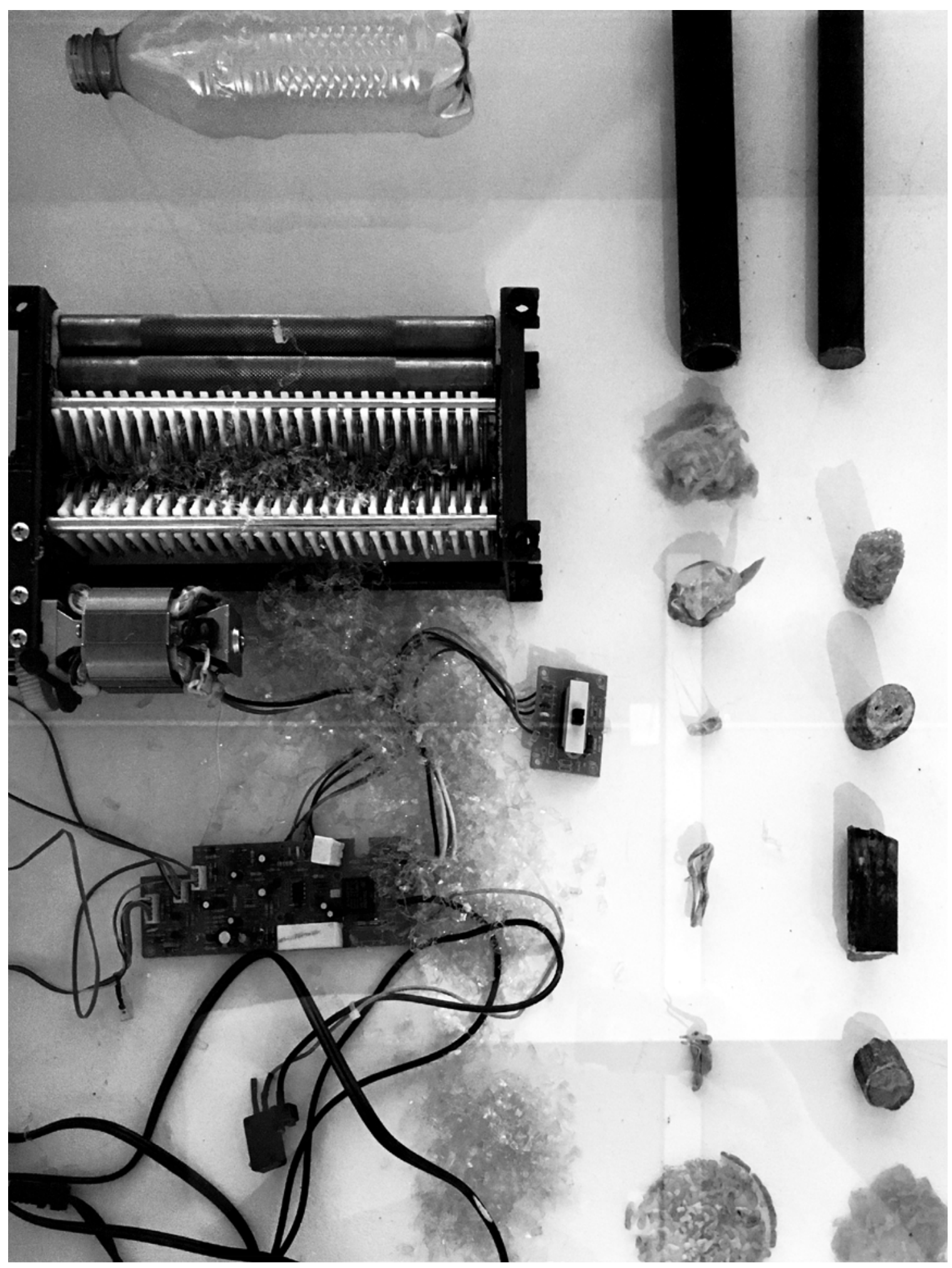

Figure 50. Macro Photography - Plastic Shedding, Melting, Compressing, and Forming Process 


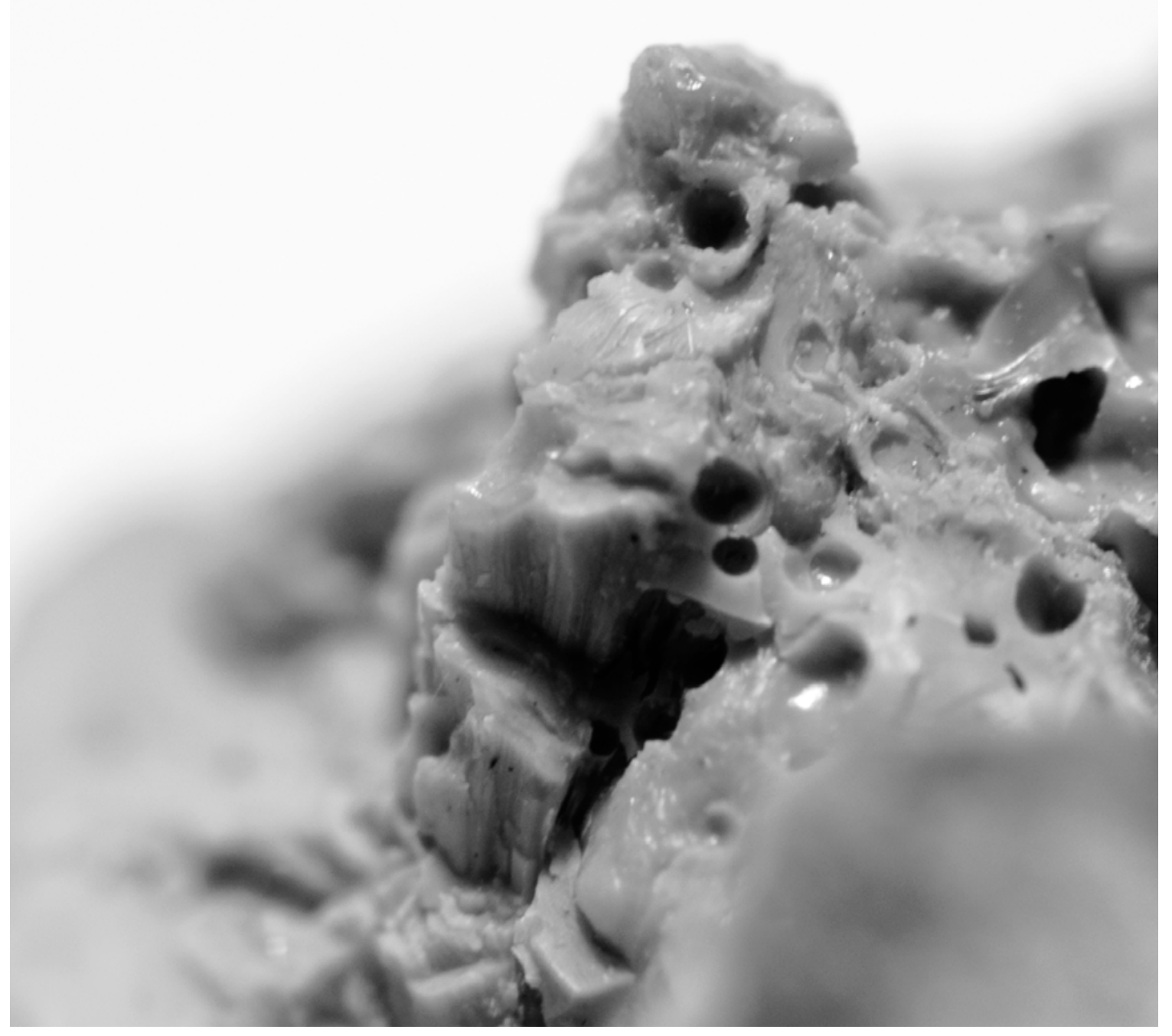

Figure 51. Macro Photography - Melted Plastic with Air Pockets 


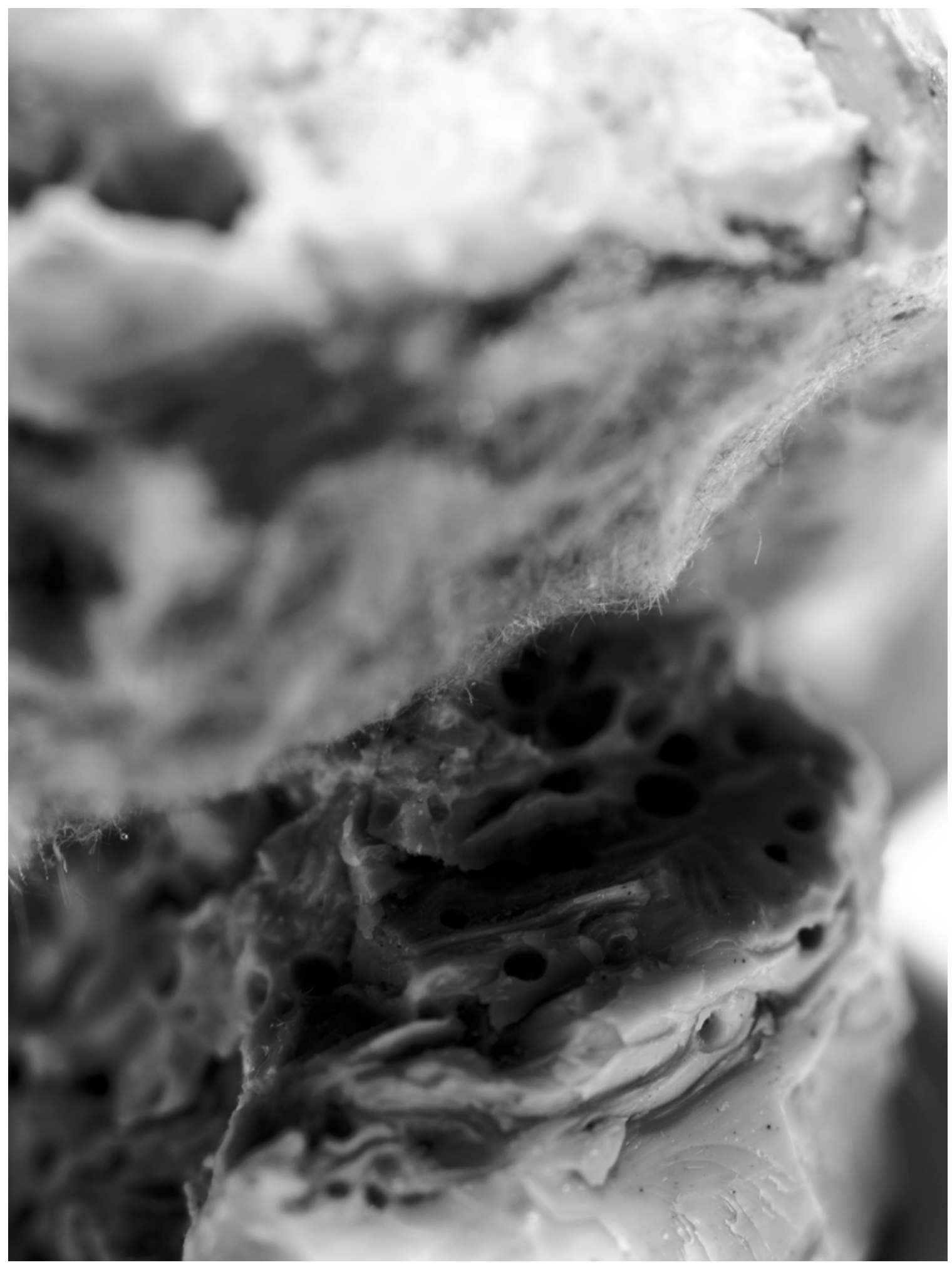

Figure 52. Macro Photography - Spatial Composition of Melted Plastic and ROXUL Insulation 


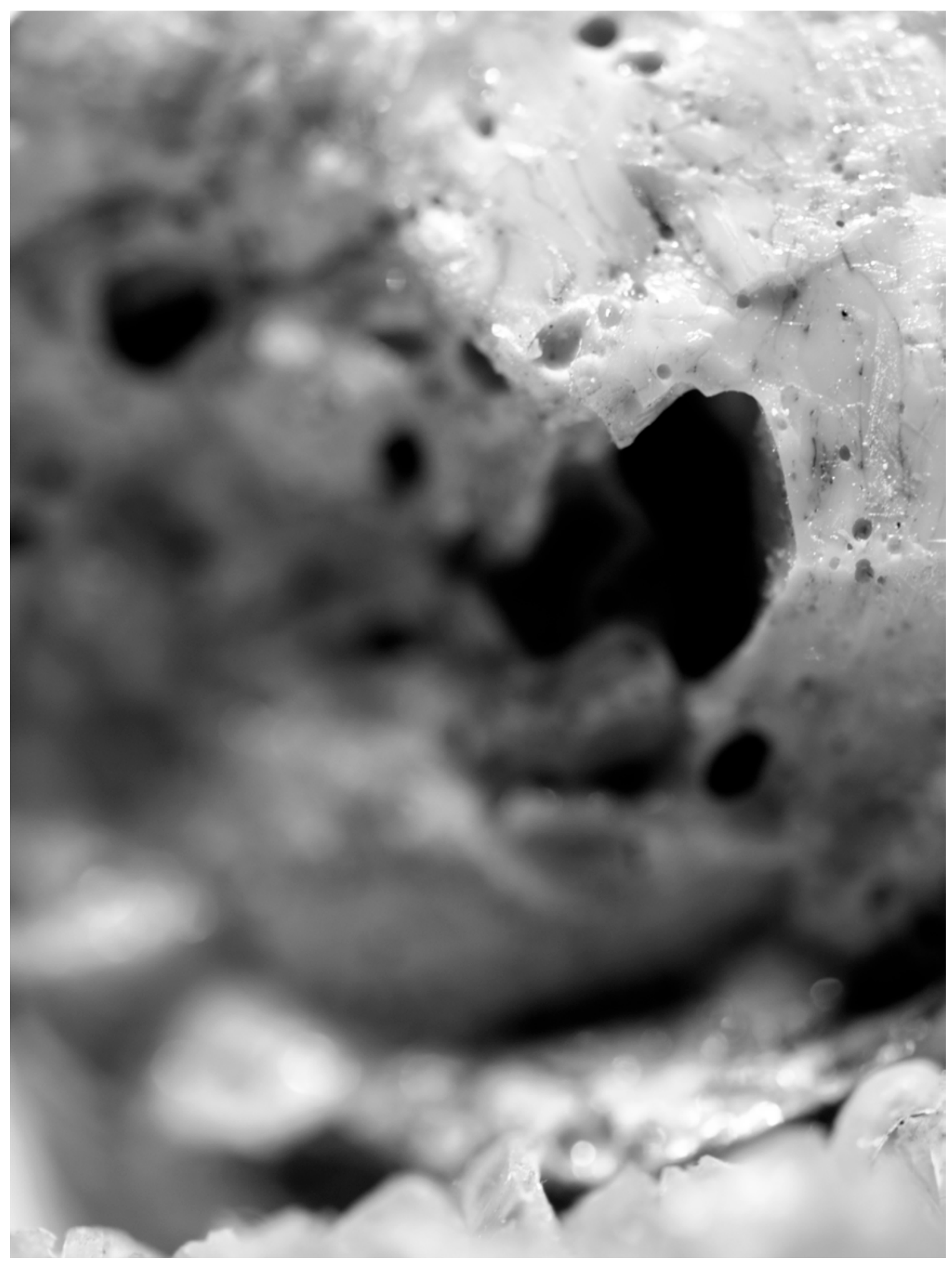

Figure 53. Macro Photography - Spatial Composition 


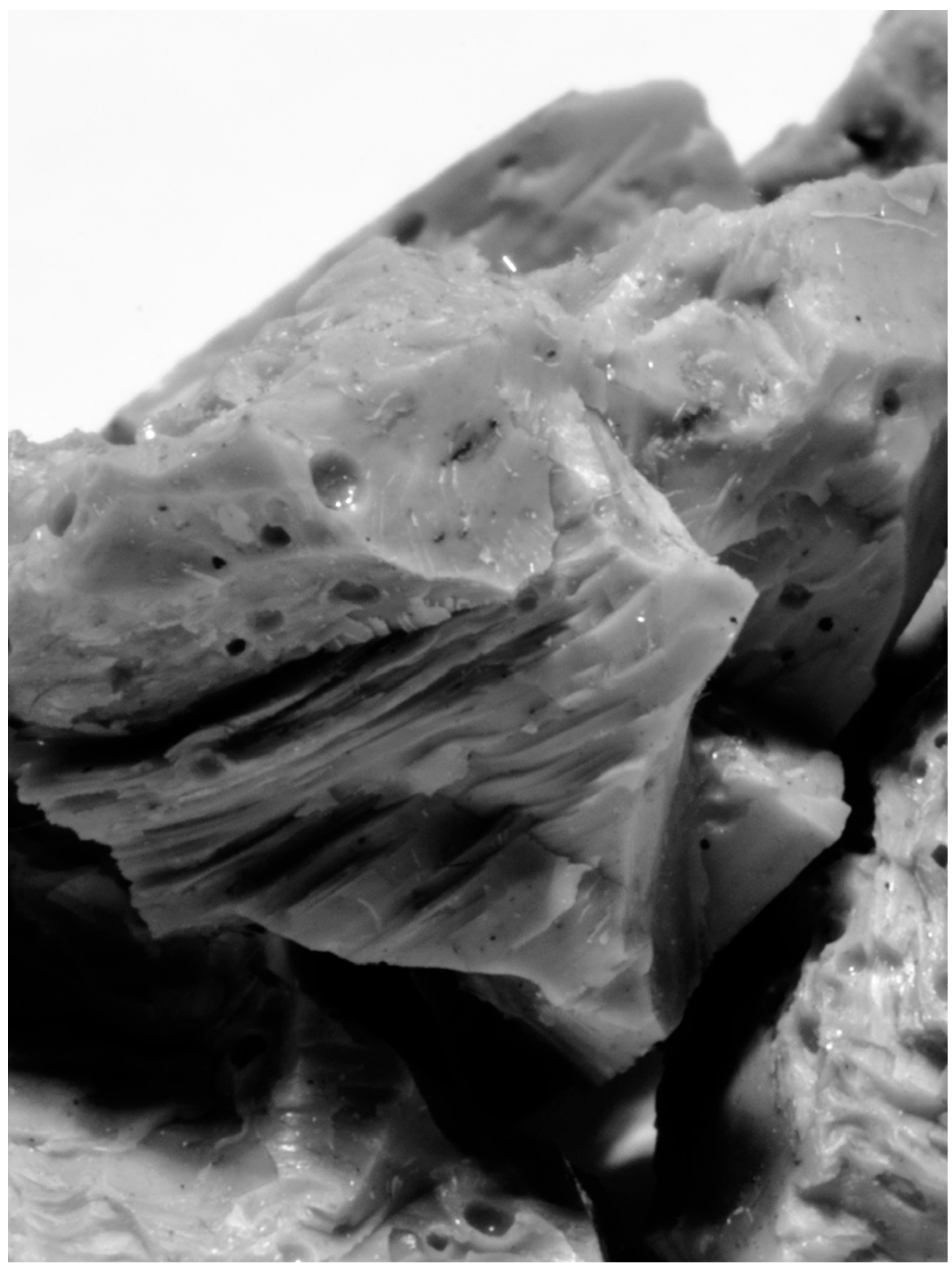

Figure 54. Macro Photography 


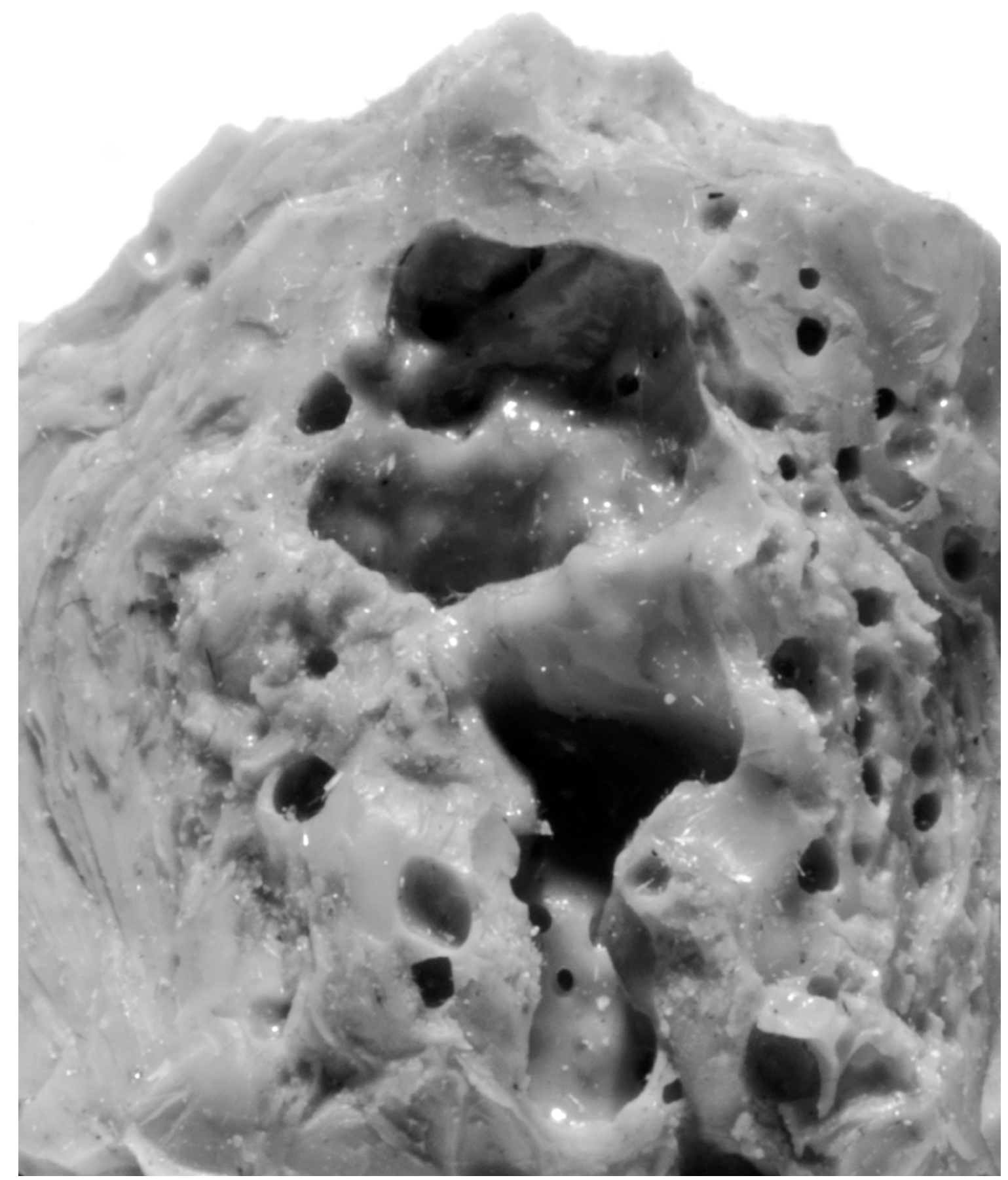

Figure 55. Macro Photography 


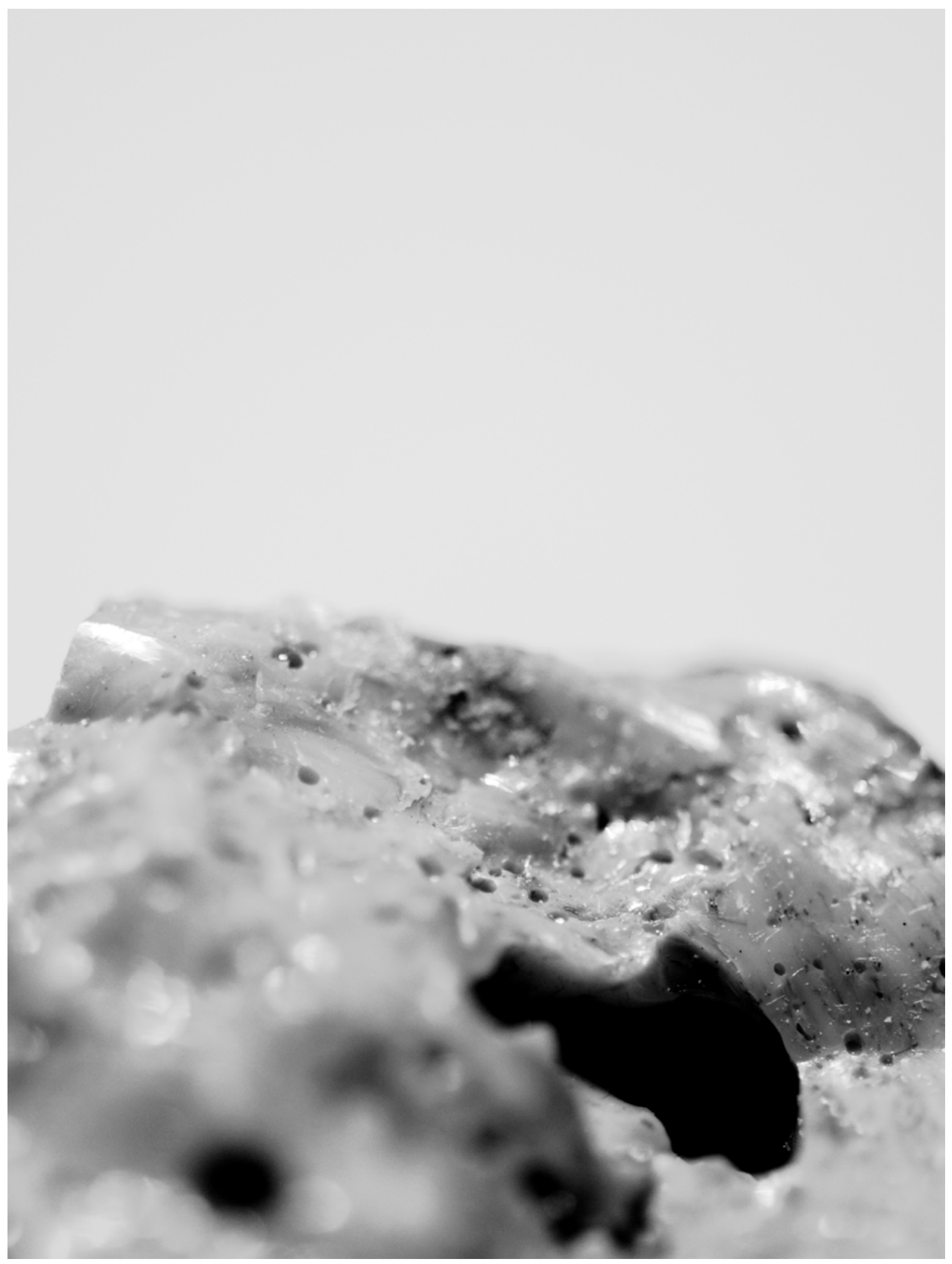

Figure 56. Macro Photography 


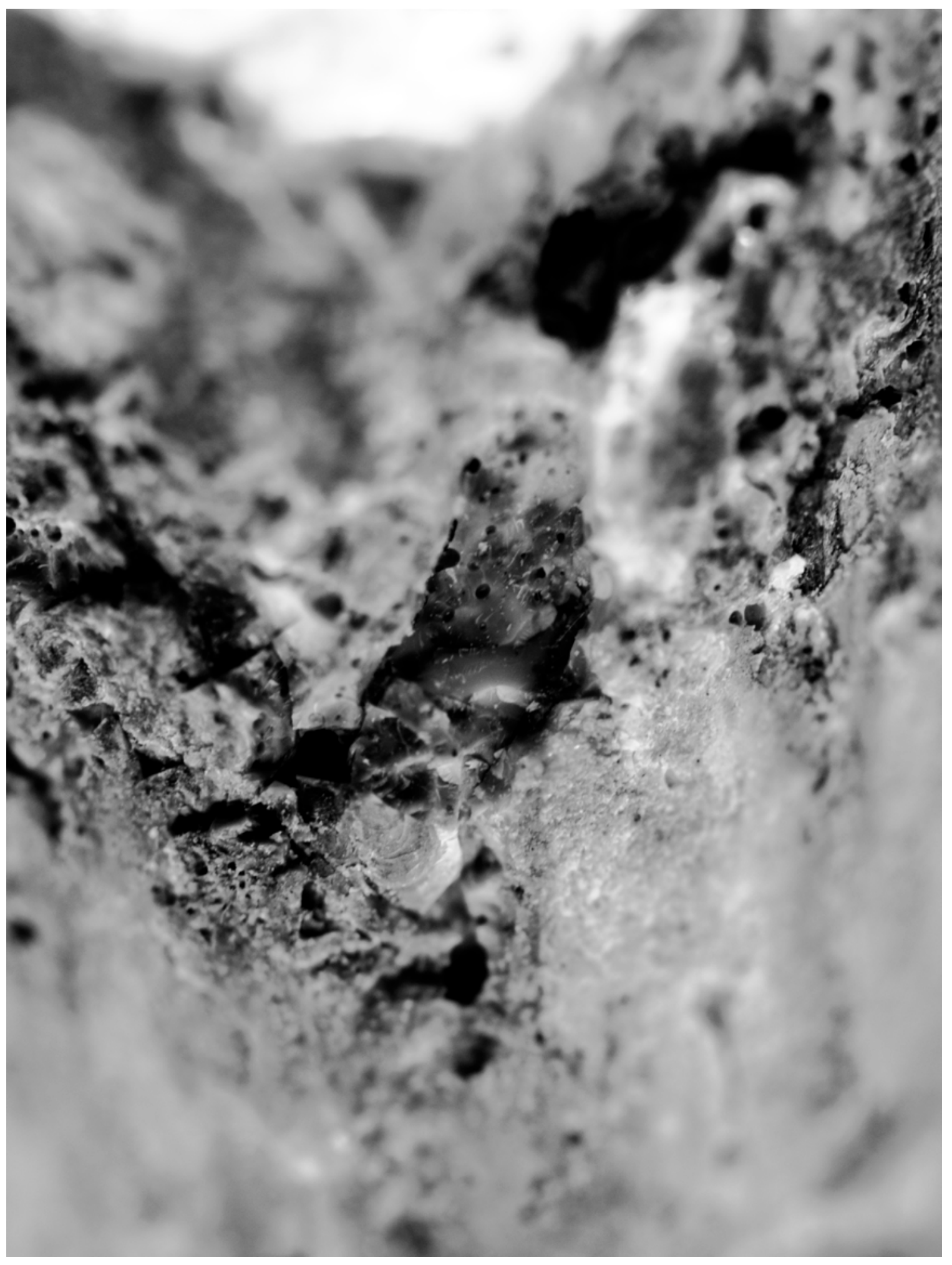

Figure 57. Macro Photography 

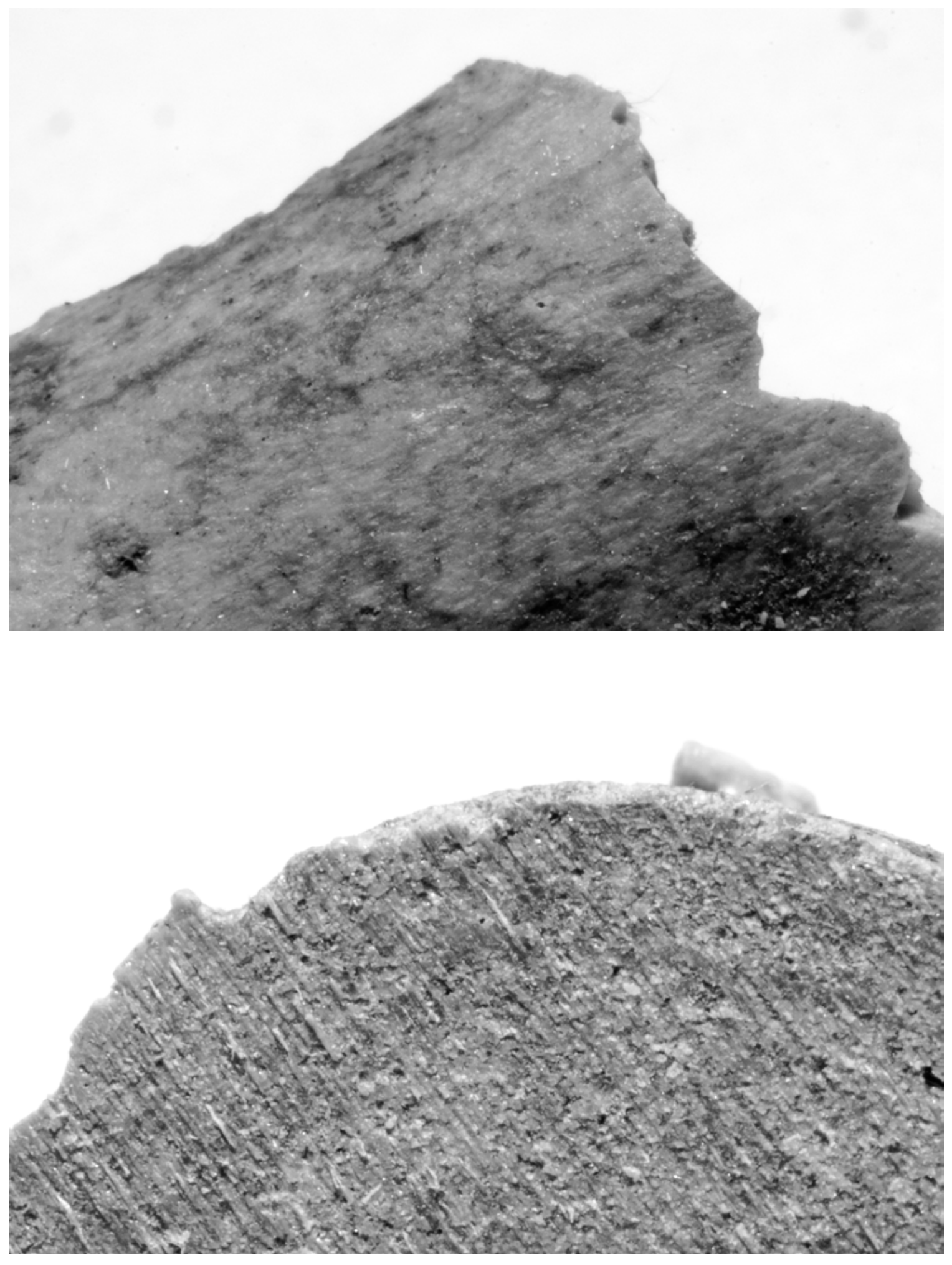

Figure 58. Macro Photography - Melted Plastic as Wood Texture 


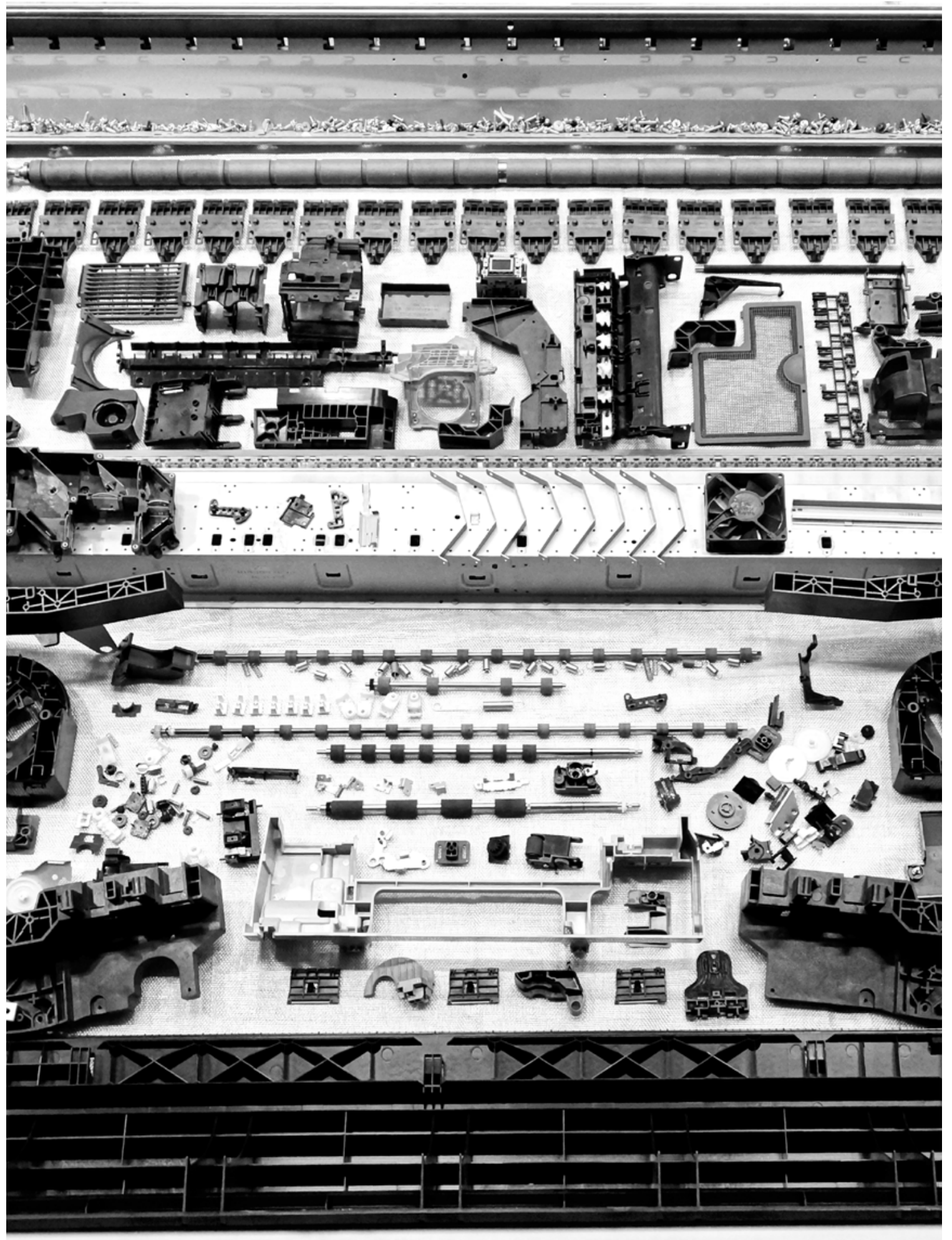

Figure 59. Process - Mechanical and plastic parts found in printers, projectors, computers and other consumer objects. Image taken during Ice Studio 2015. 


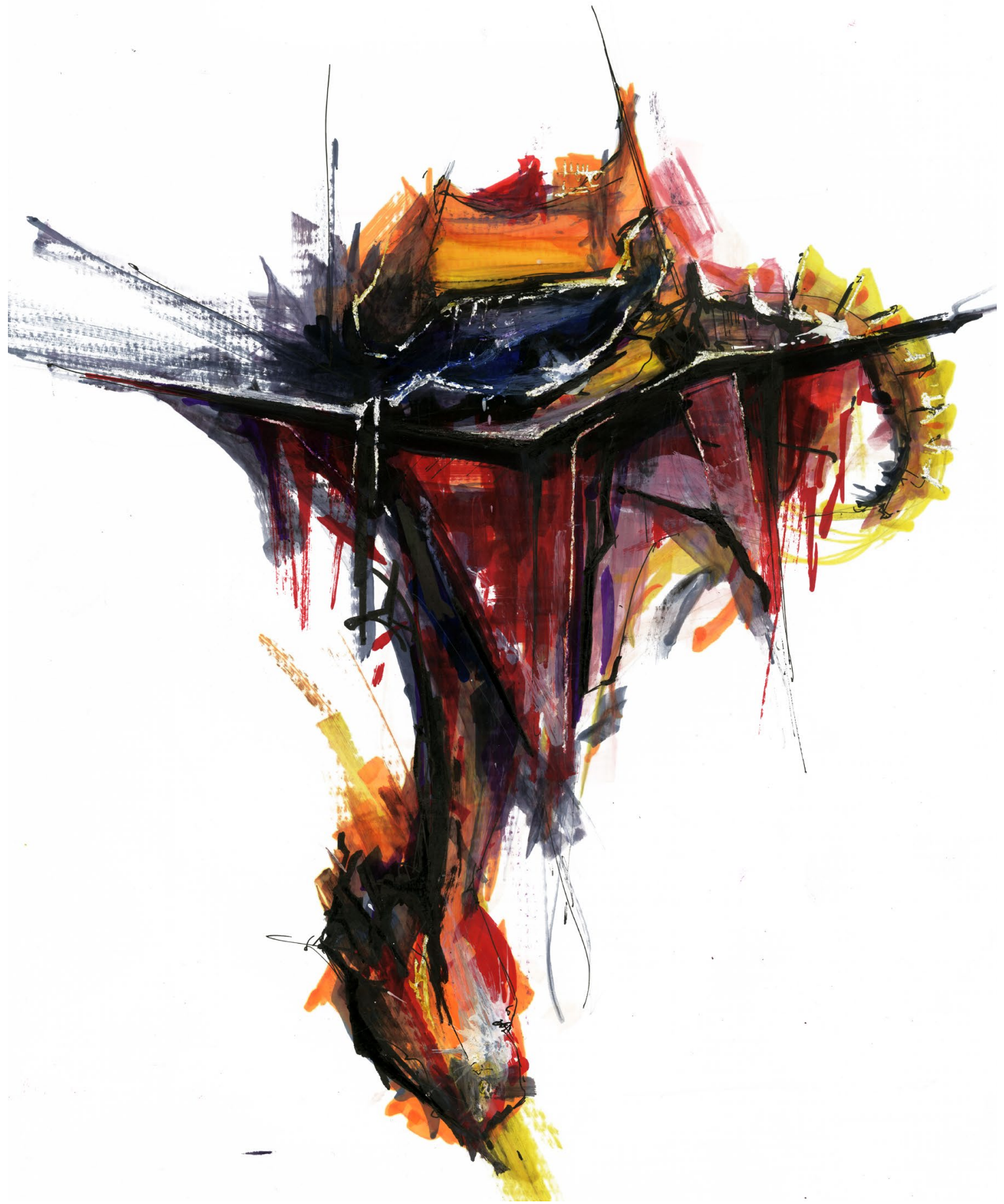

Figure 60. Process Drawing - Plastic Eating Machine Above and Below Water. 


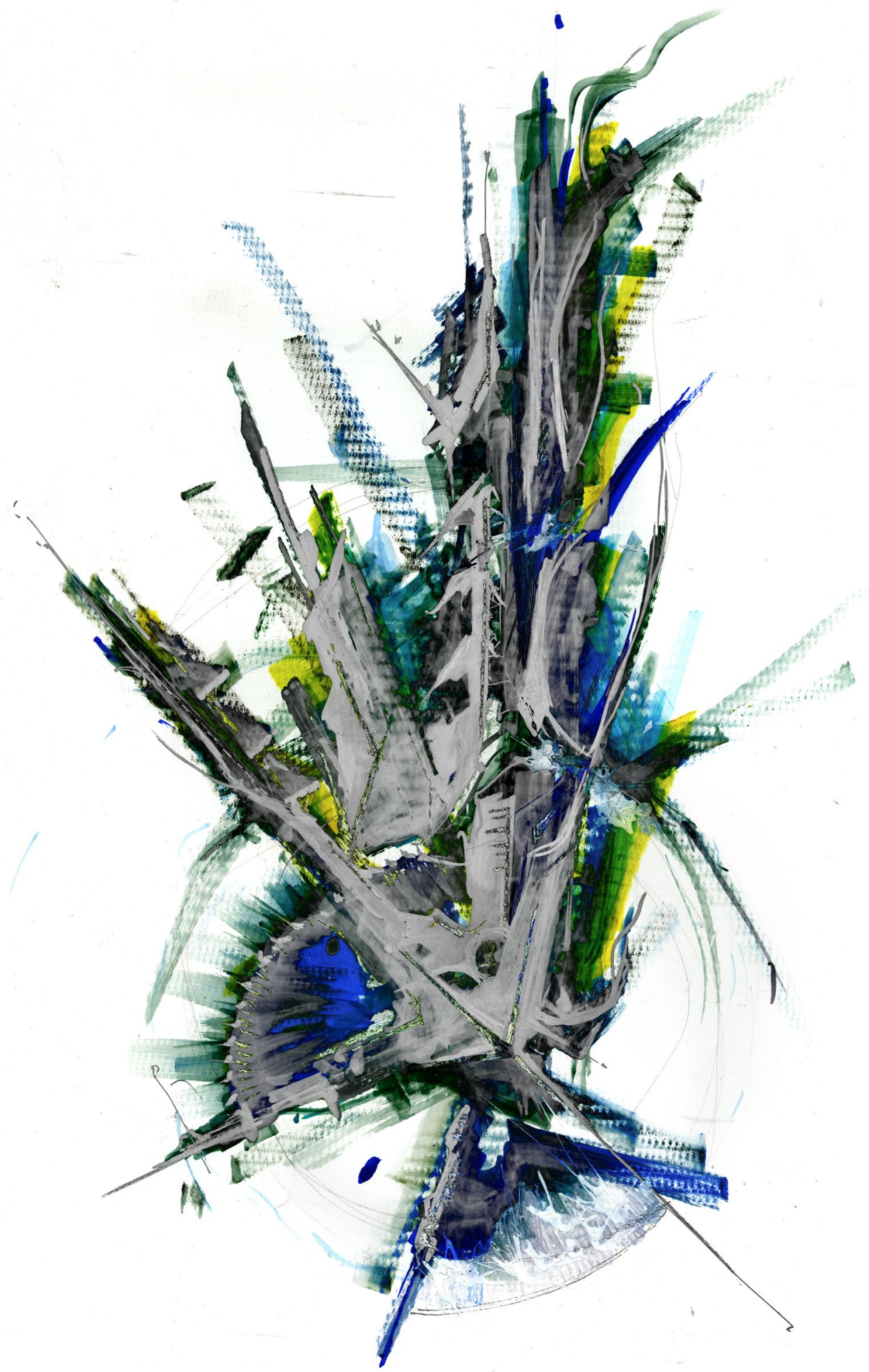

Figure 61. Process Drawing - Development of Plan 


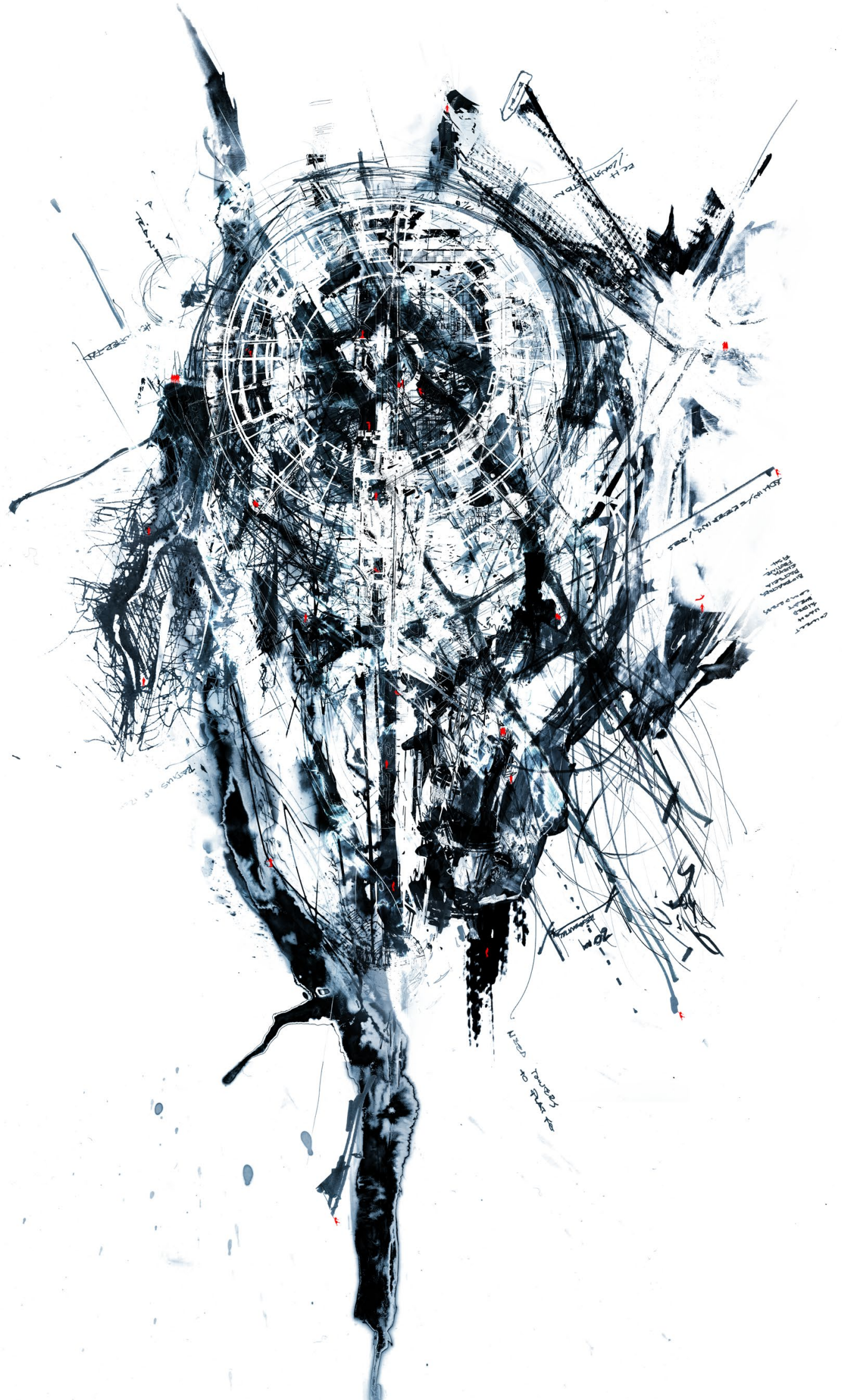

Figure 62. Hybrid Exploration Drawing 

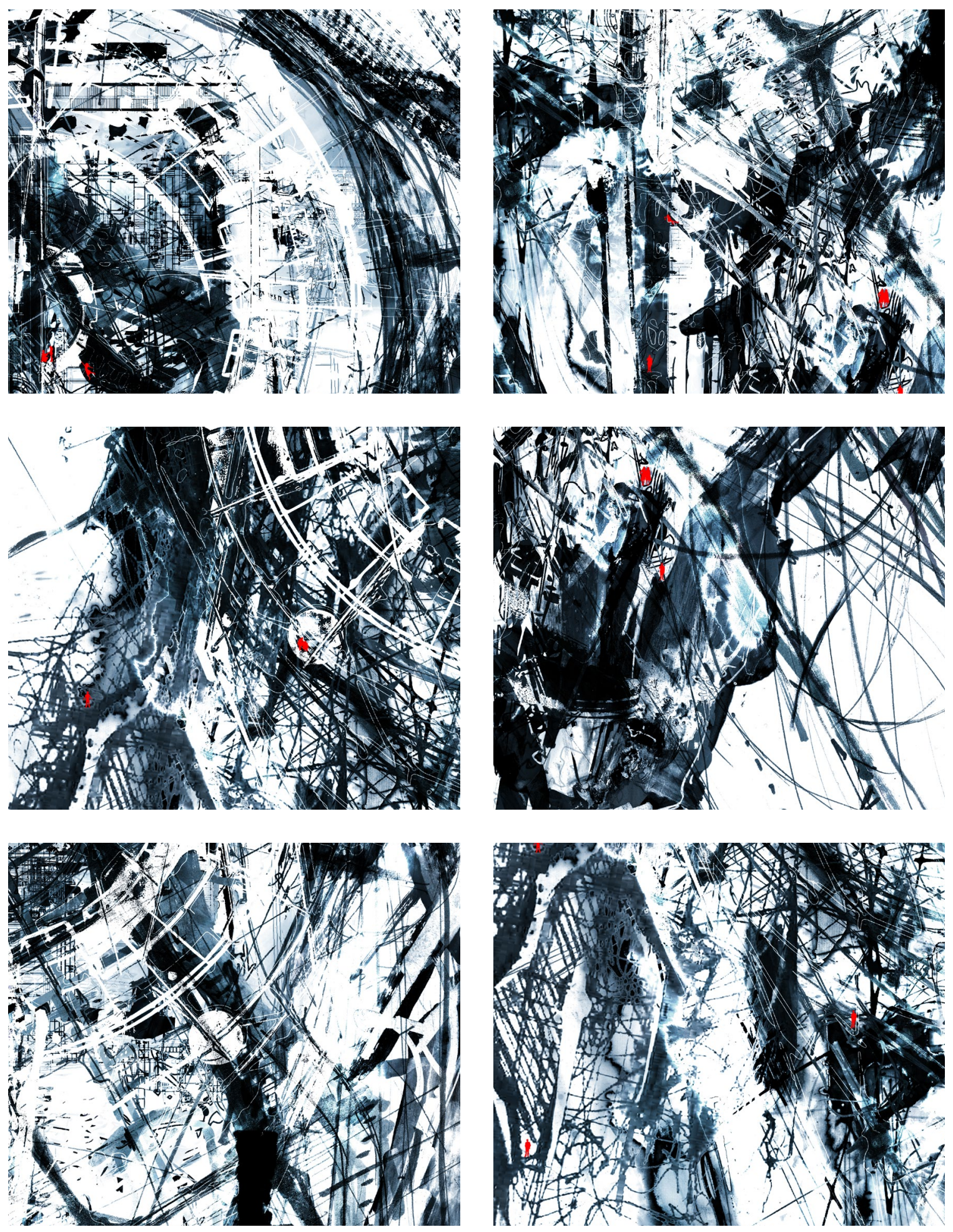

Figure 63. Hybrid Exploration Drawing - Each line (or part) has a meaning waiting to be uncovered 


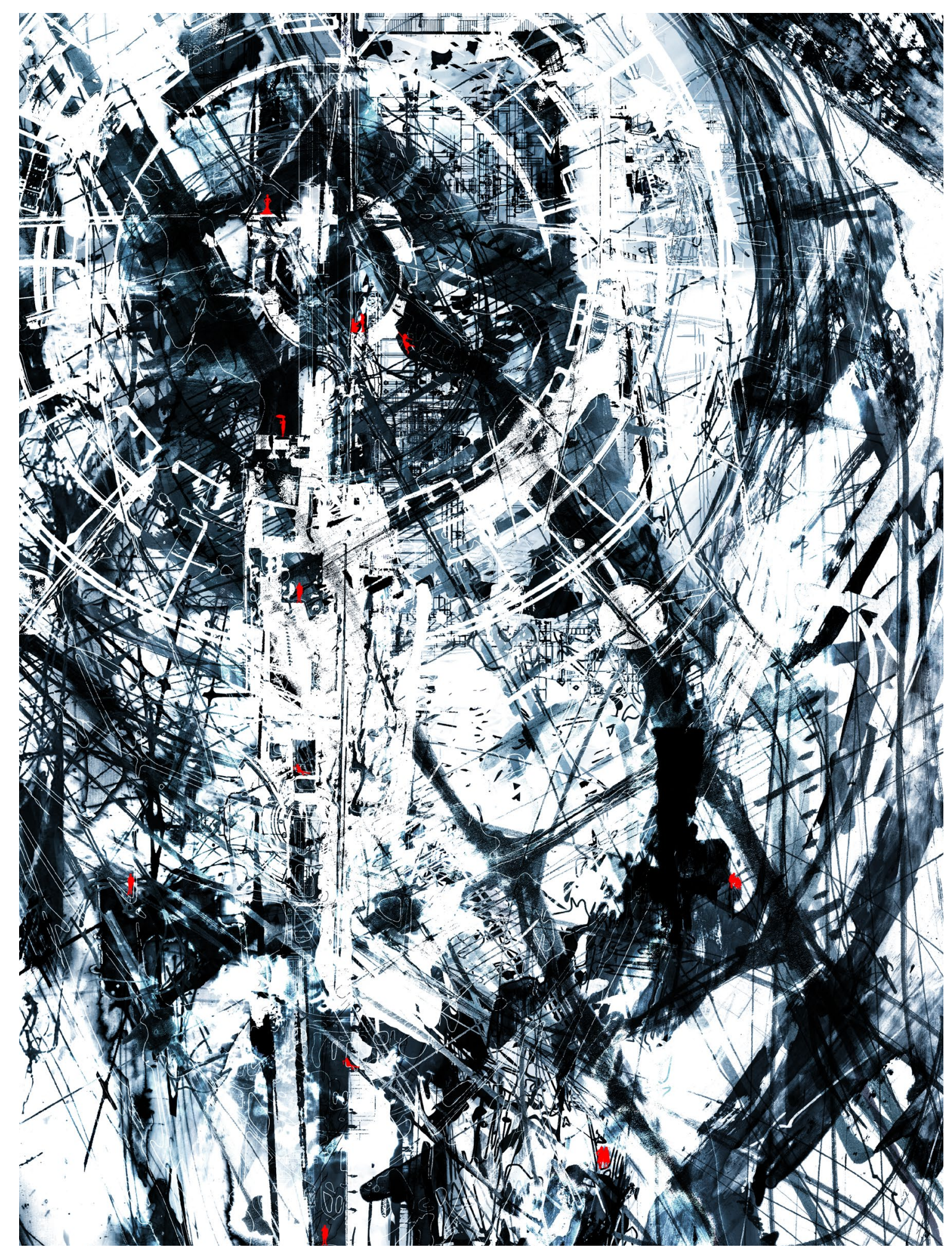

Figure 64. Detail of Hybrid Exploration Drawing 


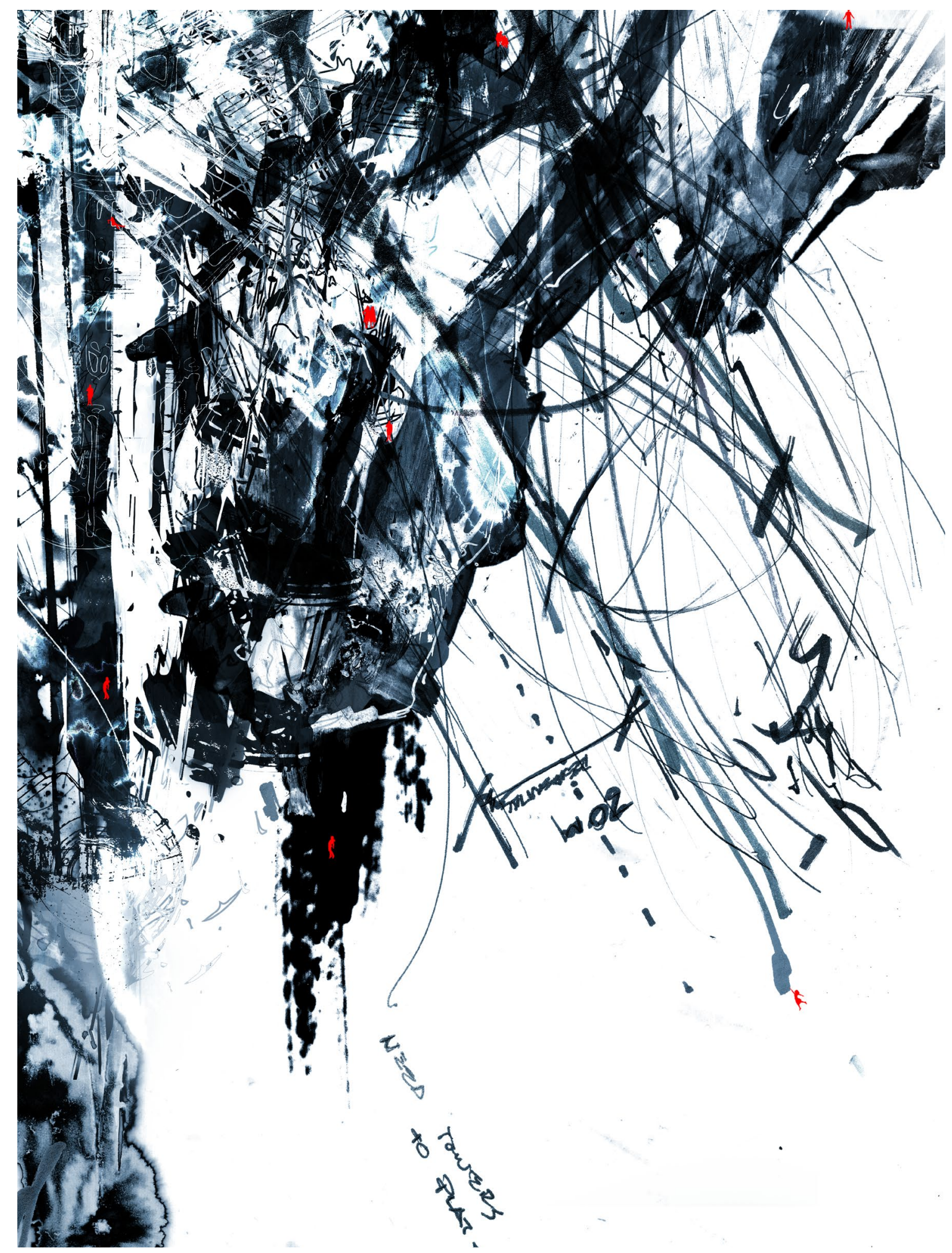

Figure 65. Detail of Hybrid Exploration Drawing 


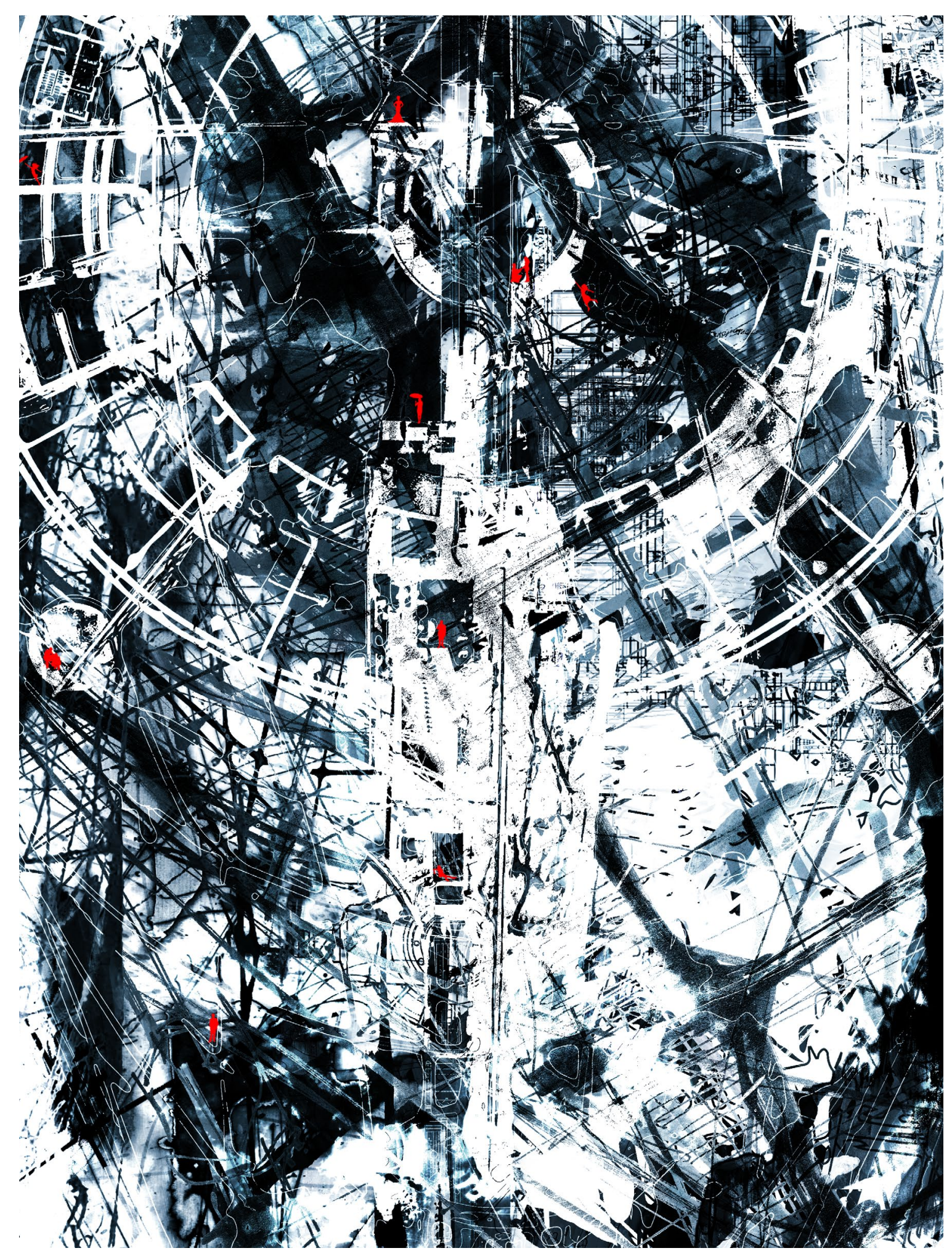

Figure 66. Detail of Hybrid Exploration Drawing 

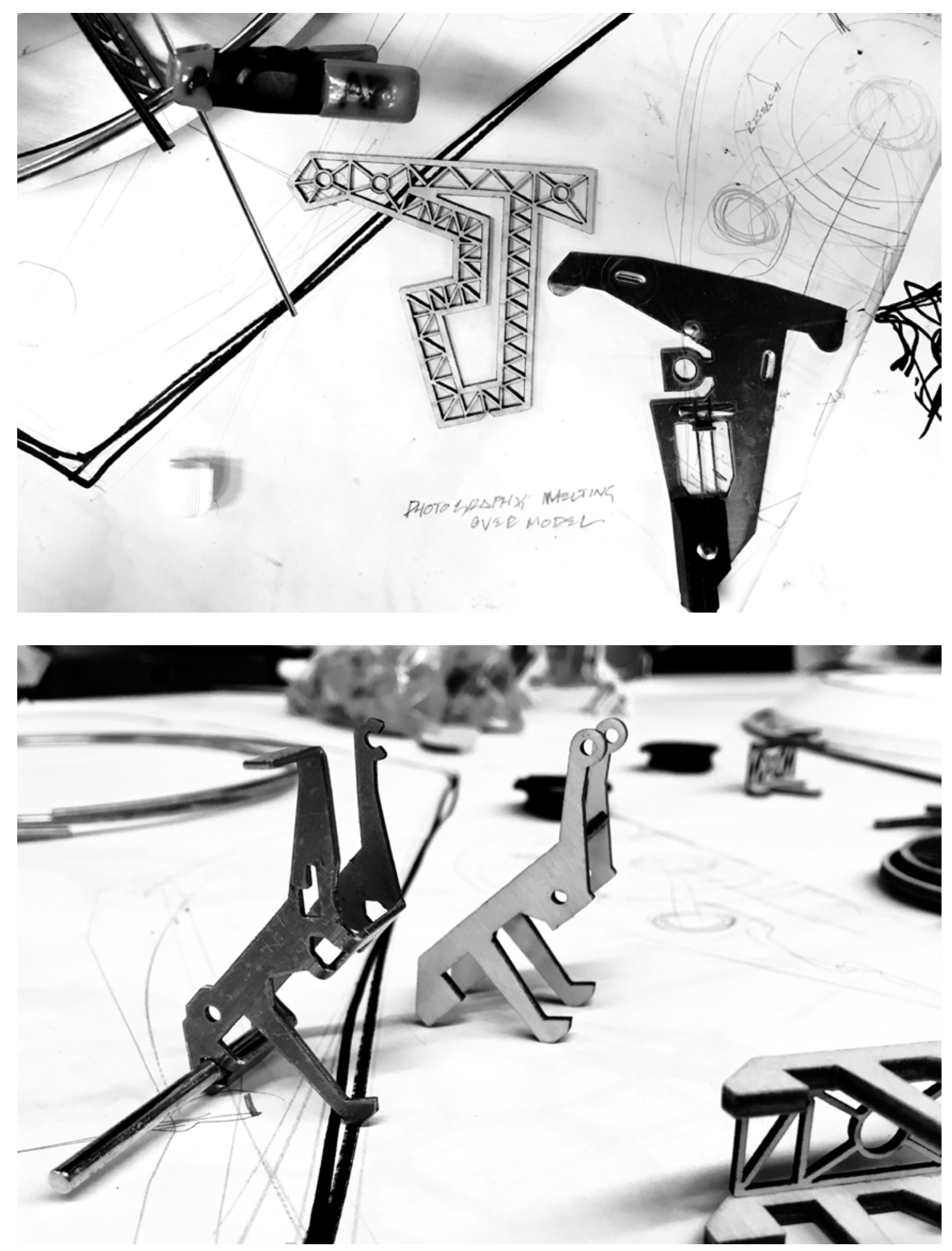

Figure 67. A comparison of the fabricated object to the found object. Interesting plastic objects were scanned, redrawn, and designed as trusses, cranes, and footings for the plastic eating machines. At this point spatial arrangements were not yet defined. 


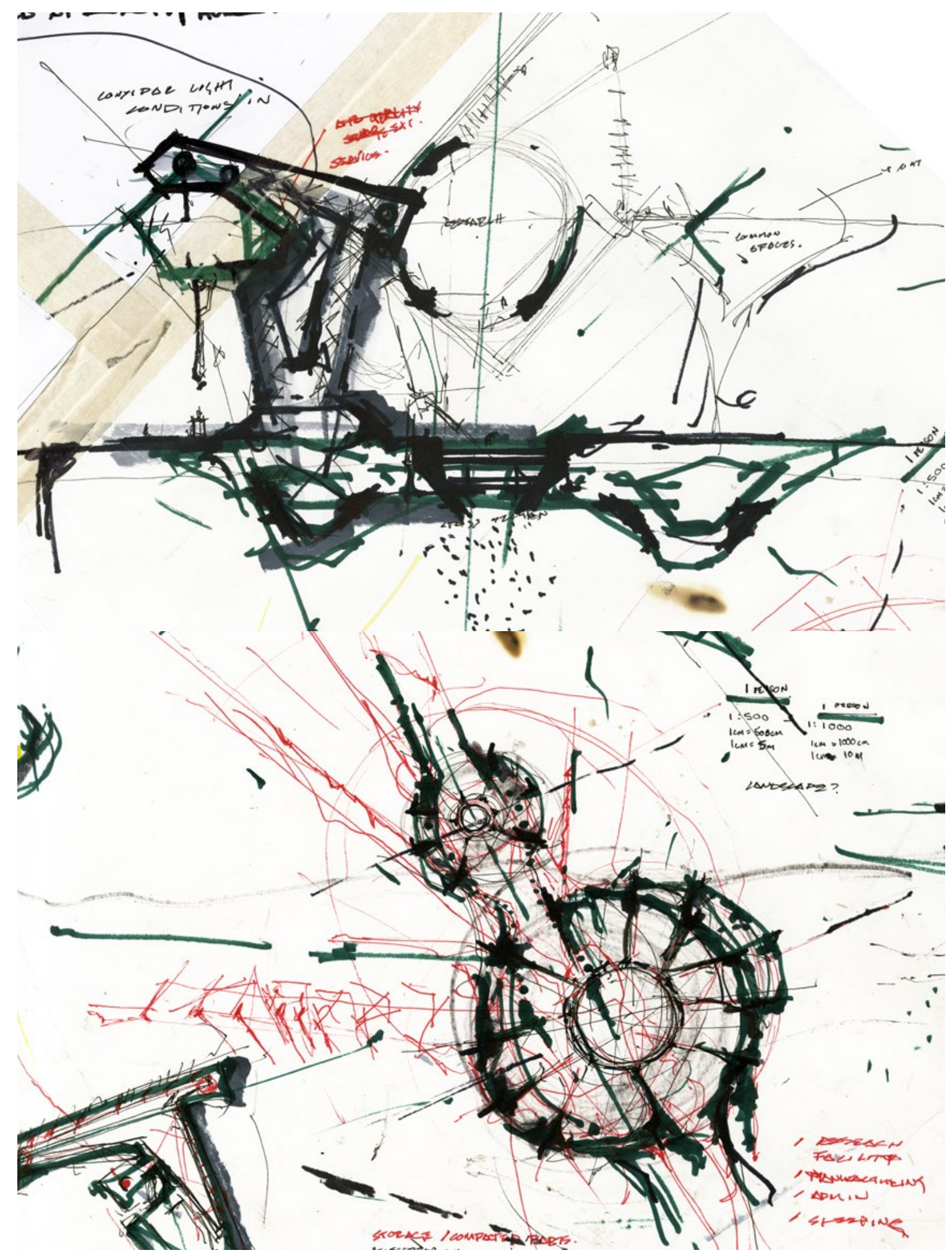

Figure 68. These sketches began to rationalize the found objects as architectural components that define space. As justified by the top image, the negative space within the truss, interpreted as section, established the living corridors and research labs. The notion of collaboration and the need to overlook the same research lead to the array of these moments, thus establishing a circular plan. 

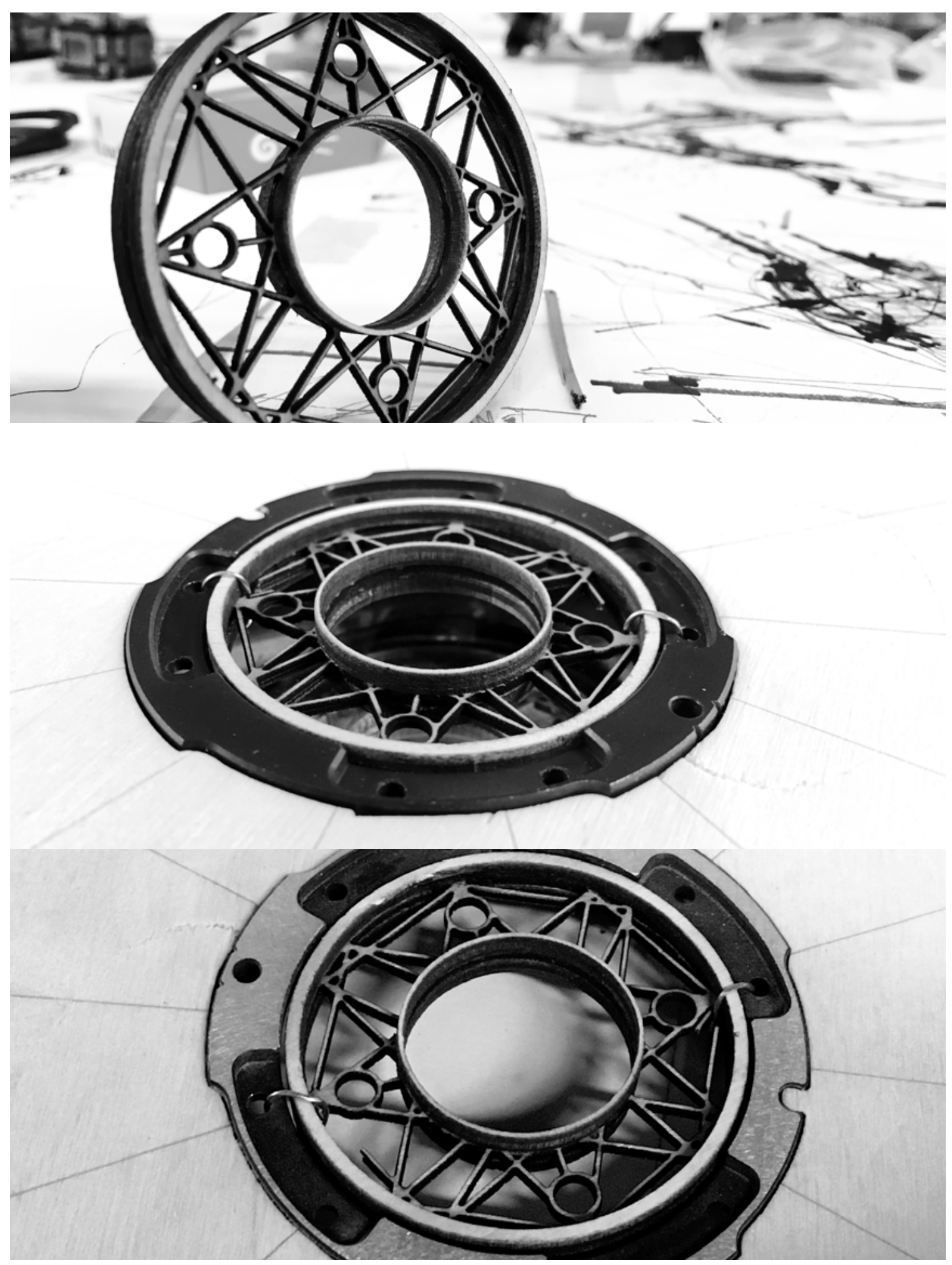

Figure 69. The fabricated object integrated with the found object. The redrawn truss is now defined by the found object (camera lens). This configuration was used as a truss system that is integrated with the machines structural cage (framing). They were used as the main support for the bridge that processes collected plastics. 


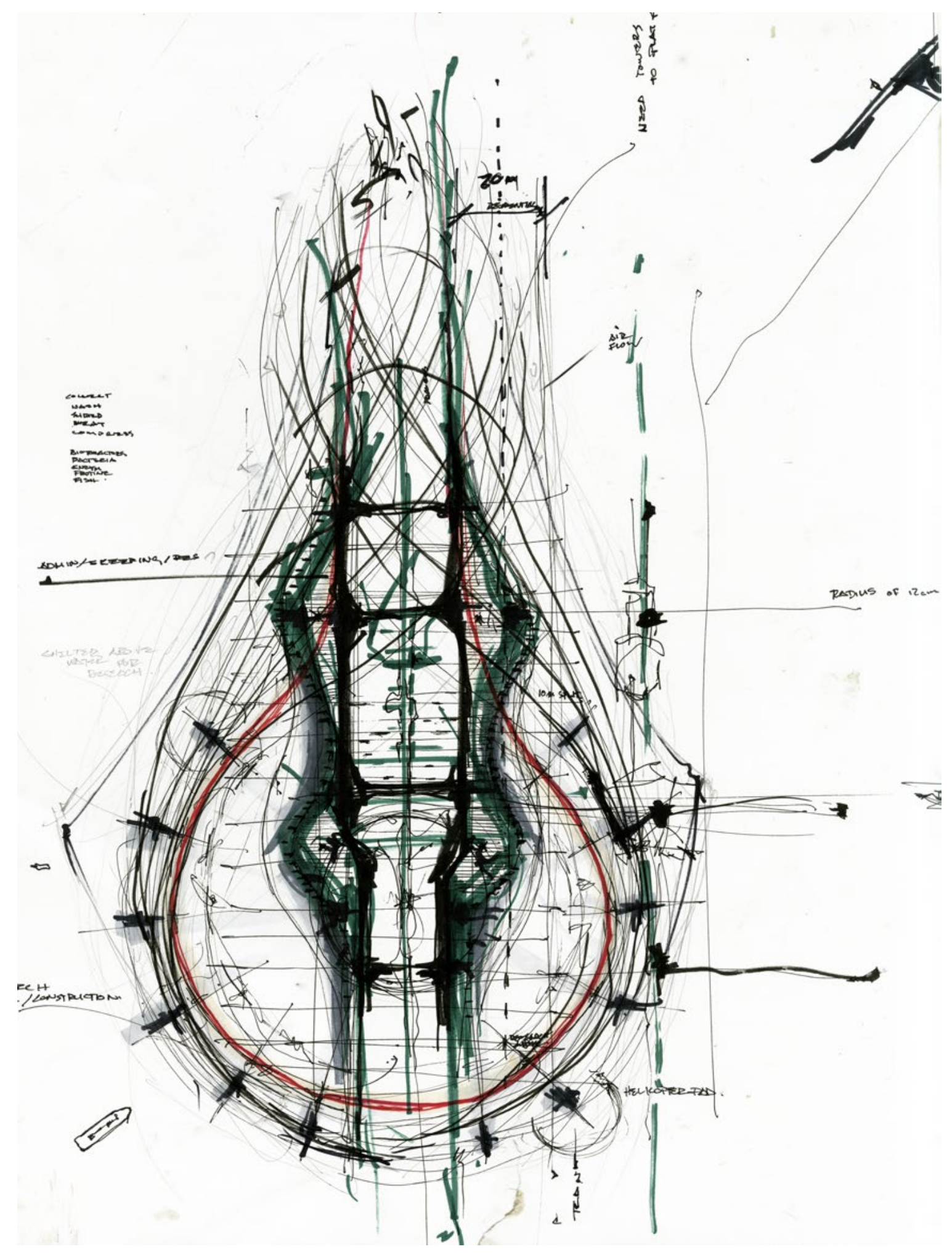

Figure 70. Hand drawing in combination with model making was essential during this design process. A symbiotic relationship between these two methods allowed for a natural progression within the development of the design. Sketches inspired model making and model making inspired sketching - this workflow established the plastic eating machines. 

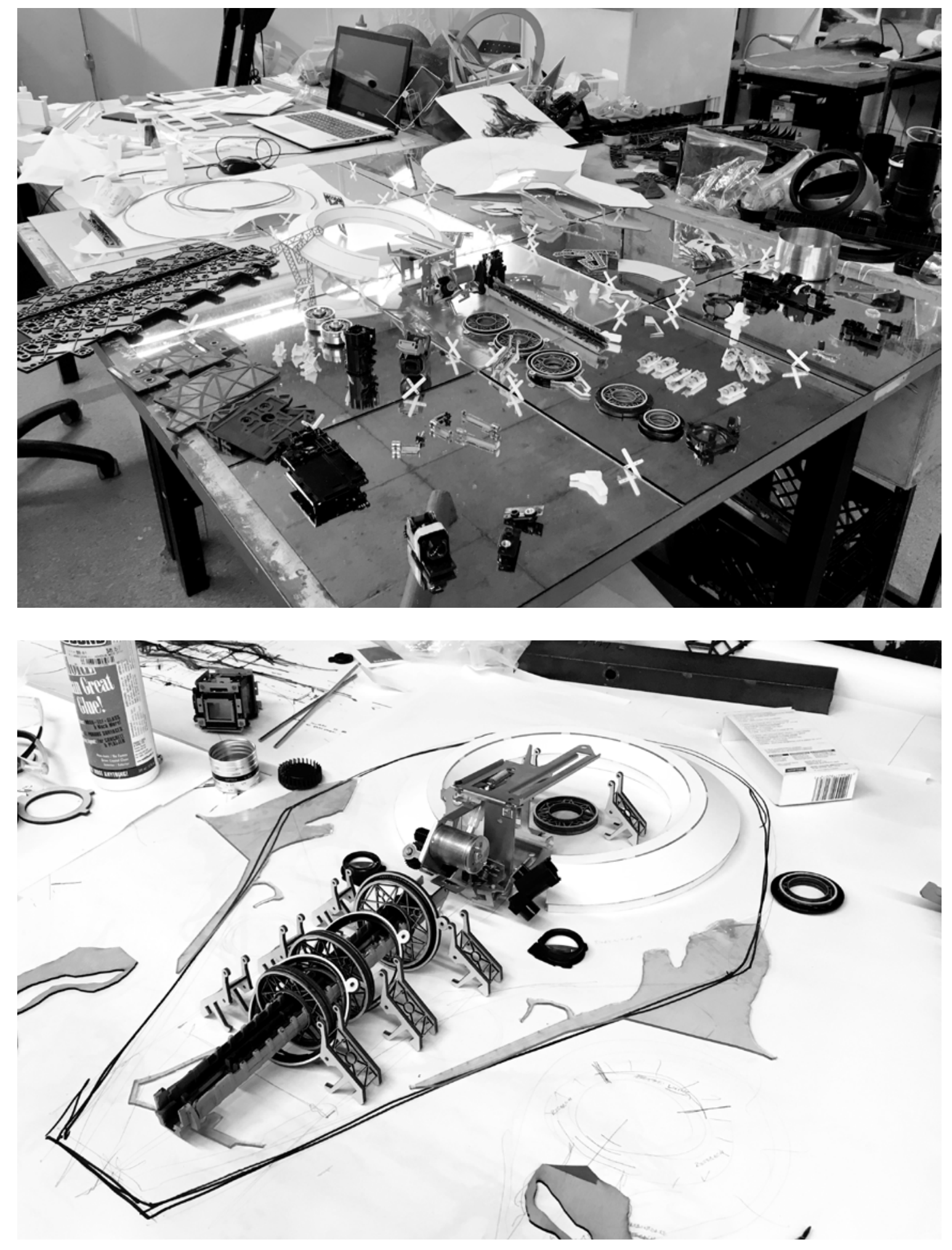

Figure 71. Establishing a base for the facility - Glass mirrors were used as representation of water. 


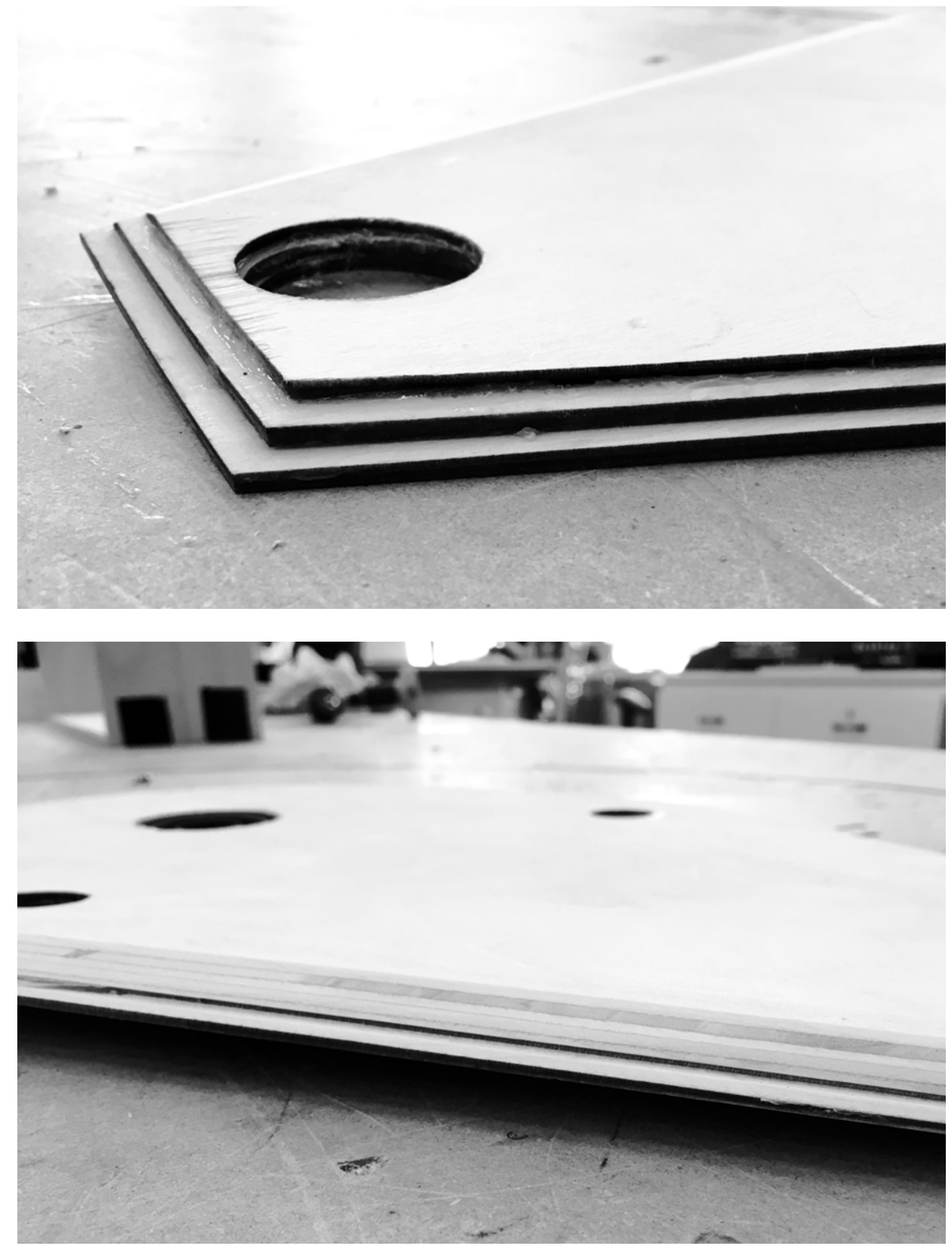

Figure 72. Laminating and sanding edges of wooden base. 

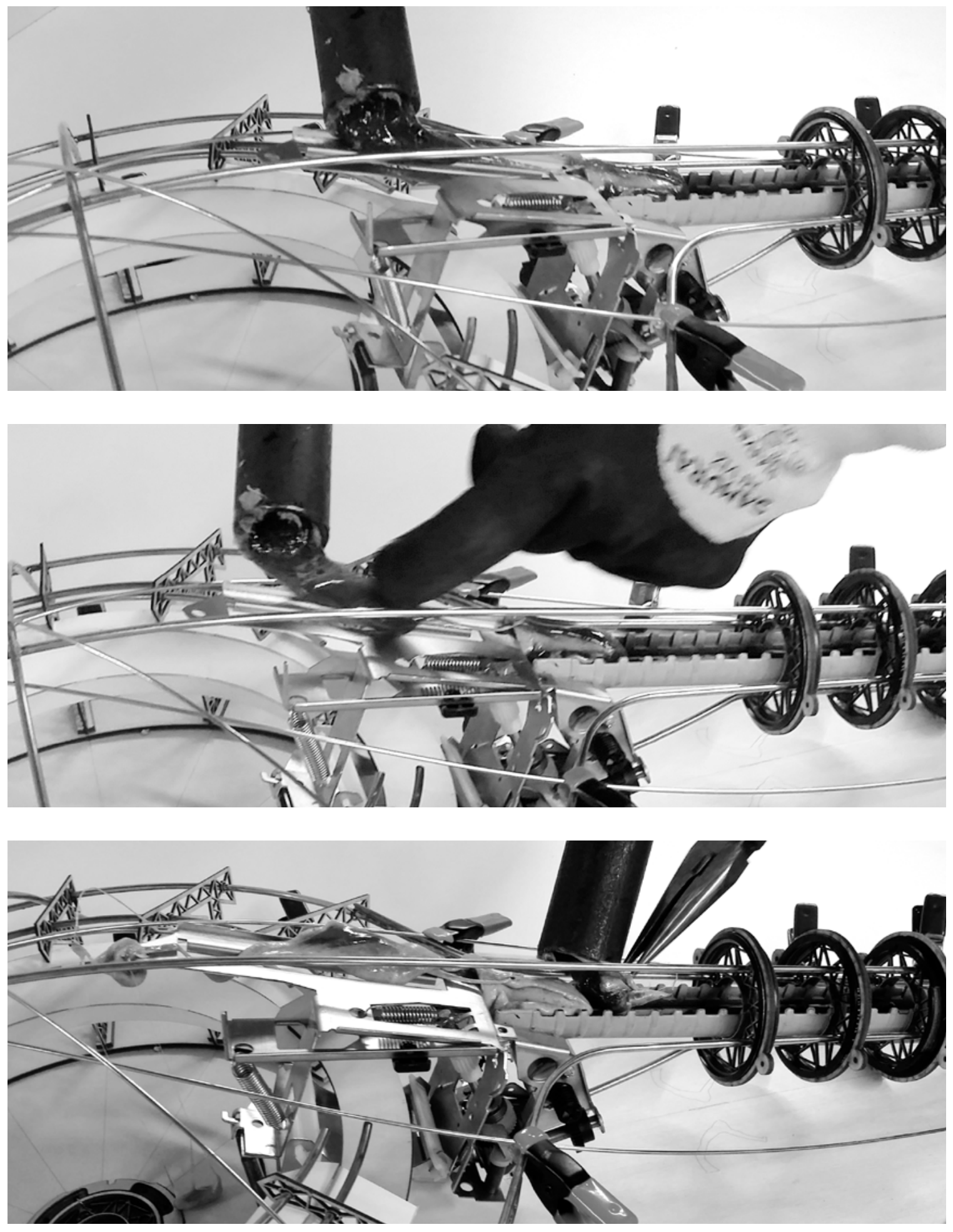

Figure 73. Pouring of PET plastic over physical model - the plastic was used as a gluing agent to stich fragments of the model together. 

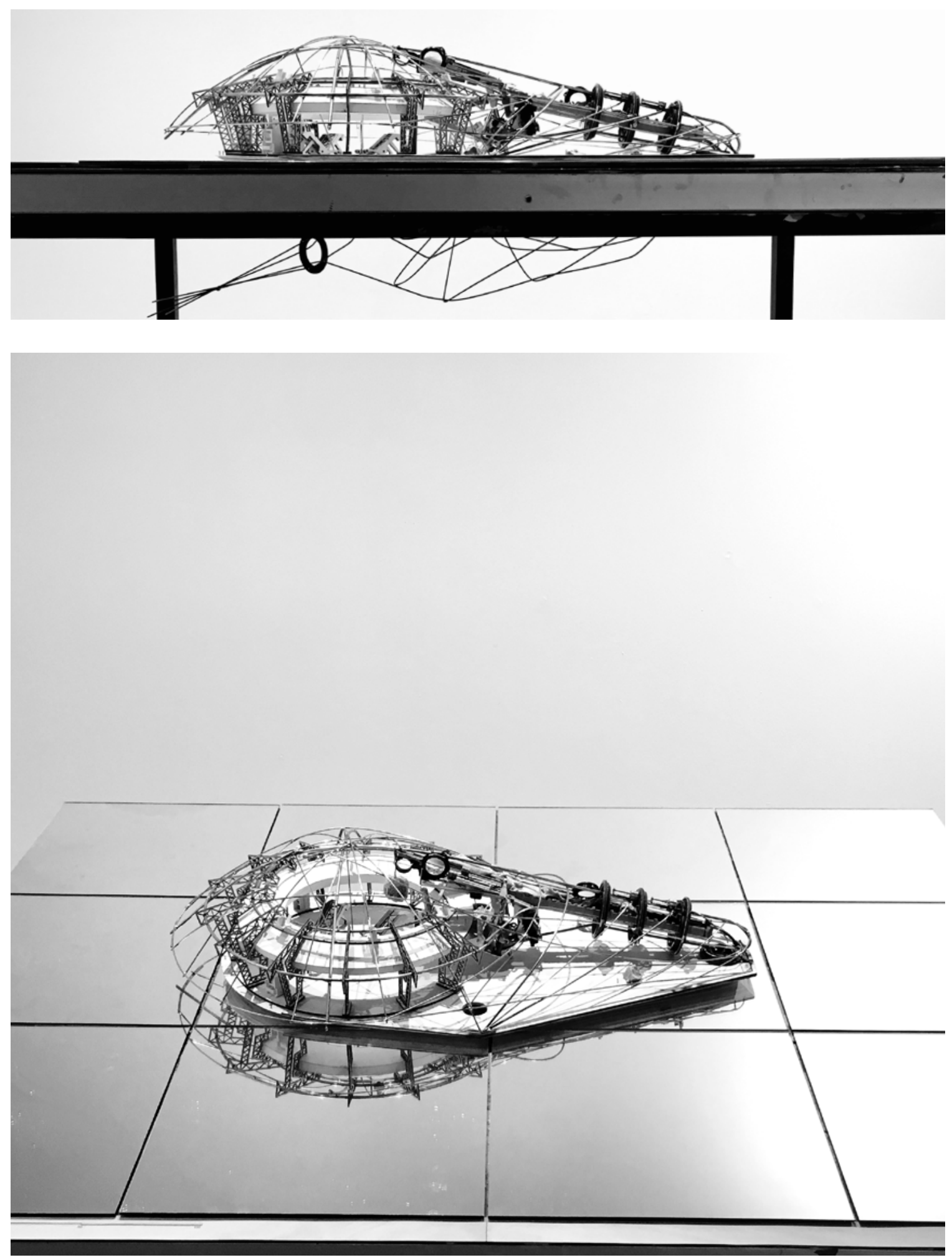

Figure 74 . The belly of the machine passes through four holes, physically connecting it to the portions above water. These images establish scale for the built project - Each tile is one foot by one foot. 


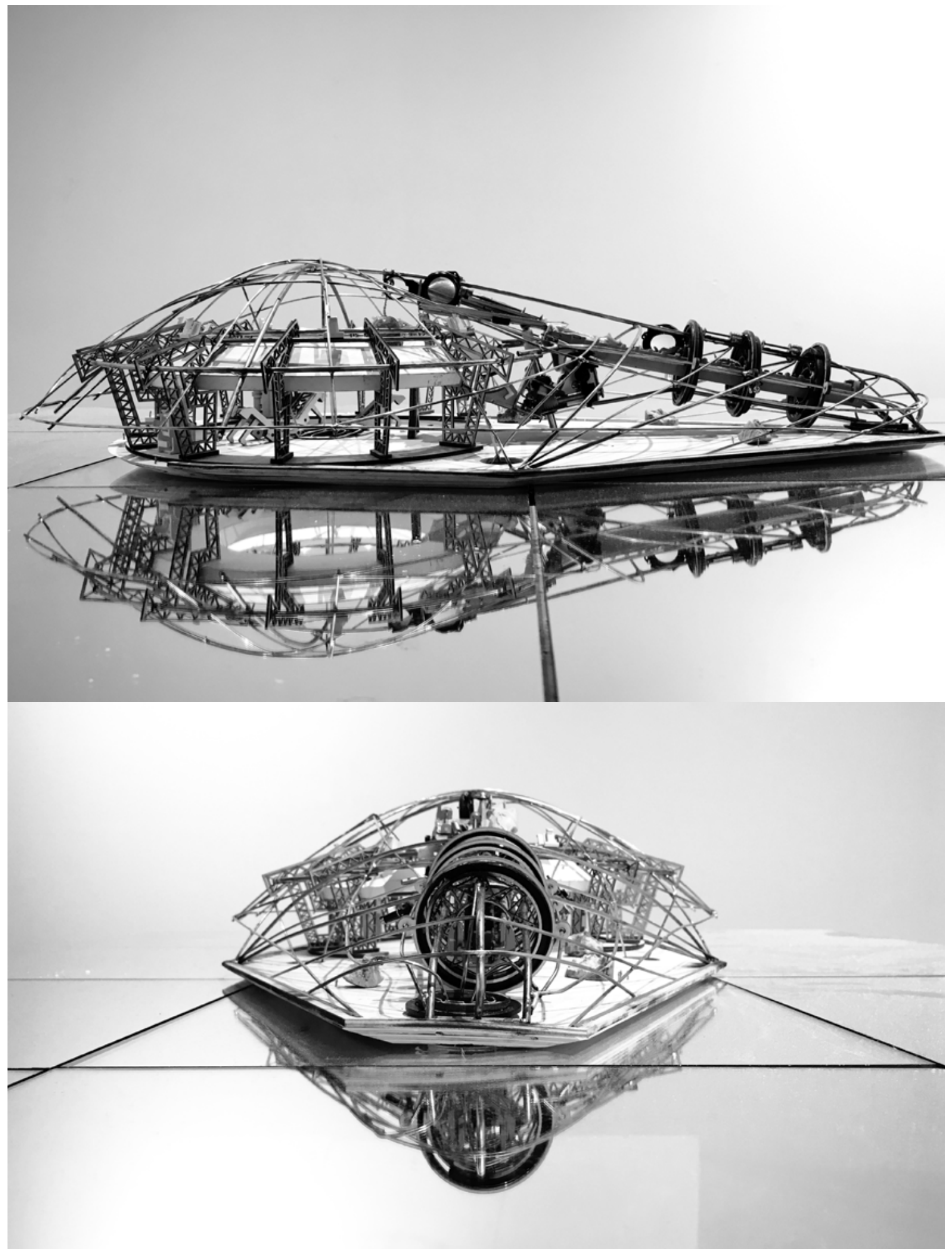

Figure 75. Elevations of the Built Model Side Elevation and Front Elevation 


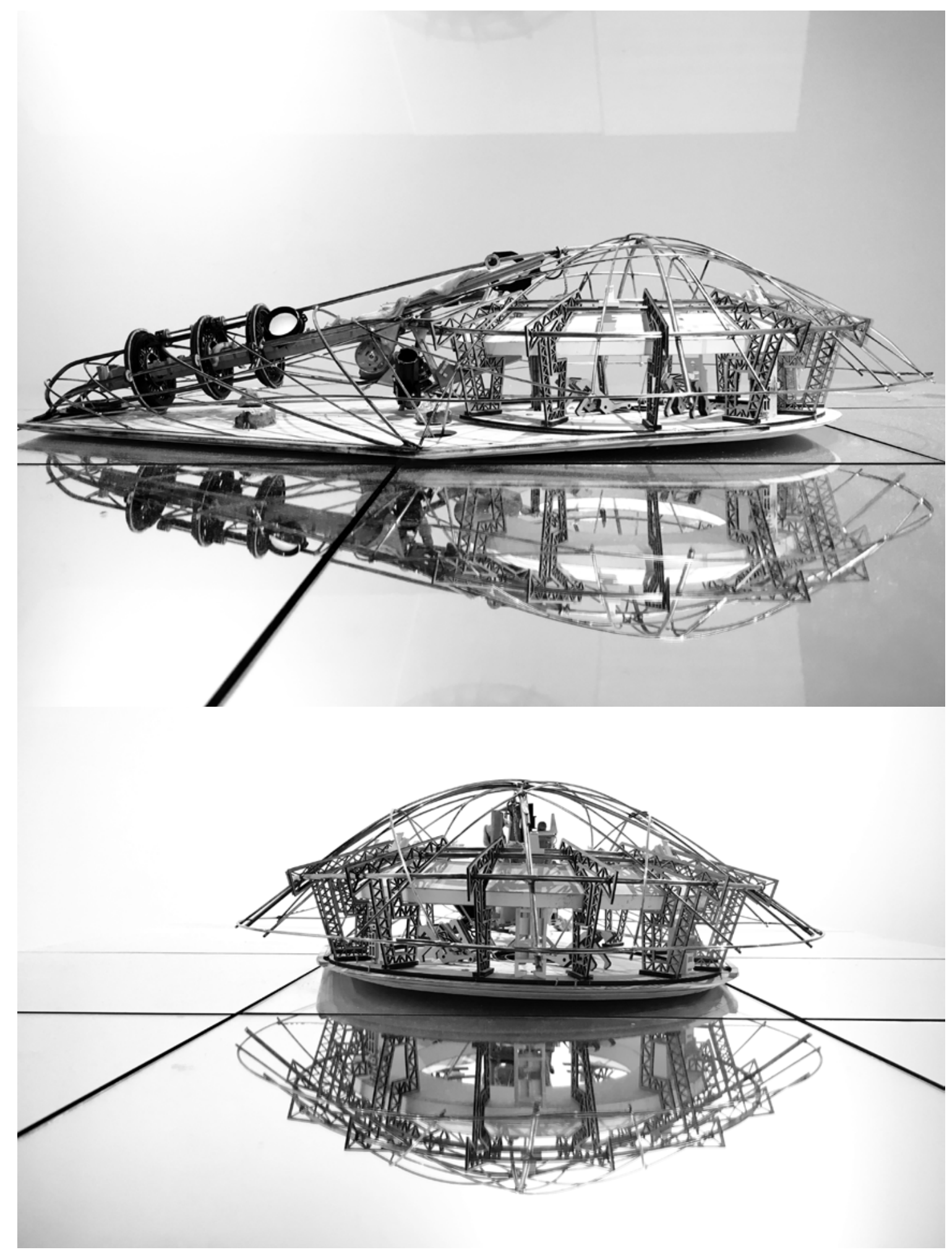

Figure 76. Elevations of the Built Model Side Elevation and Rear Elevation 


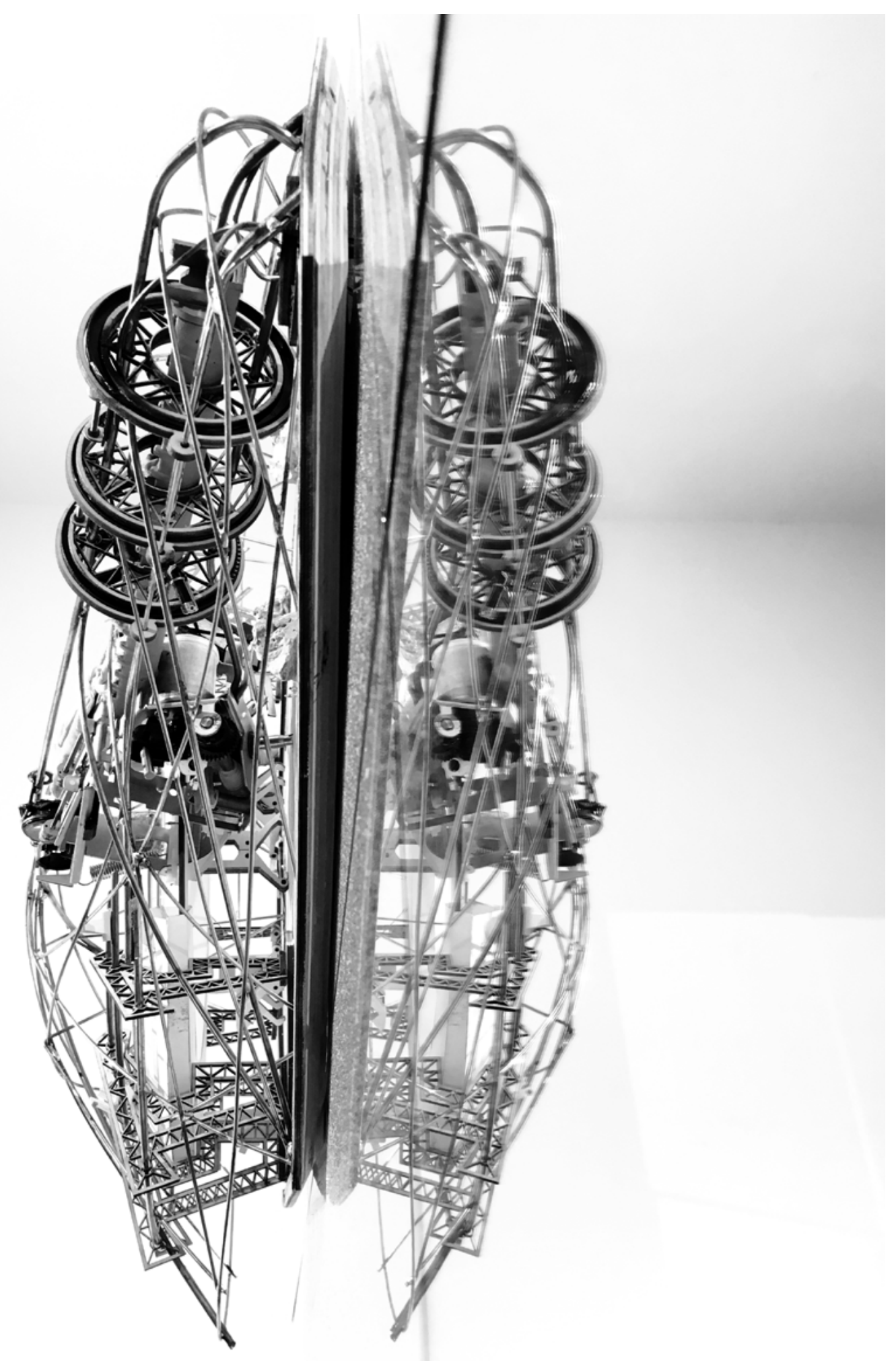

Figure 77. Angled perspective of machine without cladding - Its form is arrow dynamic, allowing the machine to harness wind energy that sweeps over and around its body. 


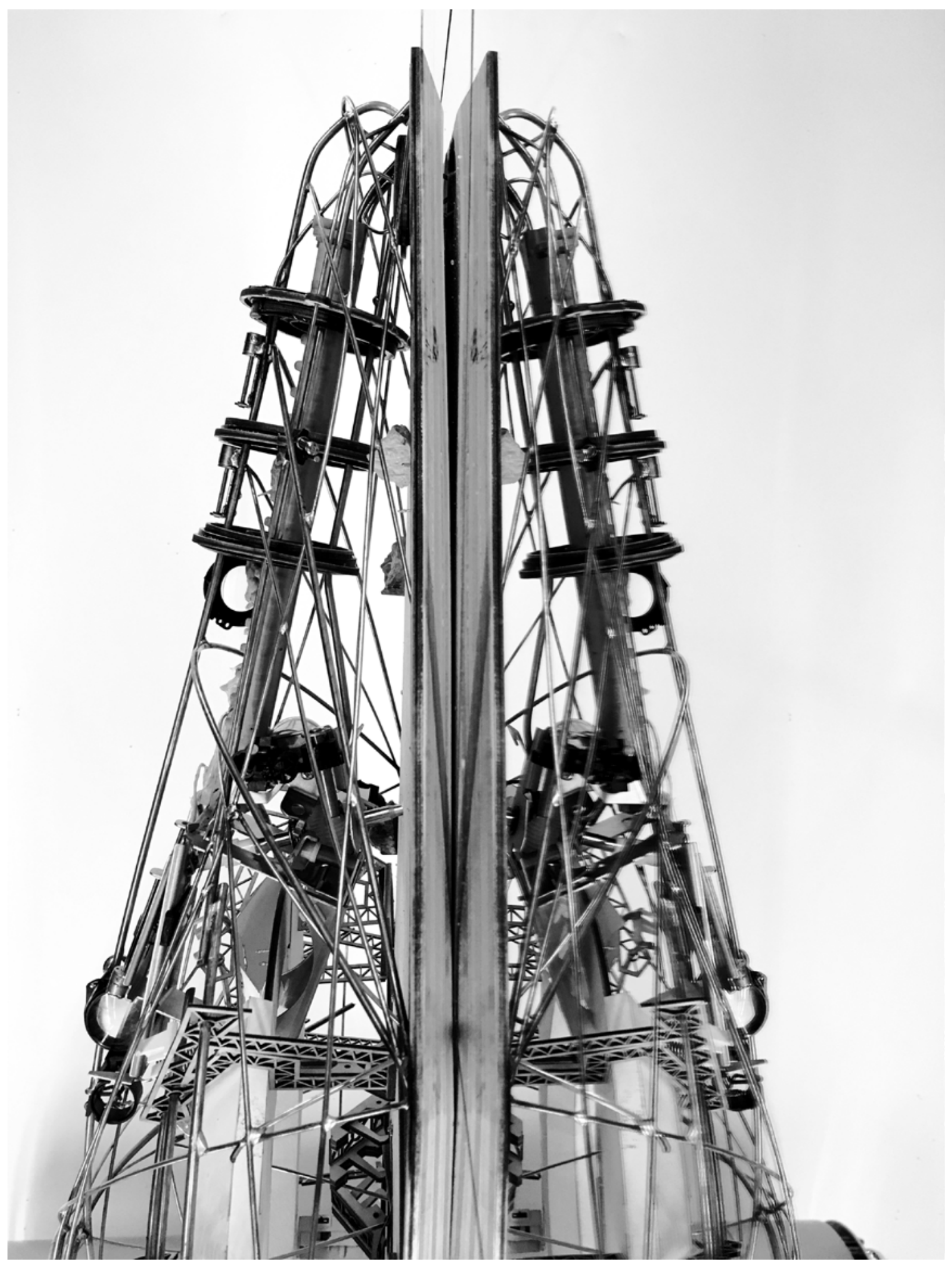

Figure 78. Nose of machine with reflection in water. 


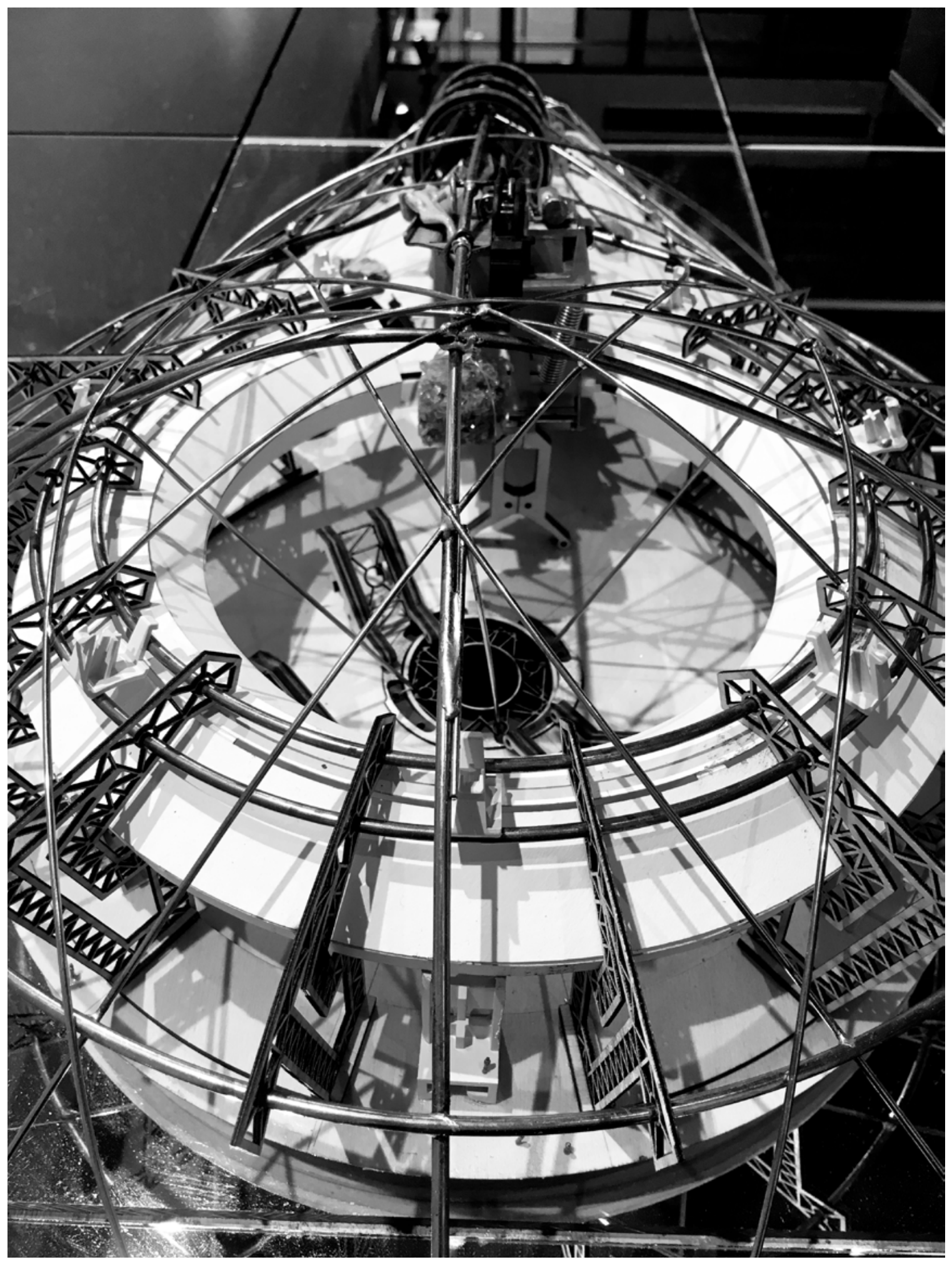

Figure 79. This image frames the living and research corridors at the rear of the machine. Structural loads are carried through the arrayed trusses along these corridors. Three structural rings counter shear forces between each truss, which also act as the foundation for a structural cage that is indented to support the cladding of the machine. 

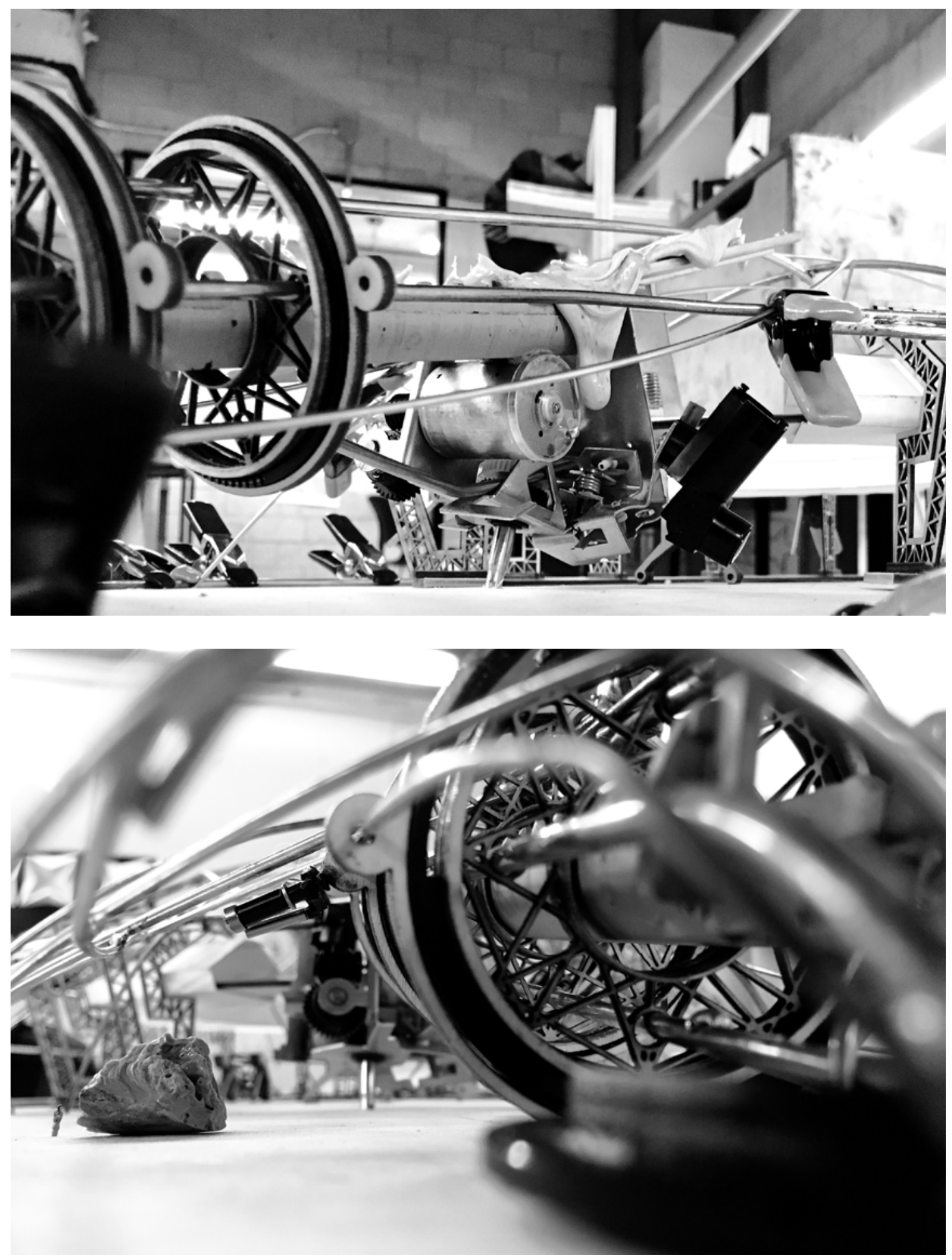

Figure 80. Interior Angles - The top image is of plastic flowing above the bioreactor zone. The use of plastic waste for 3D printing is depicted in the lower image. Excess plastic waste flows down a central axis and is processed to be 3D printed into useful components for the machines. 

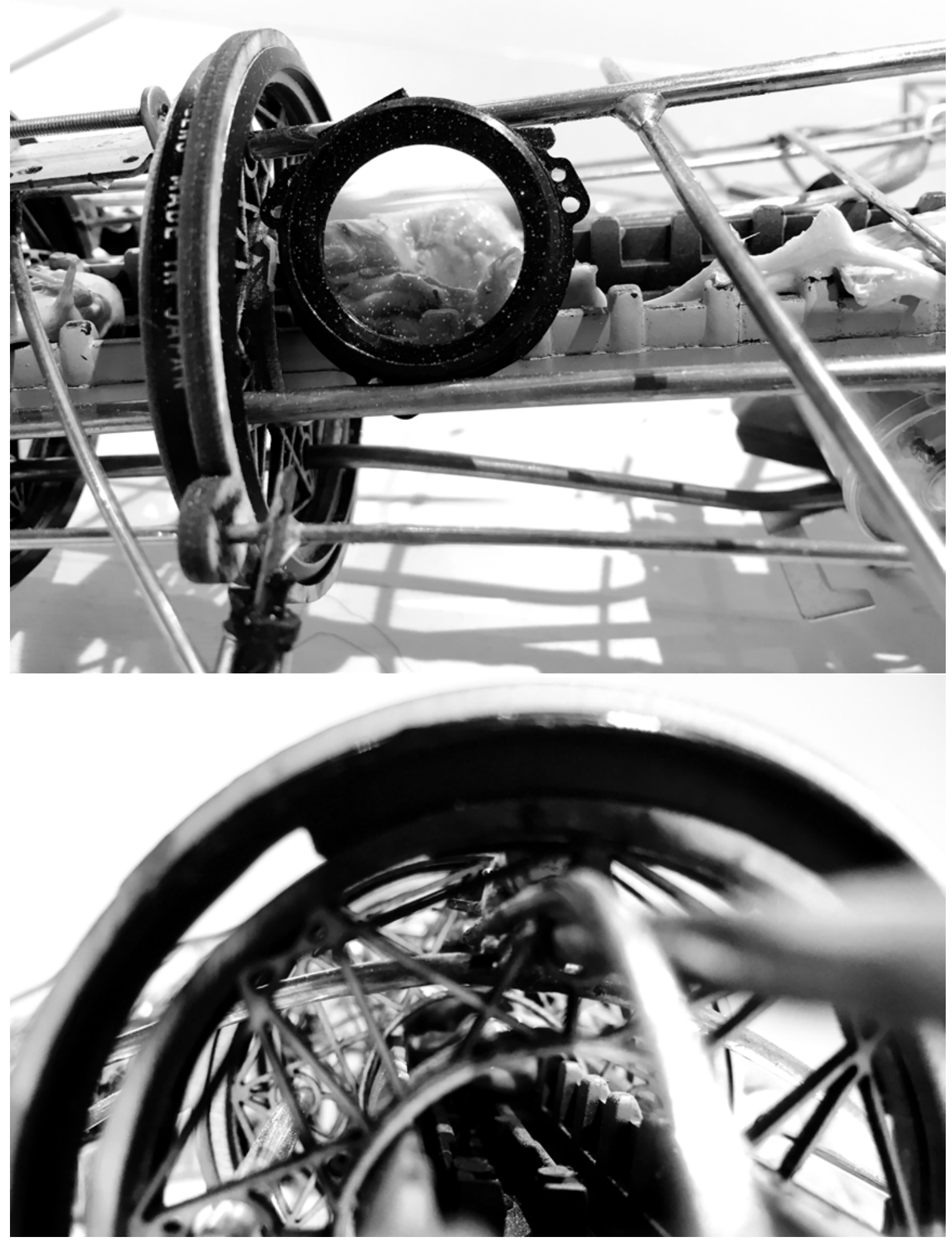

Figure 81. Interior Angles - The top image revels a moment where massive lenses are used to melt collected plastics at specific melting points. Much like methods discussed in Figures 42-49, these lenses would heat large metal chambers allowing for a consistent melting point throughout the process. The image below revels the depolymerization bridge passing though trusses which are integrated with the machines structural cage. 


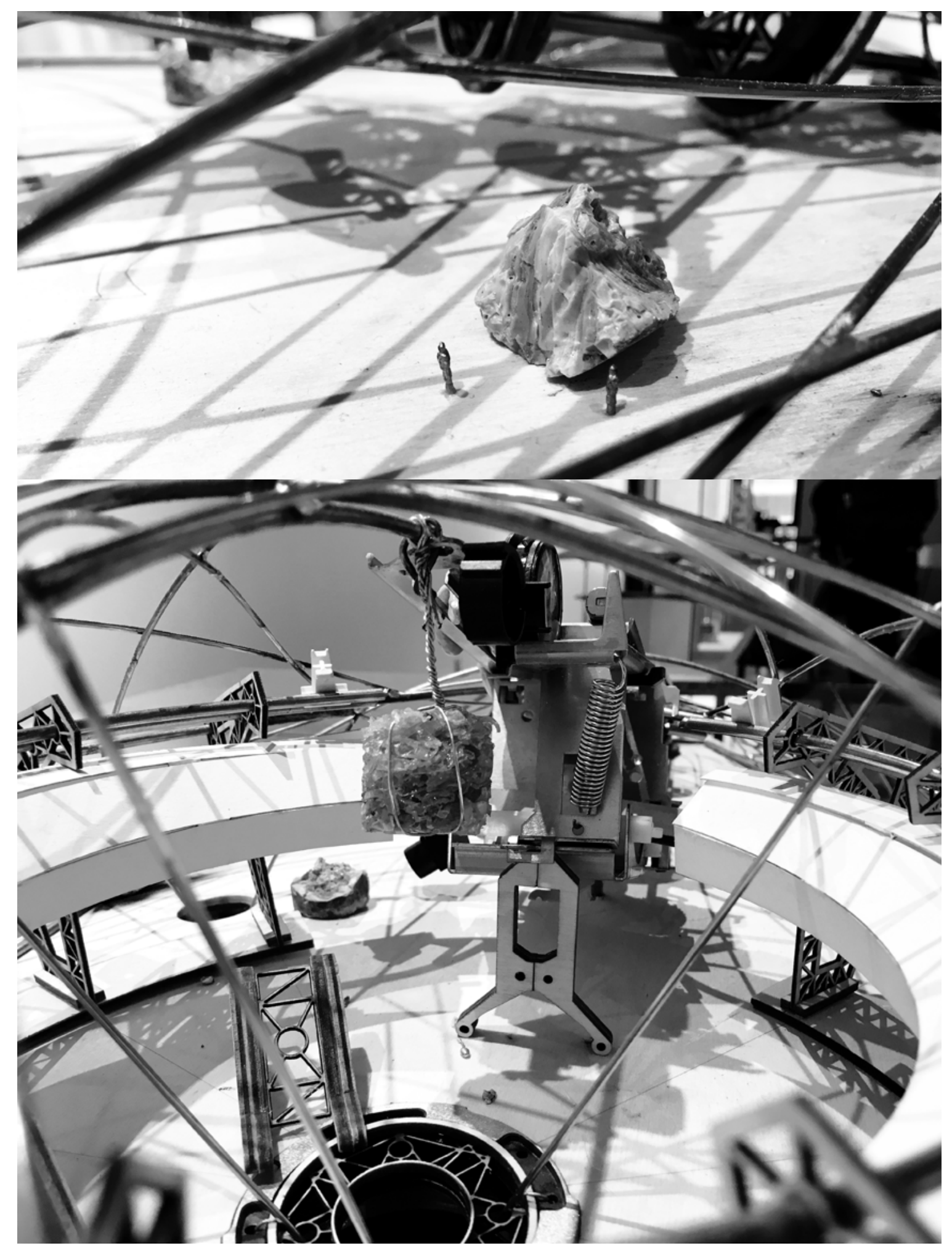

Figure 82. Interior Angle - The lower image depicts a scene where stitched microplastics are being extracted within the bioremediation zone.

This process is surrounded by living and research corridors. 


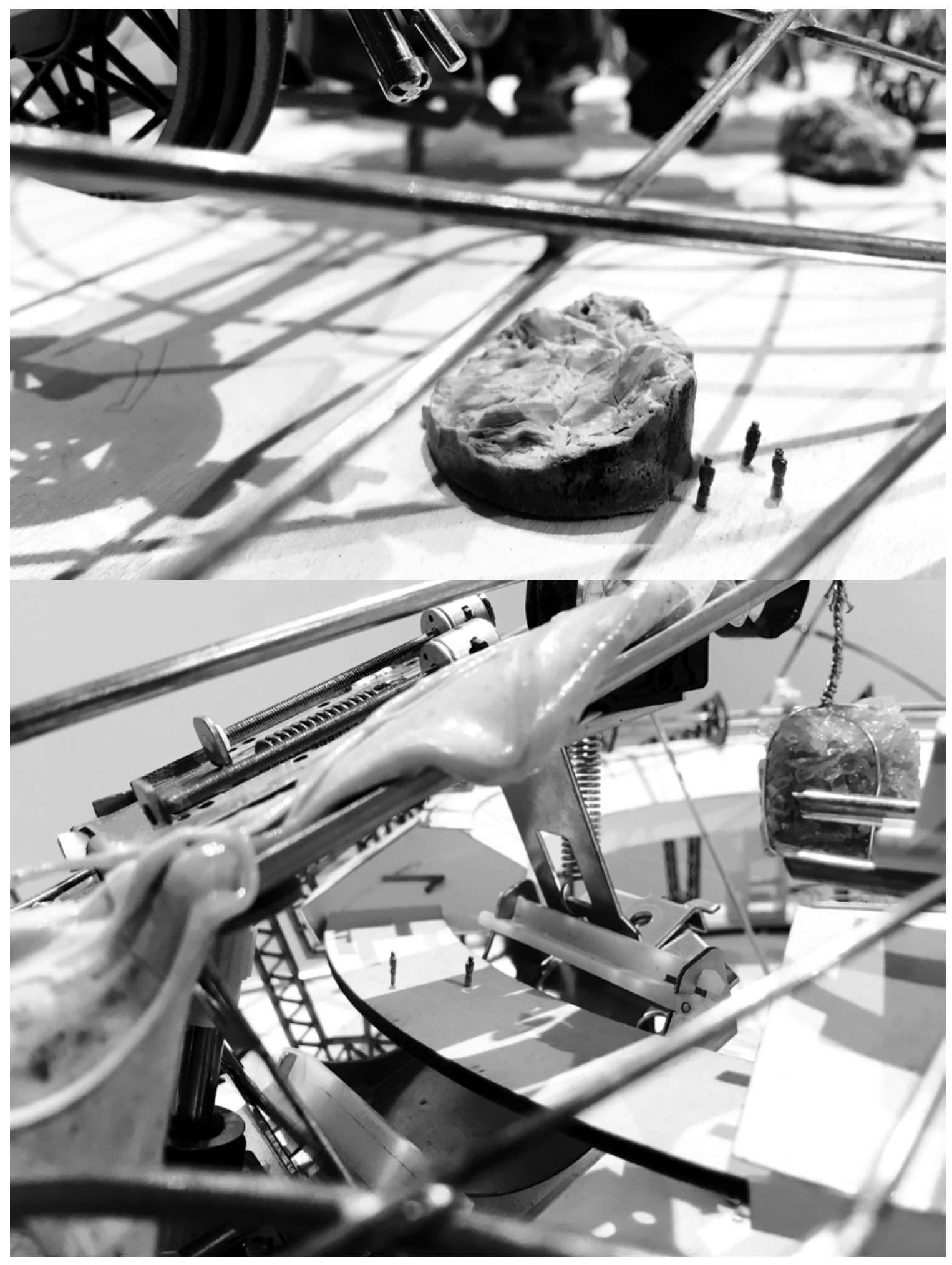

Figure 83. Interior Angle - Scientist and researchers experiment with plastic prototypes that are made from plastic waste in the image above. The lower image depicts a plastic skin forming above a bridge. 


\section{Chapter: Conclusion}

How can a relationship between architecture and plastic packaging be developed? How can weaving, lamination and shredding of repurposed

plastic, in combination with vacuum forming and $\mathrm{CNC}$ fabrication be used to create new ways of thinking and making with waste?

To answer these questions, this thesis had two modes of enquiry: one speculative and the other scientific. The strength of this thesis remains as speculative design which calls attention to plastic pollution in aquatic ecosystems. It emphasizes the need for decisive action that will remediate and prevent future plastic problems.

This research and restoration program will benefit future generations by boosting the economy and ensuring plastic free water. Our knowledge and understanding of materials is driven by an inherent curiosity that must be harnessed for scientists to uncover exactly how this waste damages our ecosystems. The desire for these rehabilitation projects justifies the proposed architecture as a speculative design to unify the various faculties involved in one central research facility (located on the plastic eating machines). This will allow for different organizations to interact and have social collisions that ultimately provoke solutions to the plastic problem. These facilities provide the opportunity to advance materials. Scientists, designers, and inventors will know exactly how not to build, or design, new materials based on the conclusions drawn via these experimentations with plastic waste.

This design approach, poetic in nature, is intended to inspire imagination resulting in creative solutions. It is not the responsibility of one individual to resolve such vast issues, it is important to play to one's strength and collaborate to supplement the weaknesses. The intersection of a common 
goal creates resolution, and it is the proposed architecture that unifies this goal.

Although physical properties of thermoplastics were investigated, this thesis does not encompass scientific or objective studies that realize building systems, or building components. These ideas remain as speculative depictions based on real world issues and the physical properties of thermoplastics investigated throughout this thesis.

The goal was to develop an understanding of how plastic packaging could be used as a building material. Throughout this process, experiments have proven that it is extremely difficult to manipulate degrading plastic unless it is shredded into smaller, more manageable pieces. Once shredded, it is relatively easy to work with, as it liquefies into a mouldable state without burning. This provides the opportunity to condense the material, which is significant, as the goal is to collect, manage, and store as much plastic as possible. Experiments resulted in successfully condensing five soda bottles, (591 $\mathrm{ml}$ each, a volume of 180 inches $^{3}$ ), into 4.32 inches $^{3}$ as shredded microplastics, and then into 1.96 inches $^{3}$ once melted and compressed. These numbers can be slightly reduced if clamping mechanisms remained air tight.

For the purpose of this project the block material was milled and used as components of the model representing the proposed architecture. However, if more plastic was collected, this material could be used as blocks that intersect and erect vertically. CNC milling would carve its form, thus providing a more dynamic surface. All waste would then be compressed into the next block material and reused for new surfaces to be milled by CNC. Much like plastiglomerates, a newly discovered plastic rock, a more compelling strategy may attempt to use the liquid plastic as a binding agent to stitch architectural components together. This construction uses as much plastic as possible and 
here, an excess of material is a reduction of pollution dispersed in the water. This method allows for the intense reduction of volume of plastic.

Another way to utilize plastic is via the collection and consumption through bioremediation. These bacteria will function to remove the plastic "stock" from the environment permanently by processing it into a protein used to promote ecological diversity and regrowth.

This research has proven that many organizations, such as the American Chemistry Council, Plasticity Forums, the Great Canadian Shoreline Cleanup, Civic Technologies for Monitoring Marine Plastics and Parley, are separately proactive when it comes to preserving aquatic ecosystems. The most difficult, yet most important step, is to halt virgin plastic productions. We must challenge industry to rethink plastic norms by holding them accountable for the products they produce. We must educate everyday people about the effects plastic packaging has on our water, the food chain, and ultimately, our bodies.

Beyond the material exploration, further thought must be given to the longevity of these structures. The next step, with regards to research, will be to study the possibility of converting plastic into fuel. Or perhaps, further research into the absorption rates of microplastics. If plastics can absorb chemicals in the water, is there potential for it to purposefully absorb smog or oil? This would make a powerful statement if a remediated product was used for another remediation process. The evolution of this project must also be considered. Once the 'flow' of fossil fuel derived plastic is stopped, and the 'stock' is fully remediated, what happens with the islands of plastic that are the plastic-eating machines? Although identified and gathered machines made of plastic are much better than dispersed microplastics, consideration must be placed on the structures' entire 'life span'. Perhaps, as the structures remediate plastic, they are also constructing their final burial ground. Or 
perhaps, the bacteria that reside within the structures consume their own habitat. The work of future scientists and designers will be to uncover methods to safely remove plastic from our planet permanently.

\subsection{Postscript}

Depicted 50 years from now, the production of plastic packaging has continued to increase which has resulted in a dystopic landscape for the machines to roam. Pungent odors from growing bacterial cultures will distinguish healing radii. An increase of malodors will correspond with the rate at which the plastic waste is being processed into protein by the bacterial enzymes. This scent will permeate the plastic-eating machines as they work constantly to rectify the ever-increasing plastic in the water around them. This process is depicted as a natural response and healing mechanism that attempts to reverse damages that have been imposed on Earth. As the 'flow' of plastic continues to increase, so does the chance of irreversible damages to the planet. Fish populations that initially thrive in 'plastic free' water begin to mutate with the surplus amount of protein and excessive feeding. Due to a lack of early initiative, in this reality plastic has left an impact on Earth that cannot be corrected. 


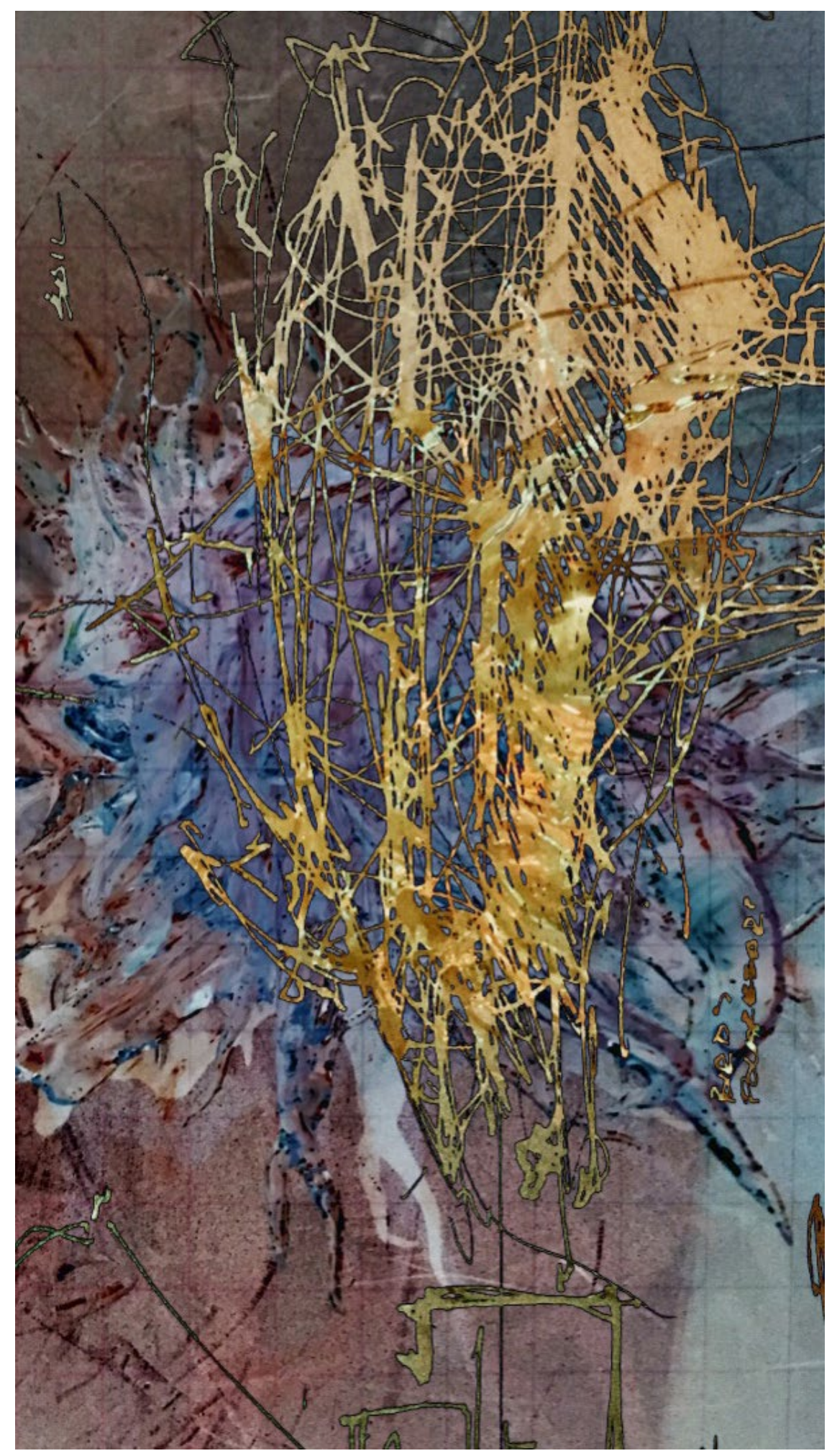

Figure 84. Concept Sketch of Plastic and Oil. 


\section{Definitions}

Biodegrade: "capable of being broken down especially into innocuous products by the action of living things." ${ }^{93}$

Biomagnifying: "the concentration of toxins in an organism as a result of its ingesting other plants or animals in which the toxins are more widely disbursed." 94

Dispersion: "the act or process of spreading or distributing over a wide area." 95

Down cycling: the act of recycling a material by mixing it with a less valuable or non-recyclable material.

Hydrocarbons: "a compound of hydrogen and carbon, such as any of those that are the chief components of petroleum and natural gas." 96

Industry: manufacturing activity as a whole, specifically here: the plastic industry.

Microplastic: small plastic particles less than $5 \mathrm{~mm}$ in size.

Monomer: "a molecule that can be bonded to other identical molecules to form a polymer." ${ }^{97}$

Plastic: "a synthetic material made from a wide range of organic polymers such as polyethylene, PVC, nylon, etc., that can be molded into shape while soft and then set into a rigid or slightly elastic form."

Plasticity: "capacity for being molded or altered, the ability to retain a shape attained by pressure deformation." 99

\footnotetext{
${ }^{93}$ Oxford University Press. The Oxford American College Dictionary. Published G.P. Putnam's Sons, 2002.

94 Ibid.

${ }^{95}$ Merriam-Webster's Collegiate Dictionary. 11th ed. Springfield, MA: Merriam-Webster, 2003.

96 Oxford University Press. The Oxford American College Dictionary. Published G.P. Putnam's Sons, 2002.

97 Ibid.

98 Oxford University Press. The Oxford American College Dictionary. Published G.P. Putnam's Sons, 2002.

${ }^{99}$ Merriam-Webster's Collegiate Dictionary. 11th ed. Springfield, MA: Merriam-Webster, 2003.
} 
Plasticizer/monomer additives: "a substance (typically a solvent) added to a synthetic resin to produce or promote plasticity and flexibility and to reduce brittleness." 100

Polymer: "a substance that has a molecular structure consisting chiefly or entirely of a large number of similar units bonded together, e.g., many synthetic organic materials used as plastics and resins." ${ }^{101}$

Polymer bond: The bonds that form between each monomer to create a polymer or polymer strand.

Polymer strands: Long strings of polymers.

Polymerization: "a chemical reaction in which two or more molecules combine to form larger molecules that contain repeating structural units." ${ }^{102}$

Repurpose: "to give a new purpose or use to." ${ }^{103}$

Recycle: "to pass again through a series of changes or treatments: to process in order to regain material for human use."104

Virgin: "free of impurity or stain, being used or worked for the first time." 105

100 Oxford University Press. The Oxford American College Dictionary. Published G.P. Putnam's Sons, 2002.

101 Ibid.

102 Merriam-Webster's Collegiate Dictionary. 11th ed. Springfield, MA: Merriam-Webster, 2003.

${ }^{103}$ Merriam-Webster's Collegiate Dictionary. 11th ed. Springfield, MA: Merriam-Webster, 2003.

104 Ibid.

105 Ibid. 


\section{References}

Abdel-Goad, Mahmoud A. -Halim. 2004. Structural material from waste plastic. Journal of Applied Polymer Science 91 (4): 2543-7.

"About the Great Lakes." Michigan Sea Grant. March 07, 2016. Accessed January 04, 2017. http://www.miseagrant.umich.edu/explore/about-the-greatlakes/.

"Areas of Concern." Government of Canada, Environment and Climate Change Canada. July 12, 2013. Accessed January 04, 2017.

http://www.ec.gc.ca/grandslacs-

greatlakes/default.asp?lang=En\&n=0F3E456F-1.

"Canada: Detroit's Southerly Neighbor." Image Journal. April 26, 2016. Accessed January 06, 2017. https://www.imagejournal.org/2016/05/03/canadadetroits-southerly-neighbor/. Image produced above is by Barbara Eckstein, licensed by Creative Commons.

Chen, Angus. "Rocks Made of Plastic Found on Hawaiian Beach." Science | AAAS. January 12, 2016. Accessed March 28, 2017.

http://www.sciencemag.org/news/2014/06/rocks-made-plastic-found-hawaiianbeach.

Cizek, Michal. Bird eating a plastic cup. Digital image. Getty Images.

Accessed January 3, 2017. https://s.w-X.co/birdplastic.jpg.

"Detroit River Area of Concern." Government of Canada, Environment and

Climate

Change Canada, Ontario Region, Strategic Integration Division, Restoration Programs. December 23, 2014. Accessed January 04, 2017.

http://www.ec.gc.ca/raps-pas/default.asp?lang=En\&n=4EF278D1-1.

"DETROIT DISTRICT." Detroit District > Missions > Operations > Detroit River, MI. Accessed January 06, 2017.

http://www.Ire.usace.army.mil/Missions/Operations/Detroit-River-MI/. Image

"Dickson \& Whinfield." The Plastics Historical Society. Accessed January 04, 2017. http://plastiquarian.com/?page_id=14270.

"Facts \& Figures." Great Canadian Shoreline Cleanup. Accessed January 04, 2017. http://www.shorelinecleanup.ca/en/content/facts-figures.

Faircloth, Billie. 2015. Plastics now: On architecture's relationship to a continuously emerging material. Abingdon, Oxon;New York, NY;: Routledge. 
"GLEAM." GLEAM | Great Lakes Environmental Assessment and Mapping Project. Accessed January 04, 2017. http://greatlakesmapping.org/. Gray-Cosgrove, C., Liboiron, M., \& Lepawsky, J. (2016). "The Challenges of Temporality to Depollution \& Remediation." SAPI ENS. Surveys and Perspectives Integrating Environment and Society, (8.1).

"Great Lakes." Government of Canada, Environment and Climate Change Canada. March 24, 2016. Accessed January 04, 2017. http://www.ec.gc.ca/grandslacs-greatlakes/.

"Great Lakes Areas of Concern." Government of Canada, Environment and Climate Change Canada, Ontario Region, Strategic Integration Division, Restoration Programs. April 30, 2015. Accessed January 04, 2017. http://www.ec.gc.ca/raps-pas/default.asp?lang=En\&n=A290294A-1.

Hand, Eric. "Trillions of Plastic Pieces May Be Trapped in Arctic Ice." Science | AAAS. January 12, 2016. Accessed March 28, 2017. http://www.sciencemag.org/news/2014/05/trillions-plastic-pieces-may-betrapped-arctic-ice.

Jordan, Chris. Bird with plastic in it. Digital image. Nature Trust. Accessed January 3, 2017. http://www.naturetrust.nb.ca/wp/blog/the-charlotte-islescleanup/.

"Lakewide Management Plans." Government of Canada, Environment and Climate

Change Canada. December 06, 2013. Accessed January 04, 2017. http://www.ec.gc.ca/grandslacsgreatlakes/default.asp?lang=En\&n=0CB6DFA3-1.

Liboiron, M. (2012). “Occasional Paper No.2: A Citizen's Guide to Plastic Pollution,” Material World Occasional Paper Series, ISSN 2158-5660.

Liboiron, M. (2013). "Modern Waste as Strategy," Lo Squaderno: Explorations in Space and Society, 29: 9-12.

Liboiron, M. (2013). "Plasticizers: A Twenty-first Century Miasma," Accumulation: The Material Politics of Plastics, Eds. Jennifer Gabrys, Gay Hawkins, Mike Michael. Routledge: 22-44.

Liboiron, M., Liboiron, F., Wells, E., Richard, N., Zahara, A., Mather, C., \& Murichi, J. (2016). "Low plastic ingestion rate in Atlantic Cod (Gadus morhua) from Newfoundland destined for human consumption collected through citizen science methods."Marine Pollution Bulletin, advanced proof. 
Liboiron, M. (2016). "Civic Technologies for Monitoring Marine Plastics," Journal of Ocean Technology 11(2): 36-45.

Liboiron, M. (2016). "Redefining pollution and action: The matter of plastics." Journal of Material Culture, 21(1): 87-110.

Meikle, Jeffrey L. 1995. American Plastic: A Cultural History. Rutgers

University Press. eBook Collection (EBSCOhost). Accessed January 2, 2017.

Plataforma SINC. "Contaminants also a threat to polar bears." ScienceDaily. www.sciencedaily.com/releases/2015/04/150407085025.htm (accessed December 27, 2016).

"Precious Plastic." Home - Precious Plastic. Accessed January 07, 2017. https://preciousplastic.com/en/.

"Plastic Breaks Down in Ocean, After All -- And Fast." National Geographic. Accessed January 04, 2017.

http://news.nationalgeographic.com/news/2009/08/090820-plasticdecomposes-oceans-seas.html.

Robertson, Morgan. 2012. Measurement and alienation: Making a world of ecosystem services. Transactions of the Institute of British Geographers 37 (3): 386-401.

Schmaltz, Jeff. A Great Freeze Over the Great Lakes. Satellite image of ice formation on all five Great Lakes. Digital Image. NASA. February 19, 2014. Accessed January 3, 2017.

http://earthobservatory.nasa.gov/IOTD/view.php?id=83169

Schmaltz, Jeff. A Great Freeze Over the Great Lakes. Satellite image of ice formation on shipping routes to Lake Erie. Digital Image. NASA. February 15, 2014. Accessed January 3, 2017.

http://earthobservatory.nasa.gov/IOTD/view.php?id=83169

Schmaltz, Jeff. Great Lakes: No Clouds. Google Earth satellite image of the Great Lakes. Digital image. NASA. August 28, 2010. Accessed January 3, 2017. http://earthobservatory.nasa.gov//OTD/view.php?id=45615.

Simmon, Robert and Allen, Jesse Landsat image, using data from the U.S. Geological Survey. Caption by Kathryn Hansen, NASA's Earth Science News Team, with Mike

Carlowicz. Accessed January 3, 2016.

http://earthobservatory.nasa.gov//OTD/view.php?id=83169 
Stouffer, Lloyd. "Plastic s Packaging: Today and Tomorrow." 1963 National Plastics Conference, November 19, 1963, 1-3.

"Toronto and Region Area of Concern." Government of Canada, Environment and Climate Change Canada, Ontario Region, Strategic Integration Division, Restoration Programs. March 13, 2014. Accessed January 04, 2017. http://www.ec.gc.ca/raps-pas/default.asp?lang=En\&n=58AC19A1-1.

Thompson, Richard C., Shanna H. Swan, Charles J. Moore, and Frederick S. vom Saal. 2009. Our plastic age. Philosophical Transactions of the Royal Society B: Biological Sciences 364 (1526): 1973-6.

Wang, Miranda. "Miranda Wang: Plastic-eating Bacteria." PARLEY. Accessed March 28, 2017. http://www.parley.tv/updates/2016/6/1/miranda-wang-plasticeating-bacteria.

Walker, Nick. "Pollution in the Great Lakes." Canadian Geographic. June 13, 2016. Accessed January 04, 2017.

https://www.canadiangeographic.ca/article/pollution-great-lakes.

"What are Plastics?" The Plastics Historical Society. Accessed January 04, 2017. http://plastiquarian.com/?page_id=14296.

"What is the Great Lakes Water Quality Agreement?" Government of Canada, Environment and Climate Change Canada. July 12, 2013. Accessed January 04, 2017. http://www.ec.gc.ca/grandslacs-

greatlakes/default.asp?lang=En\&n=45B79BF9-1.

Woglom, Emily. "The Most Important Congressional Action on the Ocean You've Never Heard of." Ocean Currents. November 15, 2013. Accessed March 06, 2017. http://blog.oceanconservancy.org/2013/11/15/the-mostimportant-congressional-action-on-the-ocean-youve-never-heard-of/.

World Economic Forum, Ellen MacArthur Foundation and McKinsey \& Company. 2016. The New Plastics Economy - Rethinking the future of plastics. Accessed January 3, 2017. http://www.ellenmacarthurfoundation.org/publications.

Zimmerman, Kim Ann. "Great Facts About the Five Great Lakes." LiveScience. May 3, 2013. http://www.livescience.com/29312-great-lakes.html. 